San Jose State University

SJSU ScholarWorks

Master's Theses

Master's Theses and Graduate Research

1995

\title{
Application of the prognostic URBMET/TVM meso- meteorological model to Phoenix Arizona
}

Charalambos Panayiotou

San Jose State University

Follow this and additional works at: https://scholarworks.sjsu.edu/etd_theses

\section{Recommended Citation}

Panayiotou, Charalambos, "Application of the prognostic URBMET/TVM meso- meteorological model to Phoenix Arizona" (1995). Master's Theses. 1096.

DOI: https://doi.org/10.31979/etd.wk93-33qv

https://scholarworks.sjsu.edu/etd_theses/1096

This Thesis is brought to you for free and open access by the Master's Theses and Graduate Research at SJSU ScholarWorks. It has been accepted for inclusion in Master's Theses by an authorized administrator of SJSU ScholarWorks. For more information, please contact scholarworks@sjsu.edu. 


\section{INFORMATION TO USERS}

This manuscript has been reproduced from the microfilm master. UMI films the text directly from the original or copy submitted. Thus, some thesis and dissertation copies are in typewriter face, while others may be from any type of computer printer.

The quality of this reproduction is dependent upon the quality of the copy submitted. Broken or indistinct print, colored or poor quality illustrations and photographs, print bleedthrough, substandard margins, and improper alignment can adversely affect reproduction.

In the unlikely. event that the author did not send UMI a complete manuscript and there are missing pages, these will be noted. Also, if unauthorized copyright material had to be removed, a note will indicate the deletion.

Oversize materials (e.g., maps, drawings, charts) are reproduced by sectioning the original, beginning at the upper left-hand corner and contimuing from left to right in equal sections with small overiaps. Each original is also photographed in one exposure and is included in reduced form at the back of the book.

Photographs included in the original manuscript have been reproduced xerographically in this copy. Higher quality $6^{n} \times 9^{n}$ black and white photographic prints are available for any photographs or illustrations appearing in this copy for an additional charge. Contact UMI directly to order.

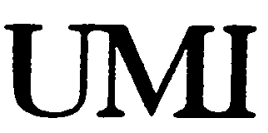

A Bell \& Howell information Company 

APPLICATION OF THE PROGNOSTIC

URBMET/TVM MESO- $\beta$ METEOROLOGICAL MODEL

TO PHOENIX ARIZONA

\author{
A Thesis \\ Presented to \\ The Faculty of the Department of Meteorology \\ San Jose State University \\ In Partial Fulfillment \\ of the Requirements for the Degree \\ Master of Science
}

by

Charalambos Panayiotou

August, 1995 
UMI Number: 1375720

Copyright 1995 by

Panayiotou, Charalambos

All rights reserved.

UMI Microform 1375720

Copyright 1995, by UII Company. Al1 rights reserved.

This microform edition is protected against unauthorized copying under Title 17, United States Code.

\section{UMI}

300 North Zeeb Road

Ann Arbor, MI 48103 
(C) 1995

Charalambos Panayiotou

\section{ALL RIGHTS RESERVED}


APPROVED FOR THE DEPARTMENT OF METEOROLOGY

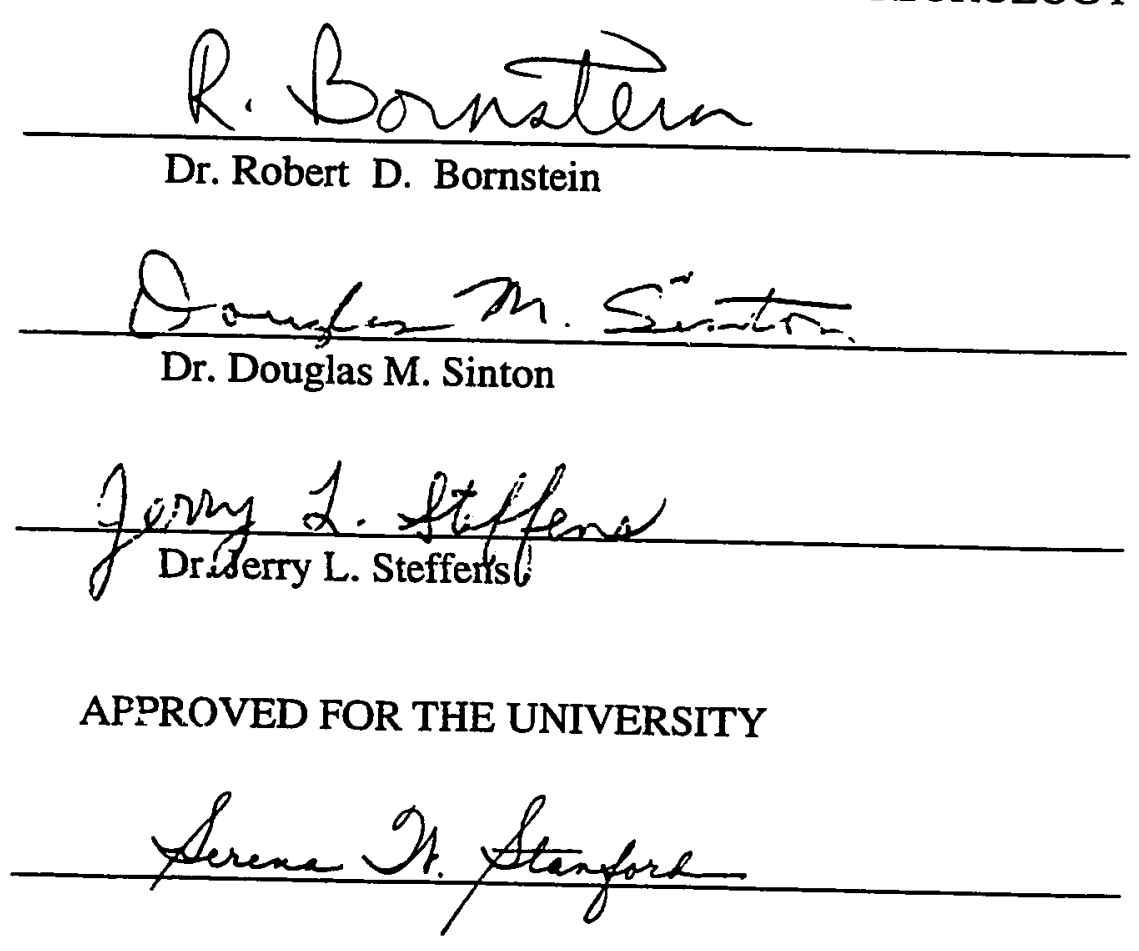




\section{ABSTRACT \\ APPLICATION OF THE PROGNOSTIC URBMET/TVM MESO- $\beta$ METEOROLOGICAL MODEL TO PHOENIX ARIZONA}

by Charalambos Panayiotou

The hydrostatic, Boussinesq, Topographic Vorticity-Mode (TVM) meso- $\beta$ numerical model was used to simulate Phoenix-area temperature and wind flow patterns for the 24 hour period beginning on 31 August at 0400 LST. Both the steep terrain of the region and soil-moisture evaporation, associated with precipitation-moistened soil, presented unique challenges to the model. Results show that the model reproduced the main features of the diurnal and spatial distributions of the thermal and wind flow fields. Predicted temperature and velocity values compared well to observed values, as differences in temperature and wind speed values were generally within $2{ }^{\circ} \mathrm{C}$ and $2 \mathrm{~m} / \mathrm{s}$, respectively.

The wet rural soil enabled formation of a daytime urban heat island, which enhanced midday upslope forcing. Mesoscale-induced downslope nocturnal flows produced significant convergence over the urban valley, while urbanization itself contributed additional mid-evening convergence. This enhanced convergence may be responsible for an observed upward trend in mid-evening monsoon precipitation amounts over the city. A pair of nocturnal anticylonic and cyclonic vortices formed downwind of the urban barrier. 


\section{ACKNOWLEDGMENTS}

The author would like to thank Dr. Robert Bornstein for his guidance and help in all stages of this publication, and for his insight in the interpretation of the current results. Special appreciation is also addressed to Mr. Frank Freedman for making his experience with the model formulation readily available to the author, and to Dr. Sandra Brazel for supplying PRISM data. 


\section{TABLE OF CONTENTS}

$\underline{\text { Page }}$

Abstract

Acknowledgments

Table of Contents

List of Tables

List of Figures

\section{Chapter 1. INTRODUCTION}

Chapter 2. METHOD

a. Model equations

b. Boundary conditions

c. Numerics

d. Topography

Chapter 3. MODEL INPUT

Chapter 4. RESULTS

a. Run 1

b. Run 2

c. Run 3

\section{Chapter 5. CONCLUSION}

References

Appendix A: List of symbols

Appendix B: Manual for topography averaging program TOPOAV 


\section{LIST OF TABLES}

page

Table 1. PRISM observation sites, locations, and elevation values.............. 35

Table 2. Soil energy-balance parameter values found in literature ............... 39

Table 3. Surface parameter values used in current study............................40

Table B-1. Sample of TOP.CTL input file ............................................. 83 


\section{LIST OF FIGURES}

Fig. 1. Typical summer dry-period surface pressure distribution (mb)

Fig. 2. Typical summer monsoon surface pressure distribution (mb)

Fig. 3. Phoenix area topographic relief map

Fig. 4. Location of variables in a computational cell; see Appendix A for definition of symbols

Fig. 5. Model domain, with topographic height (m), land-use types, and observation Sites 1-19

Fig. 6. NWS wind speed $(\mathrm{U})$ and direction (dd) profiles at Tuscon $(787 \mathrm{~m}$ M.S.L.) on 31August at $1200 \mathrm{GMT}$

Fig. 7. NWS wind speed $(\mathrm{U})$ and direction (dd) profiles at Tuscon $(787 \mathrm{~m}$ M.S.L.) on 1 September at 0000 GMT

Fig. 8. NWS wind speed (U) and direction (dd) profiles at Winslow (1487 m M.S.L.) on 31 August at 1200 GMT

Fig. 9. NWS wind speed (U) and direction (dd) profiles at Winslow (1487 m M.S.L.) on 1 September at 0000 GMT

Fig. 10. Initial wind speed vertical profile used in simulation

Fig. 11. NWS temperature profile at Tuscon ( $787 \mathrm{~m}$ M.S.L.) on 31 August at 1200 GMT

Fig. 12. NWS temperature profile at Tuscon ( $787 \mathrm{~m}$ M.S.L.) on 1 September at 0000 GMT

Fig. 13. NWS temperature profile at Winslow ( $1487 \mathrm{~m}$ M.S.L.) on 31 August at 1200 GMT 
Fig. 14. NWS temperature profile at Winslow (1487 m M.S.L.) on 1 September at $0000 \mathrm{GMT}$

Fig. 15. Initial temperature and potential temperature vertical profile used in simulation

Fig. 16. Base-Run 1 predicted surface and $12.5 \mathrm{~m}$ temperatures versus observed $1.63 \mathrm{~m}$ temperatures at: (a) Site 16, (b) Site 14, (c) Site 2, (d) Site 1, (e) Site 18, (f) Site 13, (g) Site 3, and (h) Site 19. Topographic height values (dotted lines) given at $250 \mathrm{~m}$ increment starting at $300 \mathrm{~m}$, while dashed "rectangle" outlines urban and suburban areas.

Fig. 17. Base-Run 1 predicted $12.5 \mathrm{~m}$ wind flow vectors on 31 August at: (a) 0600 LST, (b) 1000 LST, (c) 1300 LST, (d) 1900 LST, and (e) 2200 LST, and on 1 September at: (f) 0100 LST and (g) 0600 LST

Fig. 18. Observed 6.25 wind flow patterns on 31 August at: (a) 0600 LST, (b) $1000 \mathrm{LST}$, (c) $1200 \mathrm{LST}$, (d) $1300 \mathrm{LST}$, (e) average of 1400 and 1500 LST, and (f) 1700 LST, and on 1 September at: (g) 0000 LST, (h) 0100 LST, and (i) 0600 LST

Fig. 19. Base-Run 1 predicted $12.5 \mathrm{~m}$ versus observed $6.25 \mathrm{~m}$ wind speed (U) and direction (dd) for: (a) Site 1, (b) Site 19, (c) Site 17, (d) Site 16, (e) Site 7, (f) Site 9, (g) Site 18, (h) Site 12, and (i) Site 11

Fig. 20. Run 2 predicted $12.5 \mathrm{~m}$ wind vectors on 31 August at: (a) 0600 LST, (b) 1300 LST, and (c) on 1 September at 0300 LST

Fig. 21. Base Run $112.5 \mathrm{~m}$ mesoscale potential temperature perturbations on 31 August at 1300 LST

Fig. 22. Difference between Base Run 1 and Non-urban Run 212.5 m potential temperature patterns on 31 August at: (a) 1300 LST, (b) 1900 LST, and (c) on 1 September at 0300 LST

Fig. 23. Difference between Base Run 1 and Non-urban Run $312.5 \mathrm{~m}$ wind vectors on 31 August at: (a) 1300 LST, (b) 2200 LST, and (c) on 1 September at $0300 \mathrm{LST}$ 
Fig. B-1. Example of DEM data-file arrangement, showing: (a) three consecutive sample data blocks and (b) their relative $W$ to $E$ geographic locations. 


\section{Chapter 1. INTRODUCTION}

Arizona is divided into a low elevation region in the southwestern part of the state, a high plateau area $(1500-2100 \mathrm{~m})$ to the northeast, and a mountain range (2700-3600 m) that extends between the northwestern and southeastern corners of the state. Winter storm systems from the Pacific frequently cross the state and produce precipitation, mostly at the higher elevations; thus, annual precipitation ranges from $0.55 \mathrm{~m}$ in mountainous areas to $0.06 \mathrm{~m}$ in the southwestern desert. Dry cold air masses from Canada also occasionally enter the area causing sharp temperature drops. Though diurnal temperature fluctuations are largest under dry summer conditions $\left(-30^{\circ} \mathrm{C}\right)$, dry winter periods provide high insolation and clear skies that produce diurnal fluctuations that can reach $22{ }^{\circ} \mathrm{C}$.

During late spring and June, the General Circulation Pacific High produces a northwesterly flow over Arizona that prevents moisture advection into the region from either the Pacific Ocean or Gulf of Mexico (Fig. 1). Monsoon conditions, however, are initiated in the beginning of July with concurrent shifts northward by the Pacific High and westward by the Bermuda High (Fig. 2). These migrations allow moisture advection into Arizona from the Gulfs of Mexico and California and from the Pacific Ocean (Balling and Brazel 1986), while the thermal trough that develops over the south California deserts also enhances this advection. 
South-central Arizona, in the rain shadow east of the Southern California mountains, has annual rainfall values that average less than $0.3 \mathrm{~m}$. Dry spring to early summer conditions are followed by the above-mentioned rainy monsoon that lasts from early July to the beginning of September. Precipitation during this period occurs due to thunderstorms produced by excessive surface heating and moisture advection from the Gulf of Mexico (Climate of the States 1972).

Phoenix is located at an elevation of approximately $330 \mathrm{~m}$ and surrounded by mountain chains (Fig. 3), the tallest of which (to the north and east) contain peaks that exceed $2000 \mathrm{~m}$. Mesoscale summertime mountain-valley flows in the Phoenix area strongly influence both local diurnal wind flows and local weather patterns. Daytime upslope forcing produces easterly to southeasterly winds in the area, while nighttime downslope winds first converge towards the flat urbanized areas and are then channeled westward into low topography regions.

Mesoscale dust events frequently also occur in Phoenix during summer, associated with high wind speed conditions produced by (most frequently) frontal activity, convective conditions, tropical disturbances, and upper air cut-off lows (Brazel and Nickling 1986). Events may last for almost an hour, and produce large shifts in both wind direction and speed. 
The summer Monsoon produces thunderstorms in the mountains surrounding Phoenix that occur mostly in the afternoon. Precipitation in the city, however, predominantly occurs in the evening, peaking near midnight. Convergence of nighttime downslope winds into Phoenix can produce this observed pattern. Hales (1977), however, suggested that nighttime easterly winds aloft during mid-evening hours act to advect evaporatively-cooled upper layers (that originate near afternoon mountain thunderstorm towers) over the nocturnal Phoenix urban heat island (UHI), thus further enhancing instability and producing precipitation.

Balling and Brazel (1986) have studied the effects of recent urbanization in Phoenix on both temperature and precipitation trends; e.g., they found minimum and maximum temperatures increased over the city. Their results also suggest that mid-evening summertime urban precipitation during 1970-1985 may be somewhat more frequent and more intense than during 1954-1970, while late evening storms may have somewhat weakened. They suggest that during mid-evening hours the UHI enhances instability and thus convection. During late evening, however, an UHI-induced upper level isobaric bulge results in gravitational drainage of colder away from a city center that retards the terrain-induced convergence toward the city and thus reduces convective activity. This latter conclusion, however, con- 
tradicts the expected UHI effects, which are to induce a warm core Low and thus convergence toward a city center.

Urban heat islands in warm dry climates like Phoenix form due to: (1) enhanced absorption of solar radiation by vertical building surfaces; (2) decreased daytime latent heat fluxes, and thus increased convective heat fluxes; (3) trapping of outgoing long-wave radiation by air pollutants; (4) anthropogenic heat rejection due to air conditioning; and (5) trapping of outgoing long wave radiation by building walls. The net result of these influences is the production of weak midday urban cool islands, followed by development of strong nocturnal urban heat islands (Bornstein 1983).

The UHI produces nocturnal urban boundary layers that are dome- or plume-shaped in low and high speed conditions, respectively. An elevated inversion that often caps this layer forms as the rural surface-based inversion is advected over a city and is converted into an adiabatic mechanically mixed layer.

Urban areas can also alter prevailing flow conditions due to heat island, building barrier, and surface roughness effects. Heat islands accelerate surface wind flow toward the thermal low at the city center. As this warm core low weakens with height, however, flow divergence aloft is produced in a manner similar to that above a sea breeze flow. The increased urban surface roughness decelerates 
winds and produces cyclonic displacement over a city (Bornstein 1987a). Such frictional retardation of sea breeze and synoptic cold fronts over New York City (NYC), and a barrier induced difluence of wind flow around it were documented by Bornstein et al. (1993).

Terrain and urban influenced mesoscale flow patterns can be simulated with prognostic or diagnostic meteorological models. Diagnostic models, such as the WOCSS mass conservation model of Ludwig and Endlich (1988), use available observation data to produce mesoscale fields. Three-dimensional mesoscale prognostic models such as Pielke $(1981,1992)$, however, produce more realistic simulations of time-varying velocity and temperature distributions. Most consist of three layers: an analytic constant-flux SBL in which mean field variables are one dimensional; an upper numerical layer in which the atmospheric hydrodynamic and thermodynamic equations are solved; and a sub-surface soil layer in which soil temperature and moisture are obtained from analytic or finite differenced solutions of the soil heat and soil moisture diffusion equations, respectively.

A problem in mesoscale modeling is the accurate numerical representation of advective processes. A large number of advection schemes have thus been proposed, each with advantages and disadvantages, e.g., fully implicit (Stone 1968) Donor Cell (Roach 1972), second moment method of Egan and Mahoney (1972), 
cubic spline quasi-Langrangian (Price and MacPherson 1973), and piecewise parabolic scheme of Collela and Woodward (1984).

Various properties should be present in the ideal advection scheme. Consistency (numerical equations should approximate analytical PDE as $\Delta \mathrm{t}$ and $\Delta \mathrm{x}$ approach zero) and convergence (numerical solutions should approach analytical solutions as $\Delta t$ and $\Delta x$ approach zero) are necessary, while rapid convergence towards the real solution is a further advantage. Schemes must also be free of linear instabilities, while aliasing (non-linear instability) should be minimized. The following numerical qualities must also be considered: correct prediction of group velocity, conservation of important physical parameters (e.g., vorticity and kinetic energy), lack of numerically induced negative values, minimum numerical dispersion, no transportive error (mass conservation), and existence of a unique solution (no splitting error). Practical factors, such as computer core and CPU requirements, and ease of implementation are also important.

The URBMET (Urban Meteorological) model is a three dimensional hydrostatic, shallow Boussinesq (and hence incompressible), vorticity mode mesoscale model originally designed for flat terrain applications by Bornstein (1986). Its distinguishing feature is that the dynamic equations are recast in a stream function 
and vorticity vector mode, and its principal advantage is thus the elimination of pressure from the equations of motion.

The model originally used the first order Donor Cell advection scheme, which is highly dispersive. Thunis (1995) thus replaced this scheme with the third order piecewise parabolic scheme (PPM) of Collela and Woodward (1984). This latter scheme is more accurate and can resolve sharper discontinuities, but has larger space/time computer requirements. It was also found (Thunis 1995) that under conditions of strong convergence near mountain tops and valley bottoms, it may become numerically unstable.

The original URBMET model was first used to simulate sea breeze flows over New York City (NYC) by Bornstein et al. (1987a). Output from these simulations was used by Bornstein et al. (1987b) as input to a modified version of the URBCON (Urban Concentration) Eulerian-grid numerical urban dispersion model of Shir and Shieh (1974) to study SO2 concentrations.

The URBMET model was extended by Schayes et al. $(1990,1995)$ to include the effects of complex topography, via transformation into the contravariant coordinate system of Pielke (1984), thus producing the TVM (Topographic Vorticity-mode Mesoscale) model. Schayes et al. (1991) then linked URBMET/TVM 
and a Lagrangian particle dispersion model for applications in complex terrain for all non-nuclear "risk industries" in Belgium.

One part of the APSIS air quality study of Athens, Greece involved a comparison by Thunis et al. (1993) of the complex wind flow fields produced by three mesoscale wind models, i.e., TVM and two non-hydrostatic models (RAMS, and MAR). TVM did as well as the other two models in reproducing sea breeze flow features. Observed urban building barrier-induced perturbations on sea breeze fronts over NYC have also been reproduced with TVM by Bornstein et al. (1994, 1995), while the model has also been applied to the Lake Fos area on the southern coast of France to simulate complex mesoscale situations involving sea breeze, lake breeze, and topographic effects (Bornstein et al. 1995).

The URBMET/TVM model has recently been applied to the San Francisco Bay Area (Meng 1995) to simulate local sea and bay breeze circulations. Output from this simulation was used by Wang (1995) as input to the Lagrangian particle dispersion model (UPDM) model of Zannetti (1986) to simulate an actual toxic plume release. The model has also been linked to the Cal Tech (CIT) photochemical air quality simulation model for simulations in Athens (Grossi et al. 1995) and to the Urban airshed Photochemical Model (UA9M) to simulate ozone levels in the New Jersey-NYC-Connecticut corridor (Rao et al. 1994). A new non-hydrostatic 
version of TVM is currently being used to simulate mountain lee waves (Thunis 1995).

Whereas previous applications have shown that the hydrostatic URBMET TVM model can correctly simulate the diurnal evolution of polluted urban, rural, and marine mesoscale flows in areas of gentle topography, it has not yet been applied to a desert climate. The purpose of the present study is to reproduce observed summertime surface and PBL temperature and wind-flow fields in the Phoenix (Arizona) metropolitan area, that form in response to the high temperatures and relatively large topographic features of the region. Another unique aspect of the current study is the gradual soil desiccation that resulted from precipitation during several days preceding the simulation period. Finally, simulation of mesoscale flows with the newly implemented Collela and Woodward (1984) PPM advection scheme is tested in TVM against the Donor Cell scheme for the first time. 


\section{Chapter 2. METHOD}

\section{a. Model equations}

The primitive equation form of the finite-differenced layer equations are derived from the exact equations of motion for a Reynolds averaged Newtonian fluid in a rotating $(x, y, z)$ coordinate system. The following assumptions have been made:

- The atmosphere is hydrostatic.

- The atmosphere is shallow Boussinesq, thus density fluctuations are ignored except in the buoyancy term in the vertical equation of motion, where they are replaced by mesoscale temperature fluctuations. This assumption produces the incompressible form of the continuity equation, from which vertical velocities are thus computed.

- Sub-saturation specific humidity $\mathrm{q}$ is conserved.

- Potential temperature can be approximated by $\theta=T+\Gamma z$.

- Radiative flux divergence within the PBL occurs only from natural gases.

- Molecular diffusion processes are ignored, as they are less important than turbulent exchange processes. 
- Mean thermodynamic and dynamic variables are defined as the sum of several parts, e.g., total mean pressure p may be written as

$$
p=p_{0}(z)+p_{n}(x, y)+p_{M}(x, y, z, t),
$$

where all symbols are defined in Appendix A. Note that $\mathrm{po}(\mathrm{z})$ is the hydrostatic variability in the absence of either synoptic forcing pn or PBL mesoscale forcing $\mathrm{pM}$. Since synoptic forcing is assumed constant in both space and time, spatial and temporal variations arise only from mesoscale motions.

Consequently, the basic Raynolds averaged equations of motion in the finite differenced layer for the URBMET model were given by Bornstein et al. (1987a) as

$$
\begin{gathered}
\frac{\partial u}{\partial t}+u \frac{\partial u}{\partial x}+v \frac{\partial u}{\partial y}+w \frac{\partial u}{\partial z}=-\frac{1}{\rho_{0}} \frac{\partial p_{M}}{\partial x}+f\left(v-v_{g}\right)+\frac{\partial}{\partial z}\left(K_{m} \frac{\partial u}{\partial z}\right)+K_{H}\left(\frac{\partial^{2} u}{\partial x^{2}}+\frac{\partial^{2} u}{\partial y^{2}}\right) \\
\frac{\partial v}{\partial t}+u \frac{\partial v}{\partial x}+v \frac{\partial v}{\partial y}+w \frac{\partial v}{\partial z}=-\frac{1}{\rho_{0}} \frac{\partial p_{M}}{\partial y}-f\left(u-u_{g}\right)+\frac{\partial}{\partial z}\left(K_{m} \frac{\partial v}{\partial z}\right)+K_{H}\left(\frac{\partial^{2} v}{\partial x^{2}}+\frac{\partial^{2} v}{\partial y^{2}}\right) \\
-\frac{1}{\rho_{0}} \frac{\partial p_{M}}{\partial z}+g \frac{\theta_{M}}{\theta_{0}}=0 \\
\frac{\partial u}{\partial x}+\frac{\partial v}{\partial y}+\frac{\partial w}{\partial z}=0 \\
\frac{\partial \theta}{\partial t}+u \frac{\partial \theta}{\partial x}+v \frac{\partial \theta}{\partial y}+w \frac{\partial \theta}{\partial z}=\frac{\partial}{\partial z}\left(K_{h} \frac{\partial \theta}{\partial z}\right)+K_{H}\left(\frac{\partial^{2} \theta}{\partial x^{2}}+\frac{\partial^{2} \theta}{\partial y^{2}}\right)+\frac{1}{\rho_{0} c_{p}} \frac{\partial Q_{N}}{\partial z}
\end{gathered}
$$




$$
\frac{\partial q}{\partial t}+u \frac{\partial q}{\partial x}+v \frac{\partial q}{\partial y}+w \frac{\partial q}{\partial z}=\frac{\partial}{\partial z}\left(K_{q} \frac{\partial q}{\partial z}\right)+K_{H}\left(\frac{\partial^{2} q}{\partial x^{2}}+\frac{\partial^{2} q}{\partial y^{2}}\right)
$$

where the assumed constant Coriolis parameter is given by $f=2 \Omega \sin \Phi$ and the assumed constant geostrophic wind speed components are obtained from observed synoptic pressure gradients by

$$
u_{s}=-\frac{1}{\rho_{0} f} \frac{\partial p_{n}}{\partial y}, \quad v_{g}=\frac{1}{\rho_{0} f} \frac{\partial p_{n}}{\partial x}
$$

The infra-red radiative flux divergence term $\partial Q_{N} / \partial z$ and the turbulence closure scheme (used to obtain vertical eddy diffusivities) are discussed below.

The upper boundary condition on pressure is not well posed in primitive equation mesoscale models, and it is also frequently a source of instability as it generates waves extraneous to the desired solution. The above equations are therefore written in vorticity form to eliminate pressure from the dynamic equations. This approach, however, requires an additional integration to recover velocity components from the required stream functions.

The vorticity vector $\omega=(-\xi, \zeta, v)$, defined by $\omega=\nabla \times V$, has the following components 


$$
\xi=\frac{\partial v}{\partial z}-\frac{\partial w}{\partial y}, \quad \zeta=\frac{\partial u}{\partial z}-\frac{\partial w}{\partial x}, \quad v=\frac{\partial v}{\partial x}-\frac{\partial u}{\partial y}
$$

The hydrostatic approximation leaves only the two horizontal vorticity components, with only vertical derivatives:

$$
\xi=\frac{\partial v}{\partial z}, \quad \zeta=\frac{\partial u}{\partial z}
$$

Thus the stream function $\Psi$ (defined by $V=\nabla \times \Psi$ ) also has only its two horizontal components ( $\phi,-\psi$ ), obtained by Gaussian elimination from the horizontal components of $\omega$ via

$$
\xi=\frac{\partial^{2} \phi}{\partial z^{2}}, \quad \zeta=\frac{\partial^{2} \psi}{\partial z^{2}}
$$

Momentum equations (1) and (2) can thus be transformed into the following horizontal hydrostatic vorticity equations (Bornstein et al. 1987a)

$$
\begin{aligned}
& \frac{\partial \xi}{\partial t}+u \frac{\partial \xi}{\partial x}+v \frac{\partial \xi}{\partial y}+w \frac{\partial \xi}{\partial z}=\xi \frac{\partial u}{\partial x}-\zeta\left(f+\frac{\partial v}{\partial x}\right)-\frac{g}{\theta_{0}} \frac{\partial \theta_{M}}{\partial y}+\frac{\partial^{2}}{\partial z^{2}}\left(K_{m} \xi\right)+K_{H}\left(\frac{\partial^{2} \xi}{\partial x^{2}}+\frac{\partial^{2} \xi}{\partial y^{2}}\right) \\
& \frac{\partial \zeta}{\partial t}+u \frac{\partial \zeta}{\partial x}+v \frac{\partial \zeta}{\partial y}+w \frac{\partial \zeta}{\partial z}=\zeta \frac{\partial v}{\partial y}+\xi\left(f-\frac{\partial u}{\partial y}\right)-\frac{g}{\theta_{0}} \frac{\partial \theta_{M}}{\partial x}+\frac{\partial^{2}}{\partial z^{2}}\left(K_{m} \zeta\right)+K_{H}\left(\frac{\partial^{2} \zeta}{\partial x^{2}}+\frac{\partial^{2} \zeta}{\partial y^{2}}\right) .
\end{aligned}
$$


The above equations were transformed by Schayes et al. (1995) into a sigma-height coordinate system to account for topographic influences. In the new

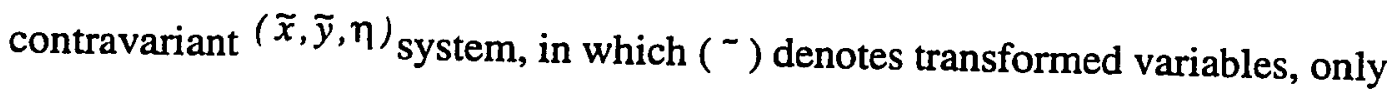
the vertical coordinate is altered (following Pielke, 1984) such that

$$
\tilde{x}=x, \quad \tilde{y}=y, \quad \eta=\frac{z_{\max }\left[z-z_{g}(x, y)\right]}{z_{\max }-z_{g}(x, y)} .
$$

This formulation is not time dependent (unlike the sigma pressure system) and has: a surface level that is terrain following, vertical grid spacing that varies in the horizontal, and transformed horizontal velocities that equal corresponding Cartesian values, as follows;

$$
\tilde{u}=u, \quad \tilde{v}=v, \quad \tilde{w}=u \frac{\partial \eta}{\partial x}+v \frac{\partial \eta}{\partial y}+w \frac{\partial \eta}{\partial z} .
$$

In the new coordinate system, equations (1), (2), and (4)-(6) become, respectively,

$$
\begin{aligned}
\frac{\partial \tilde{\xi}}{\partial t}+\tilde{u} \frac{\partial \tilde{\xi}}{\partial \tilde{x}}+\tilde{v} \frac{\partial \tilde{\xi}}{\partial \tilde{y}}+\tilde{w} \frac{\partial \tilde{\xi}}{\partial \eta}=\tilde{\xi} \frac{\partial \tilde{u}}{\partial \tilde{x}}-\tilde{\zeta}\left(f+\frac{\partial \tilde{v}}{\partial \tilde{x}}\right)-\frac{g}{\theta_{0}} \frac{\partial \theta_{M}}{\partial \tilde{y}}-\frac{g}{\theta_{0}} \frac{\partial \theta_{M}}{\partial \eta} \frac{\partial z_{g}}{\partial \tilde{y}}\left(\frac{\eta-z_{\max }}{z_{\max }-z_{g}}\right) \\
\\
+f_{z g}^{-2} \frac{\partial^{2}}{\partial \eta^{2}}\left(K_{m} \tilde{\xi}\right)+f_{z g}^{-1} K_{H}\left[\frac{\partial^{2}\left(f_{z g} \tilde{\xi}\right)}{\partial \tilde{x}^{2}}+\frac{\partial^{2}\left(f_{z \xi} \tilde{\xi}\right)}{\partial \tilde{y}^{2}}\right]
\end{aligned}
$$




$$
\begin{aligned}
& \frac{\partial \tilde{\zeta}}{\partial t}+\tilde{u} \frac{\partial \tilde{\zeta}}{\partial \tilde{x}}+\tilde{v} \frac{\partial \tilde{\zeta}}{\partial \tilde{y}}+\tilde{w} \frac{\partial \tilde{\zeta}}{\partial \eta}=\tilde{\zeta} \frac{\partial \tilde{v}}{\partial \tilde{y}}+\tilde{\xi}\left(f-\frac{\partial \tilde{u}}{\partial \tilde{y}}\right)-\frac{g}{\theta_{0}} \frac{\partial \theta_{M}}{\partial \tilde{x}}-\frac{g}{\theta_{0}} \frac{\partial \theta_{M}}{\partial \eta} \frac{\partial z_{g}}{\partial \tilde{x}}\left(\frac{\eta-z_{\max }}{z_{\max }-z_{g}}\right) \\
&+f_{z g}^{-2} \frac{\partial^{2}}{\partial \eta^{2}}\left(K_{m} \tilde{\zeta}\right)+f_{z g}^{-1} K_{H}\left[\frac{\partial^{2}\left(f_{z \xi} \tilde{\zeta}\right)}{\partial \tilde{x}^{2}}+\frac{\partial^{2}\left(f_{z \xi} \tilde{\zeta}\right)}{\partial \tilde{y}^{2}}\right] \\
& 0=\frac{\partial}{\partial \tilde{x}}\left(f_{z g} \tilde{u}\right)+\frac{\partial}{\partial \tilde{y}}\left(f_{z g} \tilde{v}\right)+\frac{\partial}{\partial \eta}\left(f_{z g} \tilde{w}\right) \\
& \frac{\partial \theta}{\partial t}+\tilde{u} \frac{\partial \theta}{\partial \tilde{x}}+\tilde{v} \frac{\partial \theta}{\partial \tilde{y}}+\tilde{w} \frac{\partial \theta}{\partial \eta}=f_{z g}^{-2} \frac{\partial}{\partial \eta}\left(K_{h} \frac{\partial \theta}{\partial \eta}\right)+K_{H}\left(\frac{\partial^{2} \theta}{\partial \tilde{x}^{2}}+\frac{\partial^{2} \theta}{\partial \tilde{y}^{2}}\right)+\frac{1}{\rho_{0} c_{p}} \frac{\partial Q_{N}}{\partial z} \\
& \frac{\partial q}{\partial t}+\tilde{u} \frac{\partial q}{\partial \tilde{x}}+\tilde{v} \frac{\partial q}{\partial \tilde{y}}+\tilde{w} \frac{\partial q}{\partial \eta}= f_{z g}^{-2} \frac{\partial}{\partial \eta}\left(K_{q} \frac{\partial q}{\partial \eta}\right)+K_{H}\left(\frac{\partial^{2} q}{\partial \tilde{x}^{2}}+\frac{\partial^{2} q}{\partial \tilde{y}^{2}}\right)
\end{aligned}
$$

where topography correction factor $f_{z g}$ is given by

$$
f_{z g}=\left(\frac{z_{\max }-z_{g}}{z_{\max }}\right)
$$

For these equations to be consistent with the hydrostatic assumption, it was assumed that horizontal gradients of the new vertical coordinate can be neglected versus its vertical gradient, i.e.,

$$
\left|\frac{\partial \eta}{\partial x}\right| \ll<\left|\frac{\partial \eta}{\partial z}\right|, \quad\left|\frac{\partial \eta}{\partial y}\right| \ll<\left|\frac{\partial \eta}{\partial z}\right| .
$$

Terrain slope angles must therefore be much smaller than $45^{\circ}$ (Pielke, 1984). The transformed horizontal stream functions $\tilde{\Psi}=(\tilde{\phi},-\tilde{\Psi}, 0)$ now become 


$$
\tilde{\xi}=f_{z \delta}^{-2} \frac{\partial^{2} \tilde{\phi}}{\partial \eta^{2}}, \quad \tilde{\zeta}=f_{z \xi}^{-2} \frac{\partial^{2} \widetilde{\psi}}{\partial \eta^{2}}
$$

and the corresponding transformed horizontal velocity values $(\tilde{u}, \tilde{v})$ are obtained from

$$
\tilde{u}=f_{z g}^{-1} \frac{\partial \tilde{\Psi}}{\partial \eta}, \quad \tilde{v}=f_{z g}^{-1} \frac{\partial \tilde{\phi}}{\partial \eta},
$$

Finally, transformed vertical velocities $\widetilde{w}$ are calculated from the transformed continuity equation (11). Note, while Bornstein et al. (1987) and others have used stream functions in conjunction with vorticity formations to insure mass conservation, they are in fact unnecessary in hydrostatic vorticity models Their use in URBMET/TVM, however, allows for its easier conversion into a nonhydrostatic mode.

TVM uses a 1.5 order turbulence closure scheme, in which transformed turbulent kinetic energy (TKE) (given by $\left.e T=\overline{\left(u^{\prime 2}\right.}+\overline{v^{\prime 2}}+\overline{\omega^{\prime 2}}\right) / 2$ ) is obtained from

$$
\begin{aligned}
\frac{\partial e_{T}}{\partial t}= & -\tilde{u} \frac{\partial e_{T}}{\partial \tilde{x}}-\tilde{v} \frac{\partial e_{T}}{\partial \tilde{y}}-\tilde{w} \frac{\partial e_{T}}{\partial \eta}+K_{m} f_{z g}^{-2}\left[\left(\frac{\partial \tilde{u}}{\partial \eta}\right)^{2}+\left(\frac{\partial \tilde{v}}{\partial \eta}\right)^{2}\right]-\frac{g}{\theta_{0}} K_{h} f_{z g}^{-1} \frac{\partial \theta_{M}}{\partial \eta} \\
& +1.2\left(\frac{\partial}{\partial \eta} K_{m} \frac{\partial e_{T}}{\partial \eta}\right)-C_{2} \frac{e_{T}^{3 / 2}}{l_{\varepsilon}}+K_{H}\left(\frac{\partial^{2} e_{T}}{\partial \tilde{x}^{2}}+\frac{\partial^{2} e_{T}}{\partial \tilde{y}^{2}}\right),
\end{aligned}
$$

where the five terms following the three advection terms represent shear production, buoyancy destruction/production, vertical diffusion, molecular dissipation of TKE, and horizontal diffusivity, respectively. Note that the 1.2 coefficient preced- 
ing the vertical diffusion term incorporates effects from the pressure correlation terms.

Horizontal diffusivity $K_{H}$ (assumed constant in the current formulation) has no physical representation and acts mainly as a numerical smoother (Pielke 1984). In complex terrain situations, however, increased vertical diffusion occurs when horizontal diffusion acts along topography-transformed surfaces, and not along horizontal surfaces (Alpert and Neumann, 1984). Under stable nighttime conditions, for example, it increases the weak vertical mixing processes and thus prevents cool air pooling into valleys. Turbulent horizontal heat fluxes were therefore transformed into:

$$
\overline{\tilde{u}^{\prime} \theta^{\prime}}=\overline{u^{\prime} \theta^{\prime}}=K_{H} \frac{\partial \theta}{\partial x}=K_{H} \frac{\partial \theta}{\partial \tilde{x}}+K_{H} \frac{\partial \theta}{\partial \eta} \frac{\partial \eta}{\partial x} .
$$

Although similar correction terms could be introduced into the vertical turbulent heat fluxes, these corrections were less important than those in the horizontal for the moderately sloped terrain configurations of Bornstein et al. (1995).

It is generally assumed that $K_{q}=K_{h}$, and that the vertical turbulent diffusion coefficients are given by

$$
\begin{aligned}
& K_{m}=C_{1} l_{k} e_{T}^{1 / 2} \\
& K_{h}=K_{q}=\alpha K_{m},
\end{aligned}
$$


where turbulent Prandtl number $\alpha$ is assumed constant. The dissipation and diffusion mixing lengths ( $l_{\varepsilon}$ and $l_{k}$, respectively ) are from Terry and Lacarrère (1983), and are able to reproduce features found with higher order turbulence closure models.

The dissipation mixing length is given by

$$
\frac{1}{l_{\varepsilon}}=\frac{1}{k\left(z+z_{0}\right)}+\frac{C_{e 1}}{h_{i}}-\left(\frac{1}{k z}+\frac{C_{e 2}}{h_{i}}\right) m_{1} m_{2}+\frac{C_{e 5}}{l_{s}}
$$

where

$$
\begin{gathered}
m_{1}=\left(1+C_{e 3} h_{i} / k z\right)^{-1} \\
m_{2}= \begin{cases}0 & , L \geq 0 \\
\left(1-C_{e 4} L / h_{i}\right)^{-1} & , L<0\end{cases} \\
\frac{1}{l_{s}}=\left\{\begin{array}{cc}
0 & , \partial \theta / \partial \eta \leq 0 \\
\left(\frac{g}{\theta_{0}} \frac{\partial \theta}{\partial \eta} / e_{T}\right)^{2} & , \partial \theta / \partial \eta \leq 0
\end{array}\right. \\
L=\theta_{0} u_{*}^{2} /\left(g k \theta_{*}\right),
\end{gathered}
$$


where the constant $C_{e i}$ values have been determined experimentally. Boundary layer height $h_{i}$ is defined as the height at which turbulent energy $e_{T}$ falls to $10 \%$ of its surface value. The first two terms in equation (17) are the surface layer and neutral mixing layer lengths, respectively, while the third term enlarges the first two when the atmosphere approaches the free convection limit, thus providing a better representation of the effect of non-isotropic eddies during convective situations. The final term imposes a lower limit on $l_{\varepsilon}$ as a function of local stability. A similar formula exists for the diffusion mixing length $l_{k}$, but with different coefficients.

Vertical turbulent fluxes in the SBL (whose top $h$ is the height of the lowest numerical temperature grid point) are considered constant with height. Horizontal wind speed, potential temperature, and specific humidity in the SBL are assumed to obey Monin-Obukhov similarity scaling via the Businger et al. (1973) forced and mixed convective functions. As these functions grow too quickly in stable conditions when $z / L$ exceeds unity (Shir and Bornstein 1977), the Noilhan (1987) formulation is used to keep SBL fluxes from approaching zero too quickly.

Scaling "friction" parameters are computed, respectively, from horizontal wind speed, temperature, and specific humidity values both at the surface and at $h$ as follows: 


$$
\begin{aligned}
& \mathrm{u}_{*}=\mathrm{kV} \mathrm{V}_{\mathrm{H}}(\mathrm{z})\left[\ln \frac{\mathrm{z}}{\mathrm{z}_{0}}-\hat{\psi}_{\mathrm{m}}(\zeta)\right]^{-1} \\
& \theta_{*}=\frac{\mathrm{k}\left[\theta(\mathrm{z})-\theta_{0}\right]}{0.74}\left[\ln \frac{\mathrm{z}}{\mathrm{z}_{0}}-\hat{\psi}_{\mathrm{h}}(\zeta)\right]^{-1} \\
& \mathrm{q}_{*}=\frac{\mathrm{k}\left[\mathrm{q}(\mathrm{z})-\mathrm{q}_{0}\right]}{0.74}\left[\ln \frac{\mathrm{z}}{\mathrm{z}_{0}}-\hat{\psi}_{\mathrm{h}}(\zeta)\right]^{-1},
\end{aligned}
$$

where non-dimensional height $\zeta \equiv z / L$, but where $z=h$ for this scaling parameter calculation.

Computed scaling parameters are used to construct SBL wind, temperature, and moisture profiles, and to obtain SBL flux values from

$$
\begin{aligned}
& \tau=\rho_{0} u_{*}^{2} \\
& H=-\rho_{0} c_{p} u_{*} \theta_{*} \\
& E=-\rho_{0} L_{v} u_{*} q_{*} .
\end{aligned}
$$

The flux values are then used as internal linkages between the SBL and finite difference layers via the vertical diffusion terms applied at $h$.

As water vapor and carbon dioxide infra-red flux divergence generally dominates that of the solar flux, this latter effect is neglected. The $\partial Q_{N} / \partial z$ term of (12) is thus evaluated using the Sasamori (1968) scheme, with $\mathrm{CO}_{2}$ concentration fixed at $320 \mathrm{ppm}$ by volume, and with absolute humidity calculated from 


$$
\rho_{v}=\frac{q p_{0}}{0.62(1-q) R_{v} T}
$$

where the $\mathrm{p}_{0}$ profile is determined from standard atmosphere values and $\mathrm{T}$ is calculated by the Poisson equation. Note that pressure appears only in this highly parameterized radiative flux divergence term.

b. Boundary conditions

Boundary conditions are specified at the six external model boundaries (i.e., the four vertical lateral boundaries, model top, and bottom of the soil/water sub layer) and at the two internal boundaries (i.e., the surface and SBL top). At the model top, the wind is geostrophic, vorticity zero, and temperature and humidity values match those of the synoptic scale. No constraints other than a zero surface value are imposed on $\widetilde{w}$, which is computed to satisfy continuity equation (11); however, the upper conditions on $\tilde{u}$ and $\tilde{v}$ imply that the vertical variation of $\tilde{w}$ at this level is zero. Note that imposition of a zero $\tilde{w}$ at the model top would be over-specification.

Complex topography in a hydrostatic PBL model also allows for the formation and propagation of (mostly) vertically propagating gravity waves in stable conditions. As these waves can reflect at the upper boundary, a horizontal filter is used at the five uppermost computational grid levels of the finite-differenced layer 
to smooth all prognostic variables (except $e_{T}$ ) at each time step by use of their four neighboring values, i.e.,

$$
\hat{\phi}_{j, k}=(1-\lambda) \hat{\phi}_{j, k}+0.25 \lambda\left(\hat{\phi}_{j+1, k}+\hat{\phi}_{j, k+1}+\hat{\phi}_{j-1, k}+\hat{\phi}_{j, k-1}\right),
$$

where $\hat{\phi}$ is any variable and $\lambda$ varies linearly from 0.0 to 0.5 from the lowest to the highest of the five grid levels, respectively.

The current open lateral boundary conditions permit perturbations to cross those boundaries; however, the current grid formulation uses stretched horizontal grid spacing near lateral boundaries to move them away from the region of mesoscale activity. This stetching, in complex terrain, can allow new perturbations to grow in these regions, which is, however, minimized by use of horizontal topography at the inner four grid points at each lateral boundary.

While surface temperature is assumed constant for sea/lake grid points, time and space varying land surface temperature and specific humidity values are calculated from the model-determined surface heat and vapor fluxes. Soil surface temperature is currently calculated from the following modified prognostic " force-restore " equation of Deardorff (1978)

$$
\frac{\partial T_{0}}{\partial t}=-\frac{c_{1} G_{0}}{c_{s} \rho_{s} d}-\frac{c_{2}\left(T_{0}-T_{b}\right)}{\tau_{d}}
$$

where the temperature in the lower soil layer $T_{b}$ is assumed constant within each soil class. This equation was developed for bare soil, but in the present applica- 
tion, vegetation is indirectly accounted for in the lateral heat flux calculation (see below). The surface soil heat flux $G_{O}$ is obtained using a residual method on the following form of the surface energy balance equation:

$$
G_{0}=(1-a) R_{0}-F_{u}+F_{d}-H-E .
$$

Surface solar flux on a horizontal surface is computed from the formulation of Schayes (1982), including a specified aerosol absorption factor, variable earthsun distance, dry air Rayleigh scattering, and water vapor absorption; surface inclination effects are included in $R_{o}$ following Pielke (1984). The upward $\left(F_{u}\right)$ and downward $\left(F_{d}\right)$ long wave fluxes are calculated from the Stefan-Boltzman law and the Sasamori (1968) scheme discussed above, respectively. Net surface all-wave radiant flux $R_{N}$ is the sum of the above three fluxes (including surface albedo effects), while SBL convective and latent heat fluxes ( $\mathrm{H}$ and $\mathrm{E}$, respectively) are known from previous time step values via (19).

Soil moisture was treated by Deardorff (1978) in a manner similar to soil temperature. This approach, however, produces unrealistic latent heat fluxes, unless a full vegetation model is simultaneously implemented. The following simple Penmann-Monteith formulation (Monteith, 1981) is thus used to compute the surface latent heat flux $E_{o}$. It uses both a similarity theory based aerodynamic resis- 
tance $r_{a}$ (from Thom and Oliver, 1977) and a specified constant surface resistance $r_{o}$ (that includes vegetative effects), as follows:

$$
E_{0}=\frac{\delta\left(R_{N}-G_{0}\right)+c_{p} \rho_{0}\left[q_{s a t}-q(h)\right] / r_{a}}{\delta+\gamma\left(1+r_{0} / r_{a}\right)},
$$

where $R_{N}$ and $G_{o}$ are obtained as described above. Finally, $E_{o}$ is used in the following prognostic surface humidity equation

$$
\frac{\partial q_{0}}{\partial t}=\frac{1}{\rho \amalg}\left(\frac{E_{0}-E}{h}\right),
$$

where SBL latent heat flux $E$ is given by (19). Following Terry and Lacarrère (1983), turbulent energy $e_{T}$ is set equal to $4 u_{*}^{2}$ at the surface, in the SBL, and at the first numerical grid point of the finite-differenced layer.

\section{c. Numerics}

The numerical procedure by which TVM solves the PBL hydrodynamic and thermodynamic transport equations at each time step in the calculation is as follows. Solar and infra red radiative fluxes are first evaluated. Surface soil heat flux values $G_{O}$ are next obtained from (21) using old $H$ and $E$ values, and then surface temperature and specific humidity values are computed from (20) and (23), respectively. Using these values, SBL scaling parameters, fluxes, and profiles are 
determined from (18) and (19). Flux values at $h$ are used to solve for TKE values via a finite-difference version of (14); these values are then used to obtain PBL diffusion coefficient profiles from (15) and (16). The remaining finite differenced transition layer equations are then sequentially integrated for potential temperature (12), specific humidity (13), and vorticity (9), (10). Finally, stream functions, horizontal velocities, and vertical velocity fields are updated via (13a), (13b), and (11), respectively, time is advanced, and all computations are repeated.

TVM employs the fractional time step method described by Bornstein and Robock (1976) and Bornstein et al. (1987a). For each prognostic equation, each one-dimensional advection equation is thus first successively solved, likewise for each one-dimensional diffusion equation, and then finally for the remaining body force or source (sink) terms.

Finite difference calculations are performed on the non-uniformly spaced, three-dimensional staggered grid of Bornstein et al. (1987a), which locates velocity components at the center of appropriate perpendicular grid cell faces, vorticities at edges above and below corresponding velocity components, and passive scalars $(\theta, q)$ at the cell center (Fig. 4). TVM carries TKE values at the centers of upper and lower cell faces, as opposed to URBMET, which carried them at cell centers. 
Its current location is more consistent with its role in the evaluation of vertical diffusivities.

Boundary conditions on the current interlaced grid require extrapolation of variables outwards across some boundaries. A phantom layer, (of one nodal point in depth) above the model top and outside of each lateral boundary, is therefore used during these extrapolative calculations.

The currently used finite-difference schemes require secondary variables defined at various nodal locations in the computational cell. Such variables are defined by either flux-weighting or linear interpolation of primary variables, as discussed in MacCracken and Bornstein (1977) and Bornstein et al. (1987a).

The Donor Cell explicit finite difference advection scheme was originally used in URBMET on a non-uniformly spaced, staggered grid-mesh. The scheme is second order accurate in space and first order accurate in time. MacCraken and Bornstein (1976) eliminated the $2 \Delta x$ waves that appeared in regions with convergent flows by replacing the original linear averaging with flux weighted averaging. This scheme is free of negative results, transportive, mass consistent, and well suited to confluent conditions such as sea breeze fronts and valley flows; it is, however, highly dispersive. 
The piecewise parabolic advection scheme (PPM) of Collela and Woodward (1984) was introduced to TVM by Thunis (1995). It employs a higher order spatial interpolation and a simpler (but more accurate) algorithm for flux calculations of non-linear wave interactions than previous PPM schemes. For equally spaced grids, smooth solutions, and with small time-steps it is fourth order accurate, while for a non-uniformly spaced grid mesh, as in URBMET, it is third order accurate. Its higher order produces a small $\mathrm{K}_{\mathrm{N}}$, which allows for the simulation of sharp spatial gradients. Such discontinuities do, however, produce low-amplitude noise, which is eliminated by "flattening" the interpolation profiles used to approximate these discontinuities; this locally reduces the order of the scheme.

This flattening technique, however, is not sufficient in near-calm conditions. The additional dissipation needed under such conditions is thus introduced by imposition of an artificial velocity at each grid that alternates in direction with each time-step.

Horizontal diffusion is approximated by an explicit three-point forward in time and centered in space (FTCS) difference scheme, which possesses second order accuracy in space and first-order accuracy in time. The implicit Crank Nicolson scheme is used for vertical diffusion. This scheme is absolutely stable, and thus allows for the use of a larger diffusion time-step than did the explicit scheme 
used in Bornstein et al. (1987a). TVM approximates body force and source/sink terms by FTCS differencing.

The time dependent (and unequal advection and diffusion) time steps of Bornstein and Robock (1976) were useful in URBMET simulations, as advection time steps were much larger than its explicit vertical diffusion time steps. With the current implicit vertical diffusion scheme, topography induced gravity-wave timesteps are generally the limiting ones. The maximum uniform time step thus allowed ranges from 30-60 seconds, dependent on model-domain topographic geometry, and on the wave-lengths of the thus induced gravity waves.

\section{d. Topography}

Measured elevation-data were obtained over INTERNET in the form of 1 deg. latitude by 1 deg. longitude USGS Digital Elevation Model (DEM) data files. Each DEM file contains a $1201 \times 1201$ array of average elevation values at a three arc-second by three arc-second ( $30 \mathrm{~m}$ by $30 \mathrm{~m}$ ) resolution. Program TOPOAV was thus developed to produce average elevation values from DEM data on any arbitrary (uniformly or non-uniformly) spaced model grid-mesh, in either rectangular coordinates or in the original spherical-grid coordinates of DEM files. A full 
description of how to obtain and manipulate DEM files, and then how to use TOPOAV is given in Appendix B.

Raw DEM files were previously compressed by program GZIP and are void of end-of-line delimiters. Decompression is achieved by use of the same program, which is widely available through INTERNET. Delimiters could then be added via UNIX command 'dd', but in the present case program CONVERT was developed to do this and to rewrite DEM files in a format compatible with TOPOAV.

Users are responsible for selecting the DEM files that completely cover a model grid domain, and must arrange them in a geographically consistent manner for use by TOPOAV. If the model domain extends outside the domain of the selected DEM files, "end-of-file" errors are generated. Extra DEM files produce no errors, but waste computer space/time resources.

DEM elevation data are each representative of an area that covers 3 arcsecond of latitude by 3 arc-second of longitude. Thus, when output average elevations are required in rectangular grids, the southern domain edge latitude is needed so that TOPOAV can adjust for the latitudinal variation in the length of a degree of longitude. The south-westernmost point included in the DEM input domain also serves as the origin of the TOPOAV input-grid.

Horizontal model grid length series are input, first for the west to east direction, and then for the south to north direction. If the required model output SW 
Horizontal model grid length series are input, first for the west to east direction, and then for the south to north direction. If the required model output SW grid origin is not identical with the DEM input data SW origin, then the W to $\mathrm{E}$ and $\mathrm{N}$ to $\mathrm{S}$ coordinate distances between the former and latter grid points are the first entries in the output $\mathrm{N}$ to $\mathrm{S}$ and $\mathrm{W}$ to $\mathrm{E}$ grid length series, respectively.

TOPOAV produces simple area-weighted average topographic height values. Fractional weights are thus required whenever a three arc-second DEM input grid overlaps two or more model output grids. The $W$ to $E$ and $N$ to $S$ weights of DEM input grid ()$_{i, j}$ are equal to the lengths $\left(W_{i}\right.$ and $W_{j}$, respectively) of the portion of each DEM grid within output model grid ()$_{\mu, \lambda}$, divided by the respective output grid length $\left(\mathrm{L}_{\mu}\right.$ or $\left.\mathrm{L}_{\lambda}\right)$. While $\mathrm{W}_{j}$ is a function only of latitude, $\mathrm{W}_{i}$ is function of both latitude and longitude due to the latitudinal variation of the W-E dimension of an arc-second. The average elevation of each model grid $\left(h_{g}\right)$ is thus given by

$$
\left(\mathrm{h}_{\mathrm{g}}\right)_{\mu}, \lambda=\frac{\sum_{i=1}^{n} \sum_{j=1}^{m} \widetilde{\mathrm{h}}_{i, \mathrm{j}} \cdot\left(W_{i}\right)_{\mathrm{j}} \cdot \mathrm{W}_{j}}{L_{\mu} \mathrm{L} \lambda} .
$$

Input to program TOPOAV is not limited to DEM data sets, but could be of any resolution in either degrees latitude/longitude or in rectangular coordinates. Thus averaging can be performed for any combination of spherical and rectangular 
no constraint exists on specified units of length of each grid cell; however, with input to output conversions from degrees to length, the units must be arc-sec and $\mathrm{km}$, respectively. 


\section{Chapter 3. MODEL INPUT}

The current study simulates temperature and wind flow patterns in the Phoenix area for the period of 30 August at 2000 LST (0400 GMT on the 31st) to 1 September at 0400 LST (1200 GMT). As the model requires a spin-up period, results will only be presented for the final 24 hours of the simulation.

During 23-29 August 1992, hurricane Lester produced heavy rainfall in Arizona in amounts that ranged from $4.5 \mathrm{~cm}$ to the NorthEast and east of Phoenix to $1.3 \mathrm{~cm}$ west of the city. For the following two days, however, stormy weather persisted only in the high plateau NorthEast of Phoenix. During 1-5 September, clear conditions and cooling temperatures were reported for all of Arizona (Weekly Weather and Crop Bulletin 1992).

The selected model-simulation domain ( 111 to $112.3^{\circ} \mathrm{W}, 33.14$ to 33.84 ${ }^{\circ} \mathrm{N}$ ) is $128 \mathrm{~km}$ long in the east-west direction, $72 \mathrm{~km}$ in the north-south direction, and $5 \mathrm{~km}$ in the vertical (Fig. 5). Most of the important regional topographic influences on wind flow patterns are thus included in the domain, i.e., the nearby mountain peaks to the north and east, as well as the South and Gila Bend mountains to the south and west, respectively. While non-averaged USGS topographic height values ranged from about $280 \mathrm{~m}$ to about $2000 \mathrm{~m}$, grid-averaged values 
ranged from $300 \mathrm{~m}$ to about $1600 \mathrm{~m}$. Domain boundaries generally coincide with flat areas or mountain ridges, except in the northeastern corner, where this was not possible. Such a configuration in combination with the current constant horizontal-terrain lateral-boundary buffer zone (discussed below) provides a numerically stable grid formulation for complex terrain flow simulations. Inclusion of the next range of even steeper topographic features, located north and east of the current model domain, would have forced an untenable compromise between horizontal grid resolution and computer storage requirements. In addition, it might have introduced non-hydrostatic topographic features.

The model domain has $42 \times 24$ regularly spaced ( $3 \mathrm{~km}$ long) grids in the $\mathrm{x}$ and y directions, respectively, because high resolution is required both near the central urban area as well as in areas with large topographic gradients. Included are three buffer points that form a zero topographic-height gradient boundary (in the direction perpendicular to each domain edge) to damp outward propagating waves. The following arbitrary non-uniform vertical grid spacing was adopted: 0 , $25,55,9,140,200,260,345,445,565,715,900,1120,1400,1725,2130,2620$, $3230,4000,5000 \mathrm{~m}$. Note that these values provide maximum resolution near the surface.

The model grid surface was separated into four land-types (Fig. 5) based on land-use patterns (determined from Phoenix urban planning maps) and the ob- 
served PRISM-network (discussed below), continuous shelter-level temperature histories. Region 2 in the central part of the domain consists of heavily urbanized downtown Phoenix and other nearby cities. Suburban Regions 3 and 4 are located to the west and northeast of Region 2, respectively. As Region 4 is higher in elevation than Region 3, its average meteorological conditions and soil type differ from that of Region 3. Rural Region 5 covers the remaining domain areas. Typical urban building-barrier topographic-heights were set at $20 \mathrm{~m}$ for the heavily urbanized region, and at $10 \mathrm{~m}$ for the two suburban areas.

Five-minute averaged PRISM meteorological data from the Office of Climatology at Arizona State University provided near-surface observations of wind and temperature values at 16 observation Sites (Table 1) within the model domain. Winds were obtained from anemometers mounted on 6.25 m masts, while temperatures were obtained at the standard shelter level of $1.6 \mathrm{~m}$. These measurements were used both to initialize (as discussed below) and to evaluate simulated results.

NWS rawinsonde observations for 31 August at $1200 \mathrm{GMT}$ and 1 September at 0000 GMT were available from both Tuscon at $787 \mathrm{~m} \mathrm{MSL}$ and Winslow at $1400 \mathrm{~m} \mathrm{MSL}$, respectively). Since the simulation start-time was at $0400 \mathrm{GMT}$ on 31 August, the wind velocity profiles at these two times (Figs. 6 and 7 for Tuscon and Figs. 8 and 9 for Winslow, respectively) were pro-rated to produce one time- 
Table 1. PRISM observation sites, locations, and elevation values

\begin{tabular}{|c|c|c|c|c|}
\hline ID number & Station Name & Latitude & Longitude & Elevation (m) \\
\hline 1 & Alameda & $33^{\circ} 23^{\prime} 47^{\prime \prime} \mathrm{N}$ & $111^{\circ} 55^{\prime} 09^{\prime \prime} \mathrm{W}$ & 340 \\
\hline 2 & Arcadia & $33^{\circ} 30^{\prime} 36^{\prime \prime} \mathrm{N}$ & $112^{\circ} 00^{\prime} 10^{\prime \prime} \mathrm{W}$ & 411 \\
\hline 3 & Collier & $33^{\circ} 27^{\prime} 46^{\prime \prime} \mathrm{N}$ & $112^{\circ} 17^{\prime} 22^{\prime \prime} \mathrm{W}$ & 354 \\
\hline 4 & Corbell & $33^{\circ} 21^{\prime} 25^{\prime \prime} \mathrm{N}$ & $111^{\circ} 49^{\prime} 41^{\prime \prime} \mathrm{W}$ & 399 \\
\hline 5 & Falcon & $33^{\circ} 28^{\prime} 09^{\prime \prime} \mathrm{N}$ & $111^{\circ} 43^{\prime} 56^{\prime \prime} \mathrm{W}$ & 450 \\
\hline 7 & Fountain & $33^{\circ} 36^{\prime} 00^{\prime \prime} \mathrm{N}$ & $111^{\circ} 42^{\prime} 33^{\prime \prime} \mathrm{W}$ & 536 \\
\hline 9 & Kay & $33^{\circ} 24^{\prime} 47^{\prime \prime} \mathrm{N}$ & $112^{\circ} 09^{\prime} 09^{\prime \prime} \mathrm{W}$ & 340 \\
\hline 11 & Pera & $33^{\circ} 27^{\prime} 51^{\prime \prime} \mathrm{N}$ & $111^{\circ} 56^{\prime} 19^{\prime \prime} \mathrm{W}$ & 416 \\
\hline 12 & Pringle & $33^{\circ} 34^{\prime} 14^{\prime \prime} \mathrm{N}$ & $112^{\circ} 06^{\prime} 27^{\prime \prime} \mathrm{W}$ & 406 \\
\hline 13 & Rittenhouse & $33^{\circ} 15^{\prime} 38^{\prime \prime} \mathrm{N}$ & $111^{\circ} 38^{\prime} 14^{\prime \prime} \mathrm{W}$ & 465 \\
\hline 14 & Sheely & $33^{\circ} 29^{\prime} 10^{\prime \prime} \mathrm{N}$ & $112^{\circ} 12^{\prime} 59^{\prime \prime} \mathrm{W}$ & 353 \\
\hline 15 & Stapley & $33^{\circ} 26^{\prime} 00^{\prime \prime} \mathrm{N}$ & $111^{\circ} 48^{\prime} 15^{\prime \prime} \mathrm{W}$ & 296 \\
\hline 16 & Steward Mount. & $33^{\circ} 33^{\prime} 30^{\prime \prime} \mathrm{N}$ & $111^{\circ} 32^{\prime} 00^{\prime \prime} \mathrm{W}$ & 475 \\
\hline 17 & Sun Lakes & $33^{\circ} 13^{\prime} 28^{\prime \prime} \mathrm{N}$ & $111^{\circ} 52^{\prime} 27^{\prime \prime} \mathrm{W}$ & 396 \\
\hline 18 & Superstition & $33^{\circ} 25^{\prime} 07^{\prime \prime} \mathrm{N}$ & $111^{\circ} 32^{\prime} 12^{\prime \prime} \mathrm{W}$ & 578 \\
\hline 19 & Spurlock & $33^{\circ} 21^{\prime} 30^{\prime \prime} \mathrm{N}$ & $111^{\circ} 27^{\prime} 19^{\prime \prime} \mathrm{W}$ & 594 \\
\hline
\end{tabular}


averaged profile for each site. These were then compared to determine the elevation above the surface at which their wind velocity first coincided; this was found to be $\sim 2 \mathrm{~km}$. A smoothed version of their common profile above this level was used to construct the upper domain-wide input initial wind speed profile (Fig. 10), with an assumed linear profile at lower elevations. As observed winds near the model top ( $5 \mathrm{~km} \mathrm{MSL}$ ) were relatively constant in time and space, they were used as the required constant input geostrophic wind velocity value, i. e., $13 \mathrm{~m} / \mathrm{s}$ from $250^{\circ}$.

Initial surface temperature for each land type at 2000 LST on 31 August was determined from their respective observed temperatures. The rawinsonde temperature profiles (Figs. 11-14) were treated in a similar manner (as described above for wind speed) to determine an assumed three-layer initial input potential temperature profile (Fig 15), in which a neutral layer was imbedded between two slightly stable layers. Potential temperature at each grid level is then calculated from this lapse rate and a background volume-averaged potential temperature. Note that this produces an initial discontinuity between the upper soil and the lower SBL boundaries which, however, is eliminated in subsequent time-steps as the value at the latter boundary is assumed to be equal to that of the former. 
A domain-wide averaged initial surface specific humidity value of 0.01 $\mathrm{kg} / \mathrm{kg}$ was derived from observed NWS 0400 GMT shelter-level dew-point depression and temperature data. An initial input vertical profile was constructed based on the assumption that this value decreased exponentially from the surface to an elevation of $2.5 \mathrm{~km}$, and remained constant at higher elevations.

To correctly reproduce wind flow patterns in complex terrain, it is necessary to first accurately simulate the diurnal and spatial characteristics of observed surface temperature fields. With the currently used "force-restore" surface temperature prediction method of Deardorff (1978), accurate predictions require accurate specification of the following energy balance parameters for each land type: deep soil temperature, soil heat capacity, albedo, emissivity, surface roughness, and resistivity to evaporation. All of these parameters, however, depend on soil moisture content, whose spatial distribution and diurnal variations are generally unknown in complex terrain mesoscale-modeling applications. Note that the Deardorff formulation implicitly assumes a constant source of soil moisture at the surface, via the specified constant "soil resistivity to evaporation" value input for each land-use type. Predicted surface evaporation rates thus depends only on the amount of energy available. Use of the "soil resistivity" parameter, however, implicitly accounts for soil moisture content variations between land-use types. First approximations to the above energy balance parameters were determined from the 
literature (e.g., Pielke 1984) based on estimates of soil moisture content (30-40\%

for rural and $20 \%$ for urban), and from previous URBMET simulations (Table 2). The final values chosen for the current simulations are shown in Table 3.

As Grossi (1993) demonstrated, the input soil heat capacity value for each land-use type strongly influences simulated daytime maximum temperature values via its dominance over the warming (or "force") phase of the surface temperature prediction equation. She also demonstrated that the input deep soil temperature value for each land-use type likewise strongly influences nocturnal minimum temperature values via its dominance over the cooling (or "restore") part of the equation. Input values of these two parameters were thus refined in a series of model "site-sensitivity" simulations until observed $1.6 \mathrm{~m}$ temperature values were inbetween simulated surface and $12.5 \mathrm{~m}$ values.

Tuning of the wind-flow field is achieved by adjustments to the input geostrophic wind speed and/or direction until differences between observed and predicted values are minimized. Small changes (5-15 deg.) in geostrophic direction generally influence flow directions in a linear manner aloft over the whole domain and near the surface in flat terrain areas (results not shown). Non-linear interactions, however, become important in domain regions with complex-terrain features, e.g., west to southwesterly input geostrophic winds produced regional 


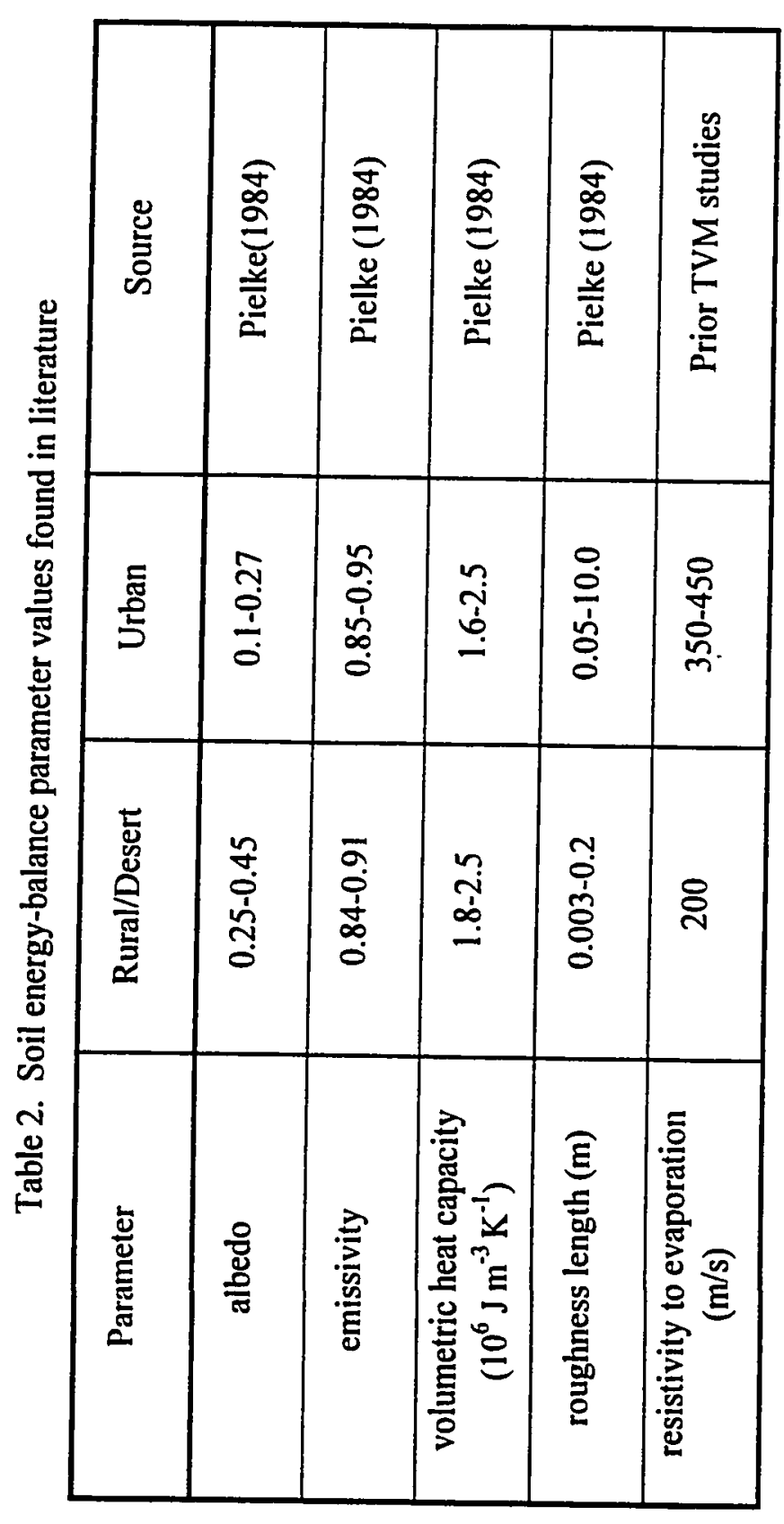




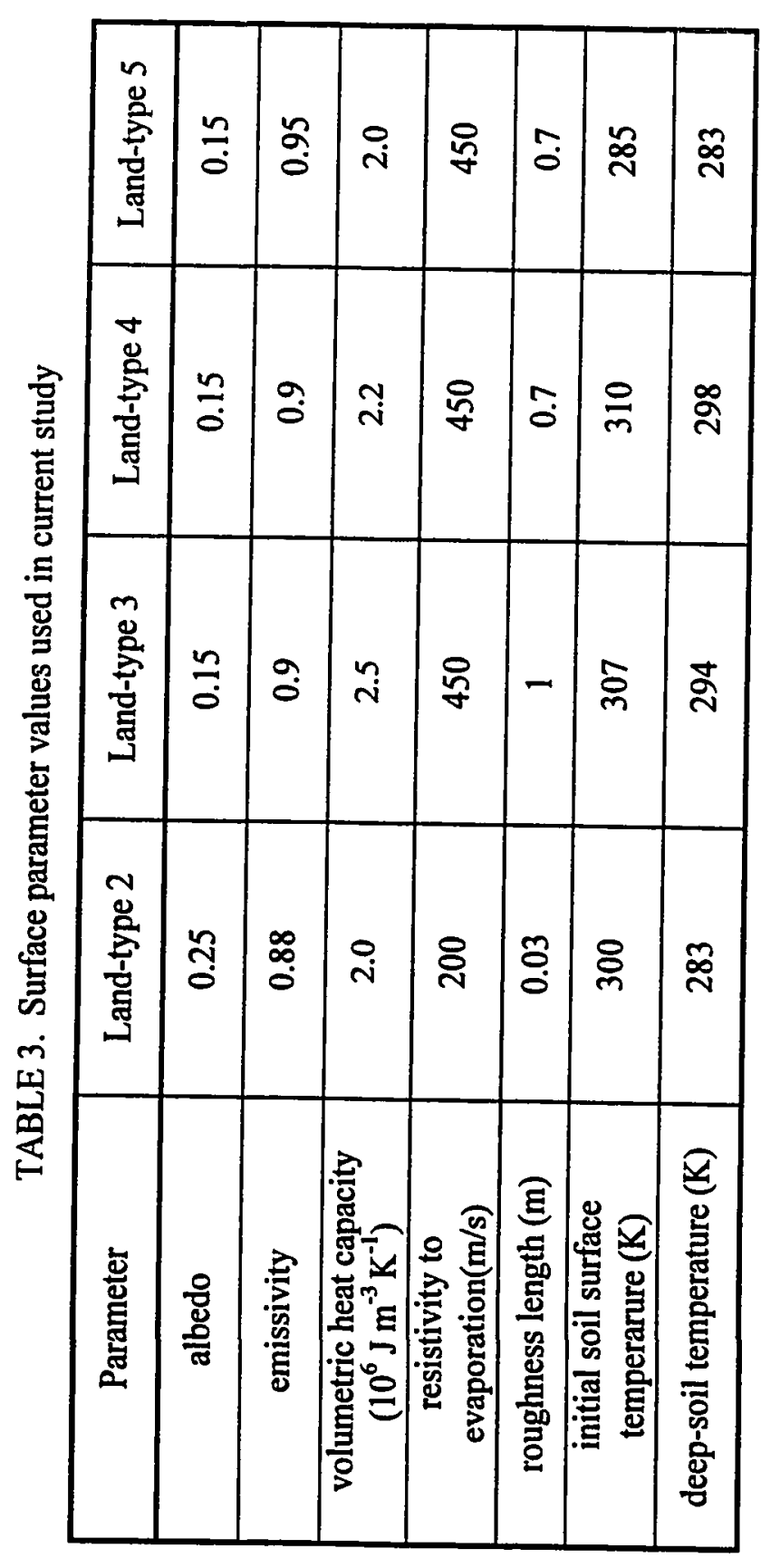


easterly nocturnal downslope and westerly daytime upslope flows, but west to northwesterly geostrophic winds produced a general westerly pattern and localized upslope/ downslope flows. Input geostrophic wind speed can either decrease or increase predicted near-surface winds, as well as influence the diurnal phase of topography induced wind patterns, e. g., reduction of input geostrophic speed from 13 to $10 \mathrm{~m} \mathrm{~s}^{-1}$ allowed for enhanced mesoscale forcing that produced early development of accelerated nocturnal downslope drainage flows. 


\section{Chapter 4. RESULTS}

Three model simulations were performed as follows: (a) a "Base-Case" simulation of observed Phoenix area flow patterns, (b) an evaluation of effects resulting from the newly implemented PPM advection scheme, and (c) a study of Phoenix area urban effects on local temperature and wind flow fields. The first simulation thus employs the PPM advection scheme and includes urban land-use grid points within the model domain. Note also that this simulation is tuned (as described above) with site by site comparisons of predicted surface and $12.5 \mathrm{~m}$ against observed $6.5 \mathrm{~m}$ temperatures. The previously used Donor Cell advection scheme replaces PPM for the second simulation, while the final simulation uses the PPM advection scheme, but does not include any urban land-use grid points.

\section{a. Run 1}

Final predicted near-surface temperature-wave phase generally matched observed values within 1-2 hours, with predicted early morning temperatures that rise faster than observed, and/or afternoon cooling that occurs somewhat too early at some sites. Predicted temperature values also generally "match" (i.e., bracket) ob- 
served $2 \mathrm{~m}$ values to within two degrees, while the short-term discrepancies that do occur are specific to land-use type.

During the first simulated morning period, for example, all suburban sites match observations to within $1{ }^{\circ} \mathrm{C}$ for most of the simulation period (e. g., Figs. $16 \mathrm{a}$ and $16 \mathrm{~b}$ ) but like many other sites they over-predict second morning temperatures by about $2{ }^{\circ} \mathrm{C}$. While western suburban sites show a $2{ }^{\circ} \mathrm{C}$ under-prediction for the first three hours of the simulation (due to a somewhat low input heat capacity value), the two eastern suburban sites show an (unexplained) $2{ }^{\circ} \mathrm{C}$ underprediction.

Predicted and observed values at most urban sites in smooth terrain also agree to within $1^{\circ} \mathrm{C}$. Typically, however, urban sites underestimate nocturnal temperatures by about $2{ }^{\circ} \mathrm{C}$ for a period of four to five hours starting around 1900 LST (Fig. 16c). An exception to this value is a $4^{\circ} \mathrm{C}$ under-prediction in the middle the urban area for about seven hours starting at about 1600 LST at Sites 1 (Fig. 16d) and 15. Exclusion from the model of outgoing long wave radiation entrapment by buildings, and of anthropogenic heat input (from air conditioning), may account for this overestimated urban cooling. Note that while the highest terrain urban Site 18 (Fig. 16e) also matches observations to within one degree for most 
of the simulation, it over-predicts second morning surface temperatures by about $2-3^{\circ} \mathrm{C}$, again due to a somewhat high input heat capacity.

All rural sites match observations to within $2{ }^{\circ} \mathrm{C}$ for most of the simulation period. Due to the large distances and terrain-height variability among rural sites, however, soil characteristics differ from site to site. First-morning predicted minimum values (within the above error band) thus range from correct at Site 13 (Fig. 16f) to high at the lowest terrain Site 3 (Fig. 16g) and to low at high terrain Site 19 (Fig. 16h). The typical $\left(1-2^{\circ} \mathrm{C}\right)$ over-prediction of the final few hours of the simulation period also occurs.

Some error in simulated surface temperature values is inevitable because the model does not incorporate a time-varying heat capacity, which in this case would arise from post-sunrise evaporation from the precipitation-moistened soil. Input heat capacity values were therefore generally lower than actual moist-soil values for the earliest two simulation phases (pre-sunrise and morning hours), and thus the model slightly overestimated both the cooling at the simulation start and the warming during the first few hours after sunrise. Due to soil moisture evaporation the actual heat capacity values gradually become somewhat smaller than model input values, and thus second-morning cooling rates are generally underpredicted. 
The above heat capacity differences are largest for rural and high elevation regions, with their high soil moisture content, and smallest for the (drier) urban regions. Note that since no observation sites exist at the large northern and northeastern mountain regions, their predicted temperature values can not be evaluated. Also note that while observed minimum temperatures are generally lower during the second morning, use of constant input heat capacity values produce approximately cyclic predicted temperatures.

The diurnal variation of predicted spatial temperature distributions (discussed with Run 3 results) sequentially produces the following three nearsurface (12.5 m) Base Case wind flow regimes: downslope drainage nocturnal flow, morning upslope flow, and afternoon synoptic-dominated flow.

In the first regime, most of the domain is dominated by a nocturnal-cooling induced easterly downslope drainage flow (e. g., at 0600 LST, Fig. 17a). Downslope flow from the steep hills at the northeastern portion of the domain produces converging flow toward the valley bottom near Site 5. Flow over the urban region then follows the NE to SW low-terrain axis, diverges around the isolated hilltop $\mathrm{SW}$ of the city, and finally funnels westward between the two hilltops in the southwestern portion of the domain. Easterly downslope flow from the mountain north of the city flows around the urban area, and then converges with the above flow to 
exit through the southwestern pass. Downslope flow also occurs into the valley near the northeastern domain corner.

Areas not influenced by the higher urban roughness have higher wind speeds, i. e., NW of the city, at the SE domain corner, and near the SW mountain. Note also that westerly flow occurs at the mountain top locations, as the strong westerly geostrophic wind at these elevations prevents formation of downslope easterly winds.

Concurrent observed winds show a similar pattern (Fig. 18a) that includes the convergence and divergence zones. As the predicted wave-like flow pattern over the uban area is, however, displaced by about 3-6 $\mathrm{km}$ to the $S$ of its observed location, the convergence zone over the city is likewise displaced. In addition, observed velocities at the southeastern part of the domain are more southerly than predicted, possibly due to the exclusion of topographic features in an arc outside the SE domain corner. Note, the lack of mountain-top observations precludes evaluation of predicted westerly mountain-top flows.

By 1000 LST, the flow over the low-terrain western and southern domain areas is dominated more by thermal forcing from the closer northern mountains than by the more distant eastern mountains, and thus the flow pattern is characterized by a series of mostly southerly localized upslope winds (Fig. 17b). Westerly flow occurs in the eastern portion of the domain, while southeasterly flow occurs 
on the eastern slopes of both the northern and northeastern mountains. Flow divergence at the southern edge of the city, with its lack of natural topographic features, will be seen in Run 3 to arise from an urban building-barrier effect, as does the flow vortex located downstream of the northeastern urban corner.

Observed 1000 LST winds (Fig. 18b) still show westerly flow over most of the domain, as observed post-sunrise soil heating rates are lower than predicted (discussed above). Simulated southerly upslope flows thus develop about two hours too early, and hence the predicted 1000 LST flow pattern correlates best with the 1200 LST observations (Fig. 18c).

The predicted local upslope regime lasts until about 1200 LST, but by one hour later (Fig. 17c), the final generally westerly flow regime begins. Flow at this time results from both the westerly mesoscale forcing of the large eastern topographic features and the imposed westerly synoptic forcing. The westerly regime is fully developed by about 1500 LST, when the westerly synoptic forcing finally overwhelms the now reduced upslope forcing (due to the afternoon surface cooling).

Westerly flow persists through the afternoon and early-evening hours with only minor changes. It is interesting to note, however, that stable layer blocking concurrent with downslope forcing from the western side of the hill that protrudes into the northern urban region, forces a southward deflection of the westerly flow 
over the urban center. This produces a terrain-following wave-like flow pattern that begins around 1700 LST and is most pronounced around 1900 LST (Fig. 17d). The observations at 1300 LST (Fig. 18d) show upslope flow in the eastern portion of the domain, as predicted. The observed flow over the city, however, is still southerly, indicating persistence of the local upslope regime. Because the roughly two-hour predicted phase lead in the flow still persists, the predicted upslope flow regime at 1300 LST coincides best with averaged observed 1400 and 1500 LST wind velocities (Fig. 18e). As also predicted, westerly winds in the low terrain regions (over and west of the city) are observed to begin at about 1500 LST and to reach peak values at about 1900 LST.

The observed terrain-following wave over the city, however, begins an hour earlier (at 1600 LST) and shows a stronger deflection than predicted. These differences result due to the smoothing of model input topography, which produces an underestimation of both the downslope and terrain-blocking forcings. Consequently, increased surface cooling is required before these forcings can overcome the synoptic forcing; the under-predicted deflection also results from this effect.

The hours between 2000 and 2400 LST constitute a transition period between the afternoon upslope and evening downslope flow patterns, e.g., the 2200 LST predicted pattern (Fig. 17e) consists of a series of localized, low-speed, downslope drainage flows. As nocturnal cooling intensifies, however, a predicted 
downslope pattern is consolidated, and thus the winds at 0100 LST on September 1st (Fig. 17f) show a generally easterly downslope flow that persists relatively unchanged until 0600 LST (Fig. 17g). Note that the predicted winds are cyclic, as this latter pattern is similar to that predicted 24 hours prior (Fig. 17a).

Observations during this transition period show no clear-cut flow pattern, as speeds are generally low, e.g., several sites at 2300 and 2400 LST (Fig. 18g) show 0-1 $\mathrm{m} \mathrm{s}^{-1}$ speeds. While comparisons between observed and predicted flow directions are thus difficult, the start of the observed downslope flow after 2300 LST means that its predicted onset was about two hours premature.

As the downslope flow intensified, wind speeds increased and an organized downslope regime became established. Wind observations an hour after midnight (Fig. 18h) therefore show an easterly downslope flow pattern that generally matches predicted values, except for the observed disturbance over the western portion of the city; this overall pattern persists until about 0400 LST (Fig. 18i). In the following few hours, however, observed wind speed values again drop to less than $1 \mathrm{~m} \mathrm{~s}^{-1}$ at most sites, an effect not reproduced in the model. This low speed period differs from the observed flow 24 hours prior, in response to changing synoptic conditions; an effect that the current formulation cannot reproduce.

While the above comparisons between observed and predicted hourly flow patterns show the model to have reproduced the main observed flow features, ad- 
ditional insight into model behavior can be obtained from site by site comparisons between the time-series of observed and predicted hourly wind velocities. Note that given the large hour to hour variations in observed velocities at many locations (e.g., Fig. 19a), site time-series were smoothed via a three-hour running averaging process.

Rural Site 19 (Fig. 19b), the highest-topography observation site, has the best match between predicted and observed wind-speeds. Differences only occur at 0600 and $1900 \mathrm{LST}$, with a $1.5 \mathrm{~m} \mathrm{~s}^{-1}$ under-prediction and a $2 \mathrm{~m} \mathrm{~s}^{-1}$ overprediction, respectively. Its wind directions also generally have the best match with observed values, but they do show the two-hour premature prediction of daytime upslope flow typical of many sites.

The remaining three rural locations (Sites 3, 13, and 17), more distant from topographic features, have larger wind-speed under-predictions. The most distant Site 17 (Fig. 19c), for example, shows the largest systematic error $\left(2-4 \mathrm{~m} \mathrm{~s}^{-1}\right)$ of all sites. Its predicted wind direction values show a larger than average phase lead (34 hours), and an afternoon NWW flow instead of the observed SSW afternoon flow, both of which indicate under-predicted mesoscale forcing by the northeastern terrain. This under-prediction results both from the exclusion of large terrain features NE of the domain and from the smoothing of model input topography. Note that the latter effect is important throughout the simulation, while the forme mostly 
affects results during the upslope regime. Also note that both under-predictions enhance the impact of the westerly synoptic flow.

The two high-topography suburban Sites 7 and 16 likewise show a good match between observed and simulated wind speed and direction values for most of the simulation period (Figs. 19d and e, respectively). Significant differences only occur around midnight, with over-predicted speeds $\left(2 \mathrm{~m} \mathrm{~s}^{-1}\right)$ at Site 7 and under predicted speeds (also $2 \mathrm{~m} \mathrm{~s}^{-1}$ ) at Site 16. This is consistent with their local downslope flow direction and the above-mentioned increased synoptic influence, which also affects predicted flow directions.

Predicted directions at Site 16, for example, compare well with observation values until 1600 LST, when the predicted flow became northeasterly (i. e., downslope) in response to the enhanced synoptic influence, while the observed flow remained southwesterly (i.e., upslope) until 2100 LST. Site 7 shows morning northwesterly downslope flow from the hills to its W (concurrent with the westerly synoptic forcing) to persist for two hours longer than observed. Its evening upslope flow, on the other hand, begins only an hour too early.

The two remaining suburban locations (Sites 9 and 14) show less accurate wind predicted velocities, as they are located in low terrain. Predicted morning speeds at Site 9 (Fig. 19f), for example, are too low by about $2 \mathrm{~m} \mathrm{~s}^{-1}$. Predicted wind directions again show the typical early development of the mid-morning 
upslope flow (by about two hours), but a larger phase-lead for the evening downslope flow (by about three hours).

The highest-terrain urban Site 18 also has the best match of the eight urban sites between observed and predicted wind velocity values (Fig. 19g). Differences only include some over-prediction (1-2 $\left.\mathrm{m} \mathrm{s}^{-1}\right)$ during both the high-speed period around 1300 LST and the low-speed period around 2100 LST. Predicted directions at this site again show early development of both predicted daytime upslope and downslope flows, but differences are generally within 20 degrees.

Largest urban wind speed under-predictions $\left(1.5-3.5 \mathrm{~m} \mathrm{~s}^{-1}\right)$ occur at Site 12 (Fig. 19h), located most distant from the high topography. Consistent with most sites, its predicted directions also show a morning phase lead of 2-3 hours. Note, however, that its afternoon direction matches observed values, as both the synoptic and thermal forcings are from the west to southwest.

Site 11 (Fig. 19i) is typical of the remaining urban smooth-terrain areas, with generally good speed results, and with direction values that again show an early development of WSW upslope flow. The persistence of this flow is an extreme example of the enhanced synoptic influence.

In summary, the current results (details discussed below) show predicted velocities to have generally reproduced observed diurnal-period phase characteristics (i.e., high daytime and low nighttime speed values, veering during warming 
hours and backing during cooling hours) at all sites. The accuracy of results, however, varies both with time of day and distance from the largest topographic features, e.g., predicted daytime speeds best match observed values at high elevation sites, but are generally underestimated at low elevation sites. Wind speed differences between observed and predicted values are typically within $2 \mathrm{~m} \mathrm{~s}^{-1}$, while local phase errors range from one to four hours.

b. Run 2

In this simulation, the first order "Donor Cell" replaced the third order PPM advection scheme for a comparison between predicted near-surface wind flows. Boundary and initial conditions were, therefore, identical to those in Base Run 1,i. e., neither the temperature nor wind-flow fields were further tuned.

Run 2 wind-flow patterns during the first two flow regimes (described above for Run 1) were similar to those of the base simulation. Donor cell results at 0600 LST (Fig. 20a), for example, show almost identical flow patterns to concurrent results from the PPM scheme. The new speeds are, however, somewhat lower (relative to those of PPM) due to an under-prediction of mesoscale forcing, which results from the high Donor Cell numerical diffusion that reduces horizontal gradients. 
Differences in flow directions first become evident during the second regime, but only in the northeastern steep-terrain region, where at 1300 LST the Donor Cell scheme fails to produce the upslope flow on the eastern mountain slopes (Fig. 20b) predicted by the PPM scheme (Fig. 17c). During the third flow regime (i. e., after 1500 LST), the Run 2 predicted flow is somewhat more westerly (again indicative of the overestimated synoptic influence) than the PPM predicted southwesterly flow. By 1900 LST (Fig. 20c ), this increased influence produces a domain-wide westerly flow, while concurrent Base Run 1 results (Fig. 17d) show both southerly and northerly flows in response to stronger local thermal forcings.

In the following three hours, the Donor Cell scheme predicts a gradual veering, so that by 2200 LST (Fig. 20d) the flow shows a general west to northwesterly pattern. At the eastern mountain slopes, the co-directional downslope and synoptic forcings produce unrealistically large wind speeds from the west that range from 5 to $15 \mathrm{~m} \mathrm{~s}^{-1}$. Over the city, winds decelerate to near calm values (due to the larger urban roughness), as they did in Run 1; however, downslope flow has failed to develop (unlike in Run 1) in regions in which it would have an easterly component.

By 0300 LST (Fig. 20e), the mostly westerly downslope winds in the western portion of the domain have become even faster $\left(20 \mathrm{~m} \mathrm{~s}^{-1}\right)$, and an unrealistically sharp velocity discontinuity has developed NW of the urban area. In addi- 
tion, the observed downslope flow still has not developed at the eastern edge of the city, as it did in the Run 1 simulations.

The high numerical dispersion of the Donor Cell scheme has a stronger impact on smoothing mesoscale thermal gradients during reduced turbulence nighttime periods. Consequently, horizontal temperature gradients sufficient to produce local downslope components strong enough to overcome synoptic forcing do not form anywhere in the domain during the second nighttime period. During the first night, however, the imposed initial surface thermal gradient was sufficient to induce easterly downslope flow.

\section{c. Run 3}

In the current simulations, differences between input urban and rural surface grid-point energy balance properties are minimal (Table 3). This is because of the high rural soil-moisture content, which increases both the rural soil heat capacity and daytime evaporative flux. Nocturnal UHI and urban cool island (UCI) values should thus be smaller than those with dry rural-soil conditions (Imamura 1991). As mesoscale flows are driven by low-level atmospheric (not soil surface) temperature gradients, temperature results are shown before velocity results, with both presented at the second vertical grid level at $12.5 \mathrm{~m}$. 
During the daytime southwesterly upslope flow period (discussed above) an UHI forms, even with the somewhat higher urban heat capacity, as the significant rural evaporative cooling suppresses rural temperatures. The UHI is maintained until about 1300 LST (Fig. 21), when $\theta_{M}$ values show a weak, urban-wide UHI. Note, values in the figure show Base Run 1 perturbations from the input volume average value. While upwind rural regions $S$ and $W$ of the city show a near uniform $\theta_{\mathrm{M}}$ value of $2.75^{\circ} \mathrm{C}$, city temperatures increase to a $>2.25^{\circ} \mathrm{C} \mathrm{UHI}$ (given the $5.0^{\circ} \mathrm{C}$ isotherm) located over the $\mathrm{N}$ and $\mathrm{NE}$ urban edges, due to warm air advection by the upslope flow.

As modeled up- and downslope motions are adiabatic (except for radiative effects), horizontal $\theta_{M}$ gradients are mostly produced by changes in land-use type. Effects arising from the Phoenix urban area are thus most clearly seen by use of predicted Base Run 1 minus Non-urban Run 3 temperature and velocity differences. Urban-impact $\theta$ s for 1300 LST (Fig. 22a) illustrates this point, as they show that the city has in fact produced an UHI of $2.9^{\circ} \mathrm{C}$ and an upwind cooling of $1{ }^{\circ} \mathrm{C}$ (due to the flow effects discussed below), consistent with the $3.9^{\circ} \mathrm{C}$ temperture range of Fig. 21.

Due to the large urban heat capacity (that suppresses daytime surface warming) and due to the afternoon urban-induced southwesterly cool air advection 
discussed below, a weak UCI develops somewhat after 1400 LST. The cool urban areas then enhance cold air drainage (discussed below) from the $\mathrm{N}$ and NE mountains, which then induces additional cooling (relative to that of Non-urban Run 3 ) both in urban areas and in the NW valley. At 1900 LST (Fig. 22b), for example, UCI values are largest (at $3^{\circ} \mathrm{C}$ ) over the central urban valleys and smallest in high terrain urban areas, where urban-induced flow effects are minimal (shown below), illustrating the importance of such urban-induced advective cooling.

This pattern persists to about 2200 LST, when the maximum UCI has weakened to about $2.5^{\circ} \mathrm{C}$ and has been confined to the low terrain axis from the NE urban valley to the SW rural region. The high urban heat capacity also begins to produce localized UHIs $\left(1^{\circ} \mathrm{C}\right)$ in the NW and SE urban regions on either side of the cool axis. By 0300 LST (Fig. 22c), these two UHIs (now $3{ }^{\circ} \mathrm{C}$ ) have expanded and now cover most of the NE and SW urban areas, while the further weakened $\mathrm{UCI}\left(1^{\circ} \mathrm{C}\right)$ is confined to the valley bottom near Site 5 .

Predicted urban induced flow patterns reflect these UHI and UCI variations, in combination with urban roughness and barrier influences. The UHI at 1300 LST described above, for example, produces the urban-impact flow of Fig. 23a that has contributed to the southwesterly upslope flow of Fig. 17c. Also seen is an urban barrier effect, which produces upwind divergence at the SW and NW urban corners and downwind convergence at the NE urban corner. 
By 2200 LST (Fig. 23b), the UCI induces a northerly downslope drainage flow component off of the northern mountain that intrudes into the urban area. This component is, however, not strong enough to overcome the (counter-directed) non-urban southwesterly flow component; when added together, they produce the flow field of Fig. 17e. This (counter-directed) UCI flow, in combination with wind speed reduction by the urban roughness, produces a city-wide deceleration of the Non-urban Run 3 southeasterly flow, resulting in enhancement of the topography-induced convergence over the eastern urban region.

Uban barrier effects at this time also (Fig. 23b) produce an anticyclonic vortex over the NW suburban region that forms as the southwesterly flow passes downwind of the NW urban edge (Fig. 5). A smaller cyclonic vortex also forms as the flow passes around the urban intrusion NE of Site 18. The location and direction of spin for both vortices are consistent with characteristics documented by Hosker (1984) for barrier flows around a single building. Such nocturnal vortices are better defined than daytime vortices, as daytime unstable stratification encourages flow over (rather than around) topographic obstacles.

The perturbation flow field at 0300 LST (Fig. 23c) shows UHI induced northerly flows that converge into each of the two warm-core urban lows, and a cold air drainage that still persists from the NE valley bottom. Note that the west to northwesterly flows of this period (Fig. $17 \mathrm{~g}$ ) at the southern portion of the do- 
main has been reinforced by this urban-induced drainage flow. The anticyclonic downwind vortex has migrated around the NW urban corner (to its current position west of the SW urban corner) due to flow direction changes during the past five hours (from southeasterly to easterly and then to northerly). 


\section{Chapter 5. CONCLUSION}

The hydrostatic, Boussinesq, Topographic Vorticity-Mode (TVM) meso- $\beta$ numerical model was used to simulate Phoenix-area temperature and wind flow patterns for the 24 hour period beginning on 31 August at 0400 LST. Both the steep terrain of the region and soil-moisture evaporation, associated with precipitation-moistened soil, presented unique challenges to the model. In addition to the study of mesoscale urban and topographic effects in the region, the newly implemented third order Piecewise Parabolic Method (PPM) advection scheme is tested against the previously used first order Donor Cell scheme. Predicted temperature and velocity values were compared to observed values from the PRISM surface network.

The PPM scheme proved capable of both resolving and maintaining the large gradients produced by the steep terrain and variable land-use pattern of the area. The highly diffusive Donor Cell scheme, however, precluded formation of strong thermal gradients. Results show the model to have reproduced the main features of the diurnal and spatial distributions of the thermal and wind-flow patterns, as predicted temperature and wind speed values are generally within $2{ }^{\circ} \mathrm{C}$ and $2 \mathrm{~m} / \mathrm{s}$, respectively, and as predicted flow patterns show good agreement with observed distributions. 
Simulated flow fields over the diurnal period are characterized by three regimes. In late evening and early morning hours, topography-induced downslope flows drain into the urban region and then channel westward toward the southwestern low topography regions. Morning and early afternoon flows, however, were dominated by upslope forcing from the northern and northeastern mountains. By mid-afternoon, surface cooling reduced the thermal forcing, and thus the flow became dominated by the strong westerly synoptic flow; this pattern persisted until mid-evening, when downslope flow began to re-develop.

The currently simulated nocturnal downslope flow, well developed by about 0000 LST, produces a significant convergence into the Phoenix valley. This convergence may be responsible for the observed nocturnal precipitation peak over the Phoenix Metropolitan Area, as compared to the afternoon peak over the mountains around the city, as suggested by Balling and Brazel (1986).

Urbanization of the area was found to produce the following simulated thermal effects: increased daytime and decreased evening temperatures both over and downwind of the urban region; localized UHIs that form after 0000 LST over the NW and SE urban areas, and reduced nighttime temperatures in the eastern urban valley. These urban thermal influences then produce the following wind-flow effects: (1) enhanced daytime upslope flow due to the UHI; (2) deceleration of the mid-evening southeasterly flow through the city due to an increased northerly 
drainage flow induced by the UCI; (3) somewhat enhanced early morning convergence due to the two UHI-induced lows; and (4) post-midnight divergence from the eastern urban valley due to a weak UCI. Simulated urban roughness and barrier effects include: (1) reduced nocturnal southwesterly flow speeds over the city, (2) divergence of flow around the upwind urban edges, and (3) production of downwind urban-edge vortices.

The mid-evening thermal and mechanical urban effects reinforce each other to produce an urban-induced low-level convergence in the eastern urban area. Late evening effects, however, counter each other to produce enhanced northerly drainage through Phoenix and to produce only a minimal urban-induced convergence.

These results thus indicate that urbanization of the area may be responsible for the somewhat upward trend in mid-evening monsoon precipitation amounts observed by Balling and Brazel (1986), but should have had only minimal effects on late evening precipitation. To accurately evaluate urban impacts on precipitation patterns, however, it is necessary to also analyze upper air effects. Future simulations should also be carried out with weaker synoptic forcings, to allow for development of stronger topographic and urban impacts.

While the Base Case simulation reproduced most observed wind and temperature features, some random and systematic differences were also observed due 
to limitations inherent in the model formulation. Such limitations include: (1) underestimation of topographic gradients from the use of grid-cell averaged topographic height values; (2) exclusion of topographic features NE of the current domain; (3) use of a constant input geostrophic wind; and (4) use of a constant input heat capacity for each land-use class.

Excluded topography NE of the domain is significantly taller than that within the domain. A systematic underestimation of west to southwesterly daytime upslope forcing is therefore inevitable. Whenever mesoscale thermal forcing is strong (dominant over synoptic forcing) and/or in the direction of synoptic flow (west to southwesterly in the current case), simulated winds are thus underestimated.

As local topographic forcing is strongest at sites in steep terrain, effects from the excluded topographic features should be more pronounced in smoothterrain regions, consistent with the too slow and too westerly predicted nearsurface daytime winds at several low-terrain sites. Direction errors are especially evident in the southeastern part of the domain, where the mesoscale and synoptic forcings were perpendicular to each other.

During periods of downslope forcing, topographic-exclusion effects are reduced due to the more localized nature of such flows. Underestimation of local topographic gradients, however, is important during such periods. This underesti- 
mation, however, is countered by the too low model input heat-capacity value in mountain regions, which produces an over prediction of downslope forcing. Predicted near-surface nocturnal wind velocities thus either show a good match or are somewhat too high.

The premature development of predicted daytime upslope flow is attributed to the model-input time-averaged constant heat capacity values for each land type that are too small during the first morning of the simulation period. Early development of the nocturnal downslope regime likewise implies that a too low heat capacity value was specified for mountain regions, although lack of appropriate surface temperature observations precludes evaluation of this conclusion. In runs with a higher mountain heat capacity (results not shown) phase errors did decrease, but daytime wind speeds showed expected additional under predictions. These results illustrate the limitations associated with the required use of a constant input heat capacity value with the force-restore surface boundary condition.

Because of the model limitations described above, it is recommended that future simulations include: (1) the non-hydrostatic version of TVM, to allow for an expanded model domain; (2) full surface energy and moisture balance boundary conditions in conjunction with a finite differenced soil layer, so that soil moisture 
(and hence soil heat capacity) varies in space and time; and (3) linkage with a large-scale prognostic model, so that synoptic forcing also varies with time. 


\section{REFERENCES}

Balling R. C., jr. and S. W. Brazel, 1986: Diurnal variations in Arizona Monsoon precipitation frequencies. Mon. Wea. Review, 115, 342-346.

Balling, R. C., jr., and S. W. Brazel, and 1987: Recent changes in Phoenix, Arizona summertime diurnal precipitation patterns. Theor. Appl. Climatol., $38,50-54$.

Bornstein, R. D., 1975: The two-dimensional URBMET boundary layer model. $J$. Appl. Meteor., 14, 1459-1477.

Bornstein, R. D., 1983: Urban barrier effects on mesoscale and synoptic systems. Preprint volume, third AMS conference on Mesoscale Processes, 21-26 August 1987 Vancouver, B.C.

Bornstein, R. D. and D. S. Johnson, 1977: Urban-rural wind velocity differences. Atmos. Environ., 11, 597-604.

Bornstein, R. D., and J. Cordova, 1991: Simulation of urban and coastal influences on the structure of the polluted boundary layer of the New York City metropolitan area. Preprint Volume Seventh AMS conf. on Air Pollut. Meteor., 14-18 Jan. 1991, New Orleans, 316-7.

Bornstein, R.D., and J. C00000ordova, 1992: Observation and simulation of urban

bar- rier effects on urban climate patterns. Presented at International Symposium on the Urban Thermal Environment (CUTEST'92), 7-10 Sept. 1992, Fukupka, Japan, 39-41.

Bornstein, R.D., and A. Robock, 1976: Effects of variable and unequal time-steps for advective and diffusive processes in simulations of the urban boundary layer. Mon. Wea. Rev., 104, 260-267.

Bornstein, R. D., and E. Runca, 1977: Preliminary investigations of $\mathrm{SO}_{2}$ patterns in Venice, Italy using linked PBL and $\mathrm{K}$-models, including removal processes. Preprint Volume AMS Symposium on Air Pollution, 28 Nov.- 3 Dec. 
Bornstein, R. D., and W. T. Thomson, 1981: Effects of frictionally retarded sea breeze and synoptic frontal passes on sulfur dioxide concentrations in New York City. J. Appl. Meteor., 20, 843-858.

Bornstein, R. D., A. Lorenzen, and D. Johnson, 1972: Recent observations of urban effects on winds and temperatures in and around New York City. Preprint AMS Conf. Urban Environ. and Second Conf. Biomet., 28-33.

Bornstein, R. D., S. Klotz, U. Pechinger, R. Street, and R. Miller, 1987a: Modeling the polluted coastal urban environment. Vol. I: The PBL model. EPRI Final Report EA 5091 for Project 1630-13, 175 pp.

Bornstein, R. D., U. Pechinger, R. Salvador, L. I. Shieh, and F Ludwig, 1987b: Modeling the polluted coastal urban environment. Vol. II: The dispersion model. EPRI Final Report EA 5091 for Project 1630-13, 123 pp.

Bornstein, R. D., P. Thunis, P. Grossi, and G. Schayes, 1995: Development of the Topographic Vorticity-mode Mesoscale (TVM) model. Part II: Evaluation. Submitted to J. Appl. Meteor., 41pp.

Brazel, A. J., and M. D. Hubble, 1993: Presented at the 8th conference of Applied Climatology, 17-22 Jan., Anaheim, and submitted to Bull. Amer. Meteor. Soc.

Brazel, and W. G. Nickling, 1985: The relationship of weather types to dust storm generation in Arizona (1965-1980). J. Climatology, 6, 255-275.

Colella, P., and P. Woodward, 1984: The piece-wise parabolic method (PPM) for gas dynamical simulations. J. Comp. Phys., 54, 174-201.

Deardorff, J., 1978: Efficient prediction of ground surface temperature and moisture, with inclusion of vegetation. J. Geoph. Res., 83, 1198-1903.

Enfield, D. B., 1981: Thermally driven wind variability in the planetary boundary layer over Lima, Peru. J. Geophys. Res., 86, 2005-2016.

Goodman, J. K., and A. J. Miller, 1977: Mass transport across a temperature inversion. J. Geophys. Res., 82, 3463-3471. 
Grossi P., J. M. Giovannoni, and A. G. Russell, 1995: Intercomparison of meteorological models applied to the Athens area, and their effect on photochemical pollutant concentrations and transport.

Hosker, R. P., jr., 1984: Flow and diffusion near obstacles. Atmospheric Science and Power Production, DOE report/TIC-2760,1984, 241-346.

Imamura, I. R., 1991: Observational studies of urban heat island characteristics in different climate zones. Ph. D. Dissertation, Institute of geoscience at University of Tsukuba, $156 \mathrm{pp}$.

Klotz, S., and R. D. Bornstein, 1985: Simulation of the coastal boundary layer over New York City using a three-dimensional higher order turbulence closure model. Preprint volume, Seventh AMS Conference on Turbulence and Diffusion, Boulder, CO., 12-15 November 1985, 151-155.

Landsberg, E. H., 1981: The Urban climate. Academic press, New York, 275 pp.

Long, P. E., and D. W. Pepper, 1978: A comparison of six numerical schemes for calculating the advection of atmospheric pollution. Preprint volume, third symposium on atmospheric turbulence, diffusion, and air quality. AMS, October 1976, Raleigh, North Carolina, 872-876.

Louis, R. J., and P. C. Kangieser, 1959: The climate of Arizona. Climates of the states, 2, 503-537.

Ludwig, F. L. and R. M. Endlich, 1987: Improvement of a mass-conserving airflow scheme. Proposal for research, prepared for U. S. Army Atmospheric Sciences Lab., and submitted to J. Applied. Meteor.

Ludwig, F. L. and R. M. Endlich, 1988: User's guide for the winds on critical streamline surface (WOCSS) code. SRI International Project No. 4354., and submitted to J. Applied. Meteor.

Lyons, W. A., R. A. Pielke, W. R. Cotton, M. Uliasz, C. J. Tremback, R. L. Walko, J. L. Eastman, 1993: The application of new technologies to modeling mesoscale dispersion in coastal zones and complex terrain. Air Pollution '93, CMP, 35-86. 
MacCracken, M., and R. D. Bornstein, 1977: On the use of flux formulations for the advection process in variable grid models. J. Comp. Physics, 23. 135149.

Mass, F. C. and P. D. Dempsey, 1985: A one-level, mesoscale model for diagnosing surface winds in mountainous and coastal regions. Mon. Wea. Review, 113, 1211-1227.

Mellor, G. L. and T. Yamada, 1982: Development of a turbulence closure model for geophysical fluid problems. Rev. Geophy. Space Sci., 20, 851-875.

Meng, J., 1995: Application of mesometeorological model URBMET/TVM to the San Francisco bay area. Draft M. S. thesis, San Jose State University.

Monteith, J. L., 1982: Evaporation and surface temperature. Quart. J. R. Meteor. Soc., 107, 1-27.

Neiburger, M., 1959: The relation of air mass structure to the field of motion over the eastern Pacific Ocean in summer. Tellus, 12, 31-40.

O'Brien, J., 1970: On the vertical structure of the eddy exchange coefficient in the planetary boundary layer. J. Atmos. Sci. , 27, 1213-1215.

Panofsky, H. A., H. Tennekes, D. H. Lenschow, and J. C. Wyngaard, 1977: The characteristics of turbulent velocity components in the surface layer under convective conditions. Boundary-Layer Meteor., 11, 355-361.

Pandolfo, J. P., 1966: Wind and temperature for constant flux boundary layers in lapse conditions with a variable eddy conductivity to eddy viscosity ratio. J. Atmos. Sci., 23, 495-502.

Pielke, R. A, 1984: Mesoscale Meteorological Modeling. Academic Press, New York, $468 \mathrm{pp}$.

Peilke, R. A., and W. A. Lyons, R. T. McNider, M. D. Moran, R. A. Tocker, R. L. Walko, and M. Uliasz, 1991: Regional and Mesoscale meteorological modeling as applied to air quality studies. Air Pollution Modeling and Its Applications VIII, 59-290. 
Pielke, R. A., W. R. Cotton, R. L. Walko, C. J. Tremback, W. A. Lyons, L. Grossi, M. E. Nicholls, M. D. Moran, D. A. Wesley, T. J. Lee, and J. H. Copeland, 1992: A comprehensive meteorological modeling system - RAMS. Meteorology and Atmospheric Physics, 49, 69-91.

Rao, S. T., G. Sistla, J. Y. Ku, N. Zhou, W. Hao, P. Thunis, R. D. Bornstein, and F. Freedman, 1994: Sensitivity of UAM-predicted ozone concentrations to wind fields in the New York Metropolitan Area. Presented at AWMA Meeting, 8-12 Nov., San Diego and submitted to Atmos. Environ.

Runca, E., 1976: An efficient air quality K-model. Presented at the Seventh International Technical Meeting on Air Pollution Modeling and its Application, Airlie, Virginia.

Russell, P. B., and E. E. Uthe, 1978: Regional patterns of mixing depth and stability: SODAR network measurements for input to air quality models. Bull. Amer. Meteor. Soc., 59, 1275-1287.

Sasamori, T., 1968: The radiative cooling calculation for application to General Circulation experiments. J. Appl. Meteor., 7, 721-729.

Schayes, G., P. Thunis, and R. D. Bornstein, 1995: Development of the Topographic Vorticity-mode Mesoscale (TVM) model. Part I: Formulation. submitted to J. Appl. Meteor., 32 pp.

Seaman, N. L., 1992: Meteorological modeling applied to regional air-quality studies using four-dimensional data assimilation. Environmental Modeling, CMP, 65-88.

Sherman, C. A., 1978: A mass-consistent model for wind fields over complex terrain. J. Appl. Meteor., 17, 312-319.

Shir, C. C., and L. J. Shieh, 1974: A generalized urban air pollution model and its application to the study of $\mathrm{SO}_{2}$ distribution in the St. Louis metropolitan area. J. Appl. Meteor., 19, 185-204.

Thunis, P., 1995: Development and implementation of the Non-Hydrostatic Topographic Vorticity-mode Mesoscale (TVM/NH) model. Draft Ph. D. Dissertation, University of Louvain la Neuve. 
Uliasz. M, and R. A. Pielke, 1993: Implementation of Lagrangian particle dispersion model for mesoscale and regional air quality studies. Air Pollution '93, CMP, 157-164.

Xiu, A. and E. J. Pleim, 1994: Implementation and experimentation of an advanced land-surface PBL model in the Penn State/NCAR mesoscale model (MM4). Submitted to A and WMA conference. 


\title{
APPENDIX A
}

\section{List of symbols}

\author{
surface albedo \\ specific heat at constant pressure $\left(=1005 \mathrm{~J} \mathrm{~kg}^{-1}\right)$ \\ $c_{1}, c_{2} \quad$ force restore constants $(=3.72,7.4)$ \\ $\mathrm{C}_{\mathrm{ei}}, \mathrm{C}_{\mathrm{ki}} \quad$ mixing lengths constants $(=15,5,0.0055,1,0 ; 15,11,0.0025,1,0)$ \\ $C_{1}, C_{2} \quad$ turbulence constants $(=0.5,0.125)$ \\ d upper soil layer thickness \\ $\mathrm{e}_{\mathrm{T}} \quad$ turbulent kinetic energy \\ E latent heat flux \\ f Coriolis parameter \\ $f_{\mathrm{zg}} \quad$ topography correction factor \\ $F_{d}, F_{u} \quad$ downward and upward IR radiative flux, respectively \\ g acceleration of gravity $\left(=9.81 \mathrm{~ms}^{-2}\right)$ \\ $\mathrm{G}_{0} \quad$ ground heat flux \\ $h \quad$ surface boundary layer height \\ $\left(h_{g}\right)_{\mu, \lambda} \quad$ average topographic elevation at model output grid $(\mu, \lambda)$ \\ $h_{i} \quad$ mixing layer height \\ $\mathbf{h}_{\mathrm{ij}} \quad$ average topographic elevation at model input grid $(i, j)$
}




\begin{tabular}{|c|c|}
\hline $\mathrm{H}$ & sensible heat flux \\
\hline$k$ & von Kármán constant $(=0.4)$ \\
\hline$K$ & vertical turbulent diffussivity \\
\hline$K_{H}$ & horizontal turbulent diffussivity \\
\hline $\mathrm{l}_{\mathrm{k}}$ & diffussivity mixing length \\
\hline$l_{\varepsilon}$ & dissipation mixing length \\
\hline $1_{\mathrm{s}}$ & limiting mixing length in stable stratification \\
\hline $\mathrm{L}$ & Monin-Obukov length \\
\hline $\mathrm{L}_{\mu}, \mathrm{L}_{\lambda}$ & $\begin{array}{l}\text { east/west and north/south lengths of model output grid }(\mu, \lambda) \text {, } \\
\text { respectively }\end{array}$ \\
\hline $\mathrm{L}_{0}$ & latent heat of water vaporization $\left(=2.510^{6} \mathrm{~J} \mathrm{~kg}^{-1}\right)$ \\
\hline m & $\begin{array}{l}\text { Number of east-west input grids fully or partially within a model } \\
\text { output grid }\end{array}$ \\
\hline $\mathrm{m}_{1}, \mathrm{~m}_{2}$ & TKE-formulation functions \\
\hline $\mathbf{n}$ & $\begin{array}{l}\text { Number of north-south input grids fully or partially within a model } \\
\text { output grid }\end{array}$ \\
\hline $\mathrm{L}_{\chi}, \mathrm{L}_{\mathrm{z}}$ & horizontal and vertical circulation scales, respectively \\
\hline $\mathrm{p}$ & atmospheric pressure \\
\hline q & specific humidity \\
\hline$Q_{N}$ & net infra-red flux \\
\hline & aerodynamic resistance \\
\hline
\end{tabular}




$\begin{array}{ll}\mathrm{r}_{0} & \text { surface resistance } \\ \mathrm{R}_{\mathrm{v}} & \text { water vapor gas constant }\left(=461 . \mathrm{J} \mathrm{K}^{-1} \mathrm{~kg}^{-1}\right) \\ \mathrm{R}_{\mathrm{N}} & \text { net surface all-wave radiation } \\ \mathrm{R}_{0} & \text { surface solar radiative flux } \\ \mathrm{t} & \text { time } \\ T & \text { temperature } \\ \mathrm{u}, \mathrm{v}, \mathrm{w} & \begin{array}{l}\text { eastward, northward, and upward wind speed component, } \\ \text { respectively }\end{array} \\ \mathrm{u}_{\mathrm{g}}, \mathrm{v}_{\mathrm{g}} & \text { eastward and northward geostrophic wind component, respectively } \\ \mathrm{V} & \text { wind velocity vector } \\ \mathrm{W}_{\mathrm{i}}, \mathrm{W}_{\mathrm{j}} & \text { east-west and north-south model input grid length, respectively } \\ \mathrm{x}, \mathrm{y}, \mathrm{z} & \text { eastward, northward, and upward Cartesian coordinate, respectively } \\ \mathrm{z}_{\mathrm{g}} & \text { topographic height } \\ \mathrm{z}_{0} & \text { roughness length } \\ \mathrm{z}_{\max } & \text { model top height }\end{array}$

Greek

$\alpha \quad$ inverse turbulent Prandtl number (= 1.35)

$\gamma \quad$ psychometric constant

$\Gamma \quad$ dry adiabatic cooling rate $\left(=9.8 \mathrm{~K} \mathrm{~km}^{-1}\right)$ 
$\delta$

$\varsigma$

$\eta$

$\theta$

$\lambda$

$v$

$\xi$

$\rho$

$\tau$

$\tau_{\mathrm{d}}$

$\phi$

$\hat{\phi}_{i, j}$

$\Phi$

$\Psi$

$\hat{\psi}$

$\Psi$

w

$\Omega$ slope of water vapor saturation pressure curve y-component of vorticity; dimensionless height topography transformed vertical coordinate potential temperature

filter coefficient

z-component of vorticity

$\mathrm{x}$-component of vorticity

density

turbulent stress

diurnal period $(=86400 \mathrm{~s})$

$\mathrm{x}$-component of stream function

dummy variable at grid point $(i, j)$

latitude

$y$-component of stream function

surface layer stability function

stream function vector

vorticity vector

angular velocity of Earth $\left(=7.29210^{-5} \mathrm{rad} \mathrm{s}^{-1}\right)$ 


\section{Subscripts}
( ) deep soil
( ) heat
( ) horizontal
( ) momentum
( ) mesoscale
( ) n synoptic scale
( ) $\quad$ static (except in $\mathbf{z}_{0}$ )
( ) moisture
( ) soil layer
( ) water vapor
( ) $\quad$ ground surface
( )* surface layer scaling factor
special
() topography
( ) turbulent component
( ) time average 
APPENDIX B

\section{TOPOAV MANUAL}

TOPOAV averages USGS 1 deg. DEM data, which come in 3×3 arc-second resolution, to any arbitrary regularly or irregularly spaced rectangular grid mesh. It also accommodates data in spherical coordinates at resolutions other than three arc-seconds, as well as data in Cartesian coordinates. Use of TOPOAV for other than DEM 1 deg. files requires minor modifications in the input reading routine (discussed below). Raw DEM files were compressed and have no delimiters, which can be added either with UNIX command dd or with use of program CONVERT (provided together with TOPOAV).

\section{a. USGS File Management}

Following is a description of how to receive DEM files. Their location, however, may change in the future. Current information can then be received from EROS DATA CENTER (1-800-252-4547).

- USGS files are available at following FTP address:

edcftp.cr.usgs.gov or 152.61.128.6

- Entry ID is anonymous 
- Entry Password is e-mail address of user

-DEM files are found in directory

/pub/data/DEM/250

Files are further organized in directories according to file name initial, e.g., new_york-e is found in sub-directory "NN". Names and locations of DEM files can be found on specially formulated 1:100000 guide maps available through USGS.

- Before transferring files, set machine to binary by typing

$$
\text { binary }<\text { ENTER }>
$$

- To get desired file, type

$$
\text { get filename <ENTER> }
$$

Note, mget can transfer several files at once, e.g., mget new_york* will transfer both new_york-e and new_york-w.

- Transferred files have no delimiters, which can be added using UNIX command "dd if=inputfilename of=outputfilename $\mathrm{ibs}=4096 \mathrm{cbs}=1024$ conv=unblock", or by running program CONVERT which is provided together with TOPOAV. The UNIX command is faster ( $45 \mathrm{~min}$. to run CONVERT vs. $3 \mathrm{~min}$. to run dd for one DEM file), but TOPOAV is specially formatted to directly read output from CONVERT. Use of dd will require either the development of a program that reads output from the dd command and then reformats it to the read specifications of TOPOAV or the adjustment of read commands in TOPOAV. 
TOPOAV accepts a DEM file via an unformatted "blank read" of 1201 blocks, each of which contains 1201 values. Each block represents a south to north strip, such that its first value represents the southernmost location, while the first block in each file represents the westernmost strip (Fig. 2.2). A full description of DEM file specifications is found in DEM data users guide 5 issued by USGS.

\section{b. Unzipping USGS Files}

- GZIP can be obtained via FTP from the following INTERNET address:

prep.ai.mit.edu or 18.71.0.38

and is then available in directory

$$
\text { /pub/gnu }
$$

Password and entry ID are same as for the above USGS file system. Following is a list of required files;

$$
\begin{gathered}
\text { gzip-1.2.4.DOS.exe } \\
\text { gzip-1.2.4.shar } \\
\text { gzip-1.2.4.tar } \\
\text { gzip1.2.4.tar.gz, }
\end{gathered}
$$

where the first file is required for a DOS system while the final three are required for a UNIX system. 
Following is a set of directions for the installation and use of program GZIP.

- With a DOS system, GZIP is ready to run. To start, type

$$
\text { gzip -h <enter> }
$$

which will provide a list of commands.

-With a UNIX system, do the following;

1) Decompress program by typing

$$
\text { gzip.1.2.4.tar <enter> }
$$

2) Configure system by typing

$$
\text { configure <enter }>
$$

3) Install program by typing

$$
\text { install <enter }>
$$

4) If super-user clearance is available, an optional extra step is recomended and may be performed by typing

$$
\text { make install <enter> }
$$

5) To remove unnecessary files (optional), such as intermediate files produced during installation, type

$$
\text { make clean <enter> }
$$

-A list of available commands is given by typing: 


$$
\text { gzip -h <enter > }
$$

\section{c. Running Convert}

Unzipped files can be directly read by CONVERT. To run it, load all files that need delimiters in the same directory as CONVERT, and type either convert -i inputfilename outputfilename \& for screen interactive execution, or convert $\mathbf{- b}$ inputfilename outputfilename \& for background execution. The file named inputfilename is converted, and the output appears in outputfilename.

\section{d. Running TOPOAV}

Output from CONVERT is formatted to be directly used by TOPOAV. File arrangement:

- The TOPOAV executable can be located in any directory referred to as the 'base' directory. All input files, including all converted DEM files and the execution control file (TOP.CTL), must then be placed in directory

\section{/base/TOPOIN}

The output file is called 'NEWTOPO' and is located in directory /base/TOPOUT 
which is produced by TOPOAV.

-TOP.CTL controls the execution of TOPOAV. It contains information concerning the DEM input grid, the mesoscale model output grid, input-file names, etc., as described below.

TOPOAV control file (i.e., TOP.CTL) description:

Following is a description of parameters in TOP.CTL; sample control file shown in Table 4.

oldsizi \& oldsizi: read format (F5.2)

The sizes, in arc-seconds or in units of length, of the initial grid resolution. oldsizi is in east/west and oldsizj is in north/south direction.

\section{Lat: read format (F5.2)}

Latitude of south-westernmost input datum. Used in conversion of USGS data from arc-seconds to $\mathrm{km}$. If input data are in Cartesian coordinates, insert a value bigger than 90.0 .

Nrows: read format (120)

Number of input files needed to cover north/south extent of domain. 
Table 4. Sample of TOP.CTL input file

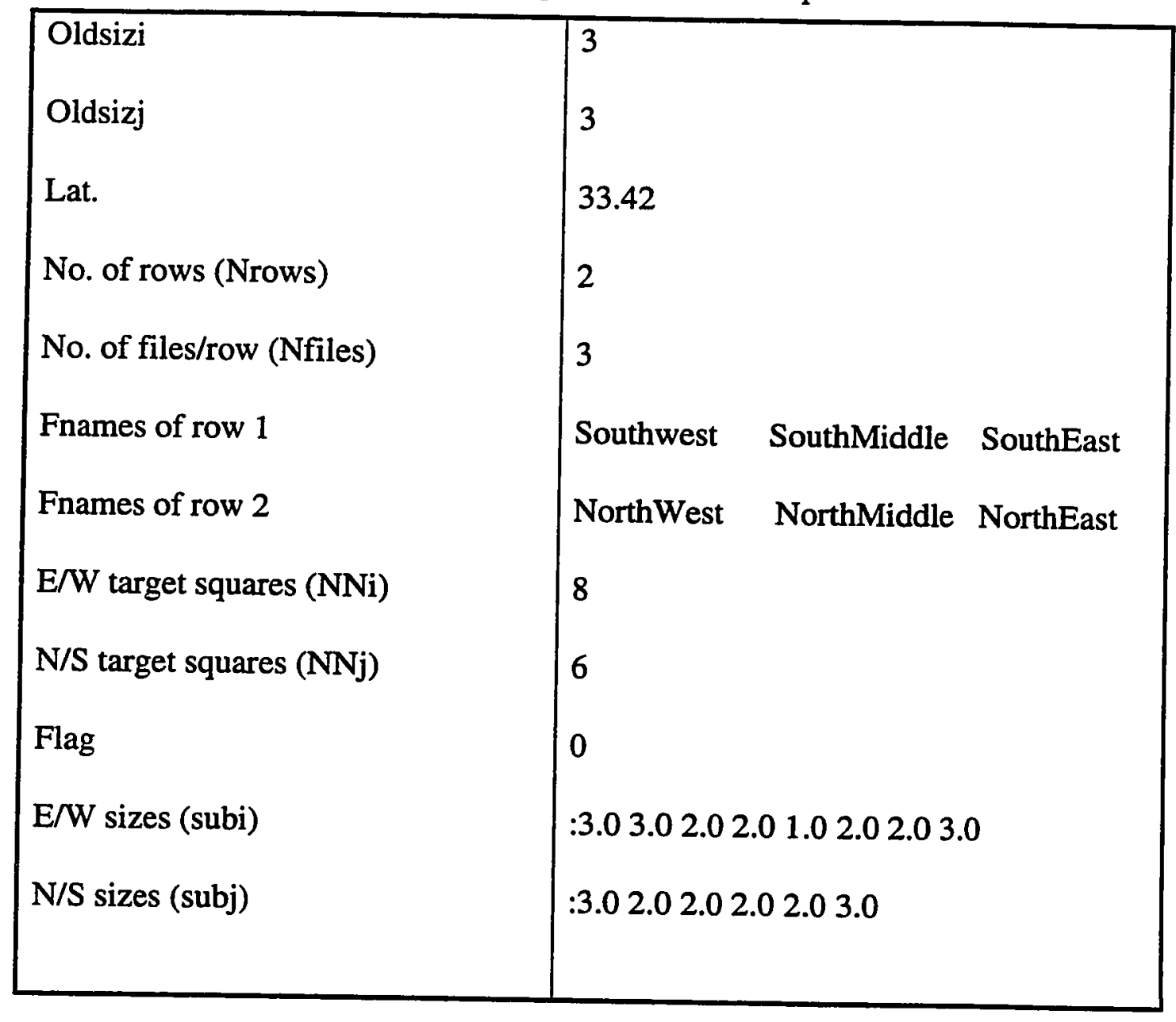




\section{Nfiles: read format (120)}

Number of input files needed to cover East/West extent of domain. Note, total number of input files is Nrows $x$ Nfiles.

\section{Fnames: read format (20A15)}

List of names of all files used as input, arranged in rows. Each row has a number of files equal to Nfiles and includes the names of all input files in a west to east domain direction at any given latitude: number of rows equals Nrows. Care must be taken so that files are arranged in correct sequence. For example, in a DEM file, the first datum corresponds to south-westernmost point of their geographical domain, while the last corresponds to north-easternmost point. Consequently, file names must be ordered such that: (a) the very first name (top left entry) corresponds to the file at the south-westernmost end of the domain, (b) the last name on the first row (top right entry) corresponds to the south-easternmost end of the domain, and (c) the very last name (bottom right entry) corresponds to the northeastern most end of the domain.

NNi: read format (I20)

Number of grid points, in west to east direction, desired for model output grid. NNj: read format (I20)

Number of grid points, in south to north direction, desired for model output grid. 


\section{Flag: read format (I2)}

Signals whether input grid origin and model output grid origin are identical, in which case Flag $=1 ;$ else Flag $=0$.

\section{Subi: read format (100F5.2)}

Array defining longitudinal dimensions for each model output grid. For irregularly spaced grids, these are not equal throughout. Note, these are real numbers and must be inserted on a single line. If input grid origin and model output grid origin are not identical, the east/west distance between the two becomes first entry.

\section{Subj: read format (100F5.2)}

Array defining latitudinal dimensions for each model output grid. For irregularly spaced grids, these are not equal throughout. Note, these are real numbers and must be inserted on a single line. If input grid origin and model output grid origin are not identical, the north/south distance between the two becomes first entry. 


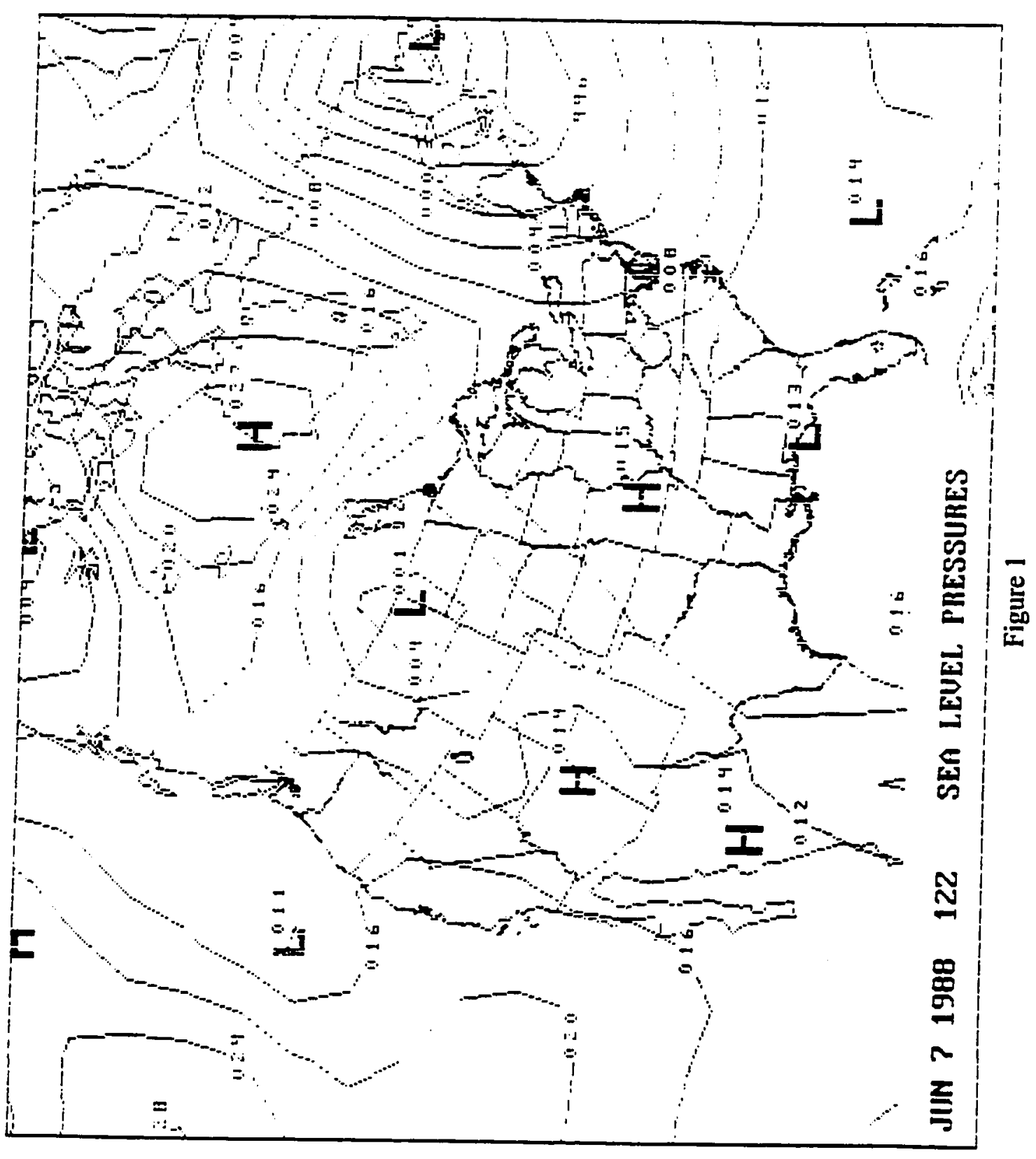




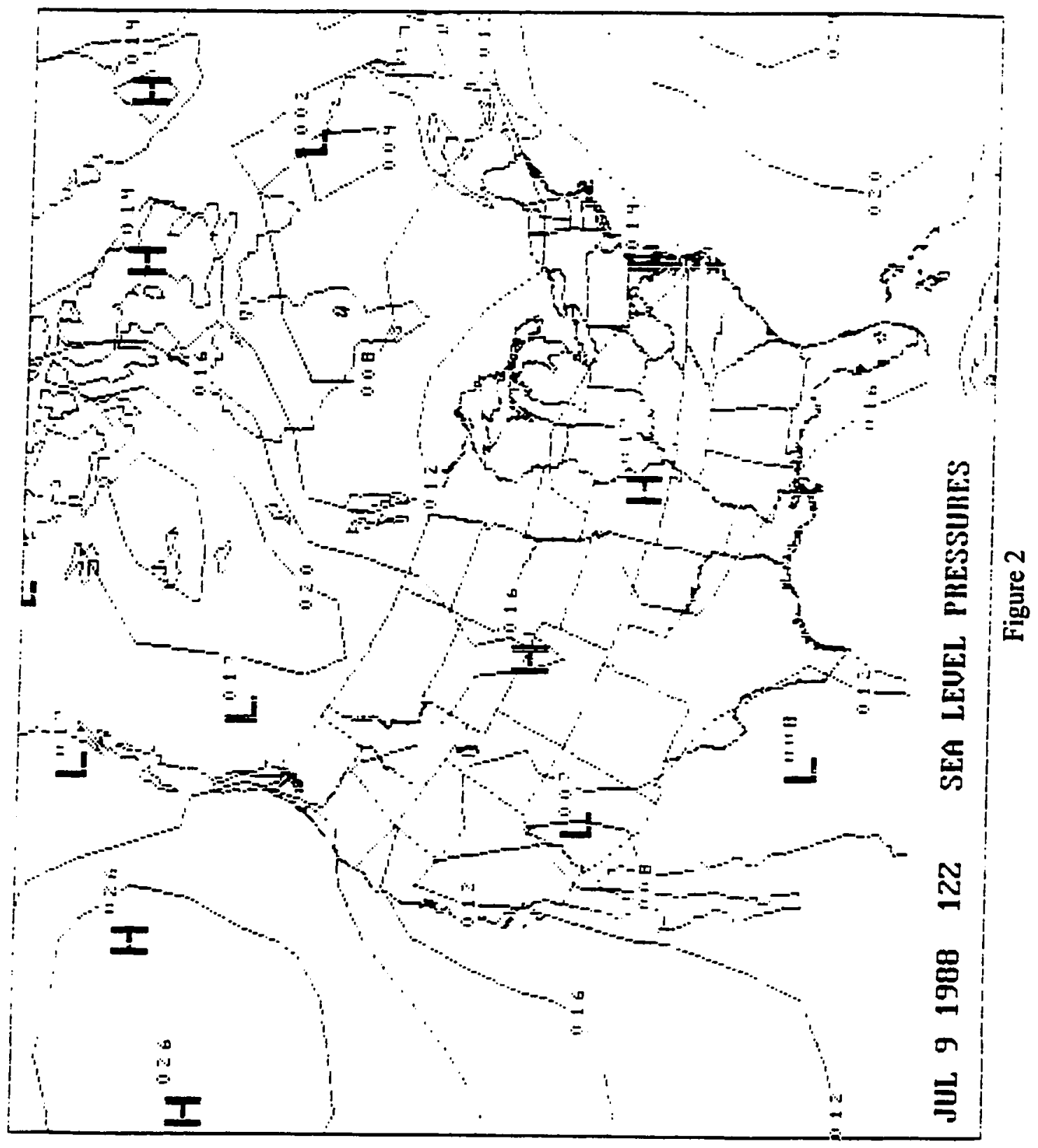




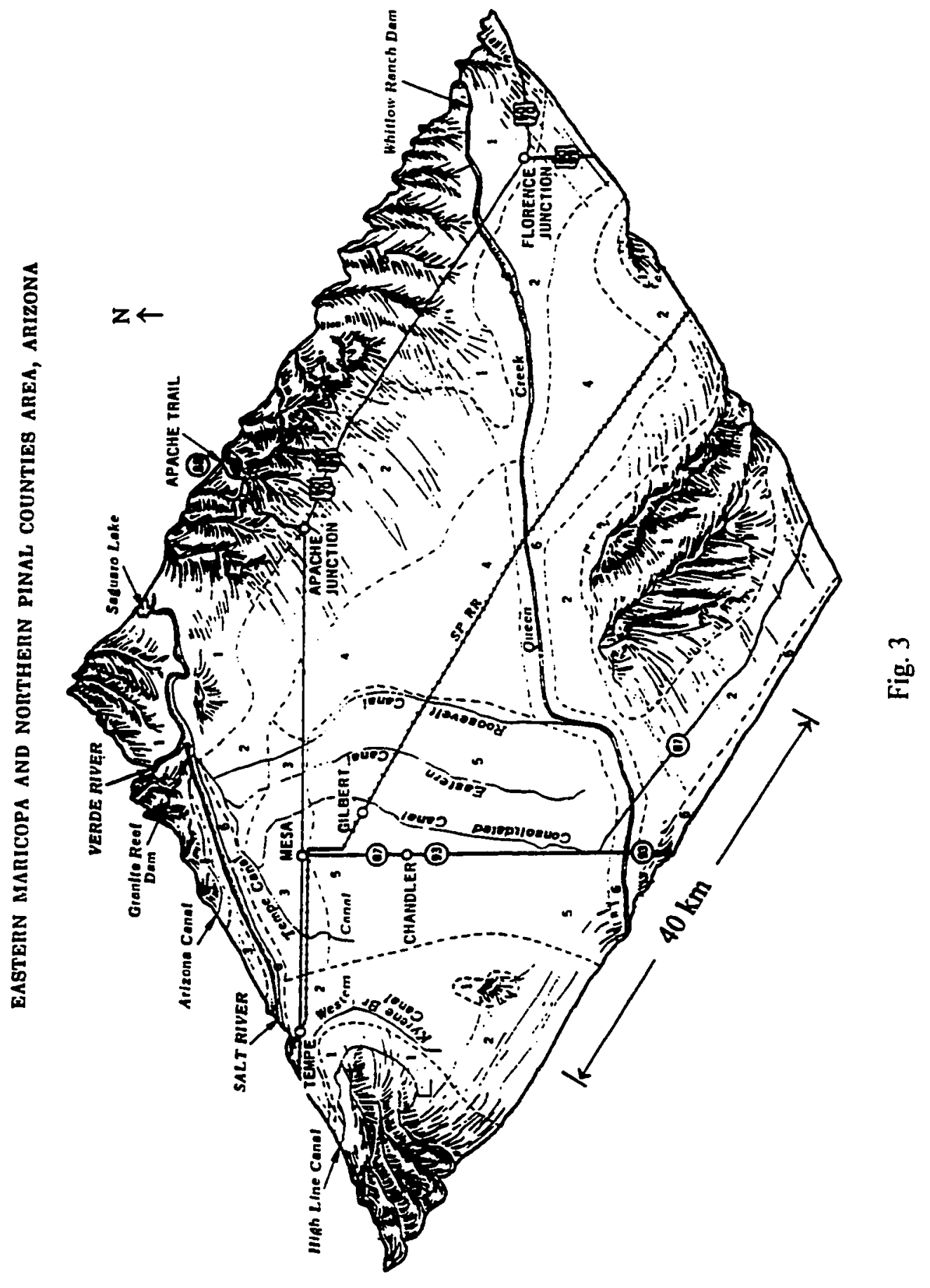




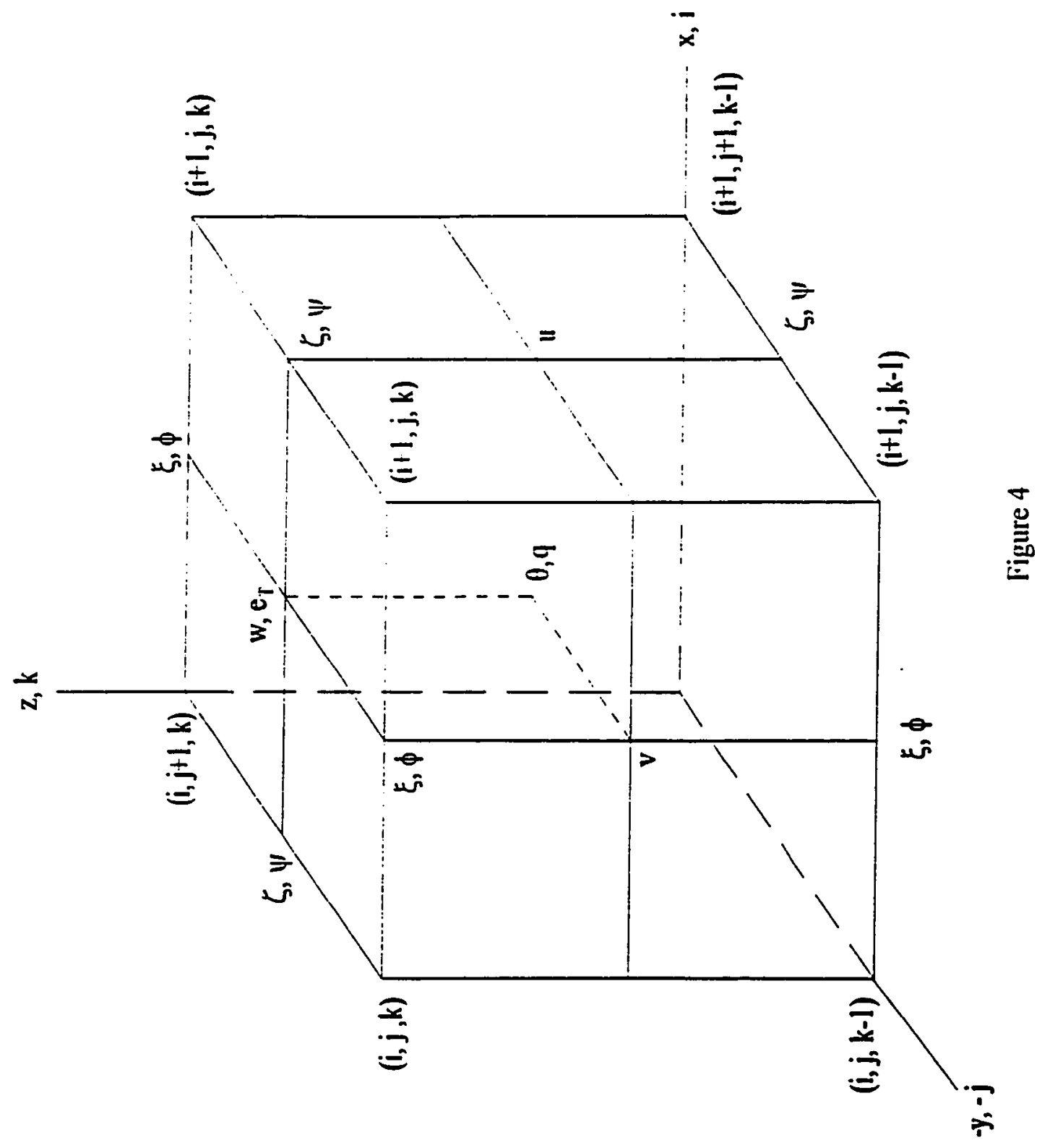




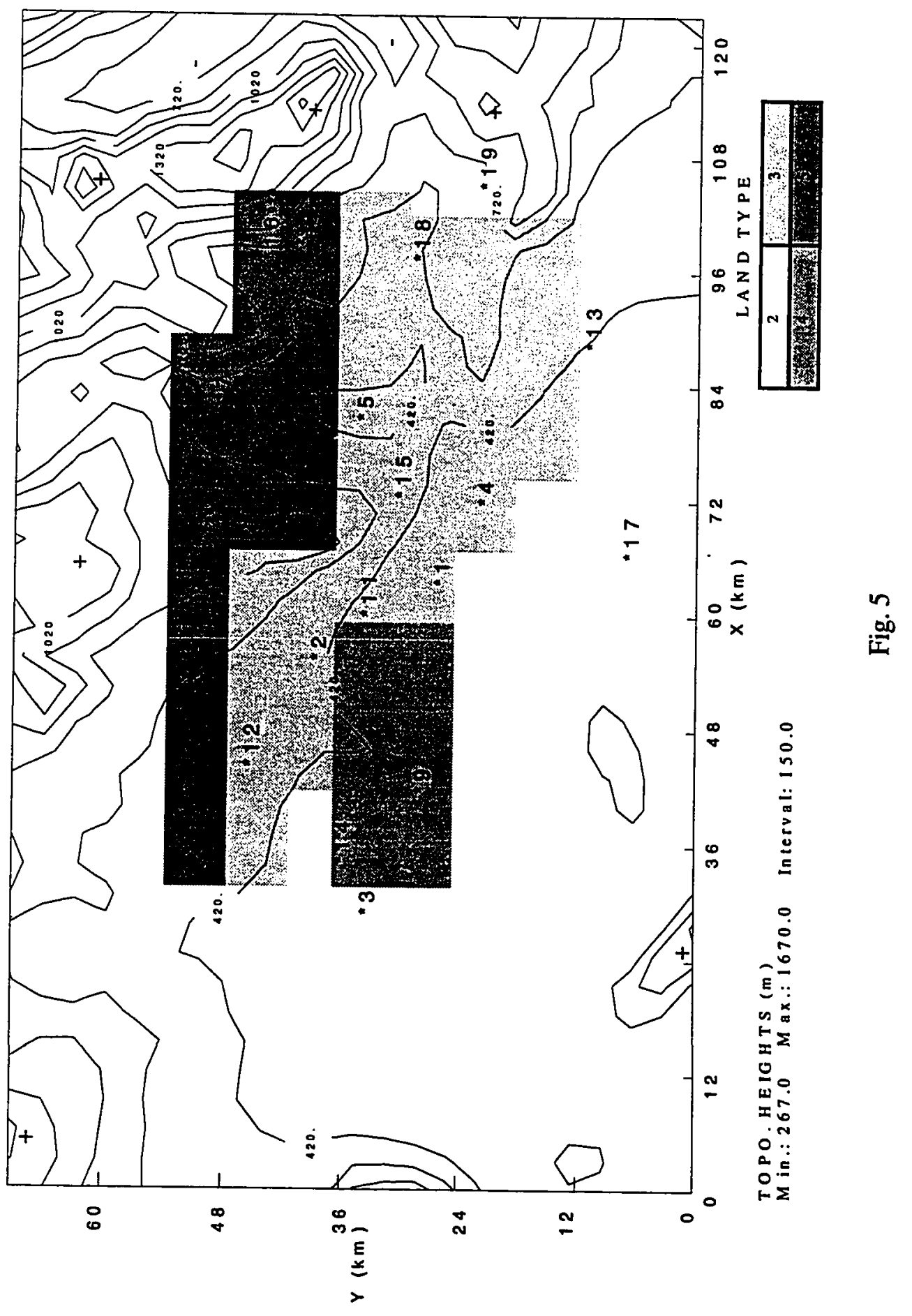



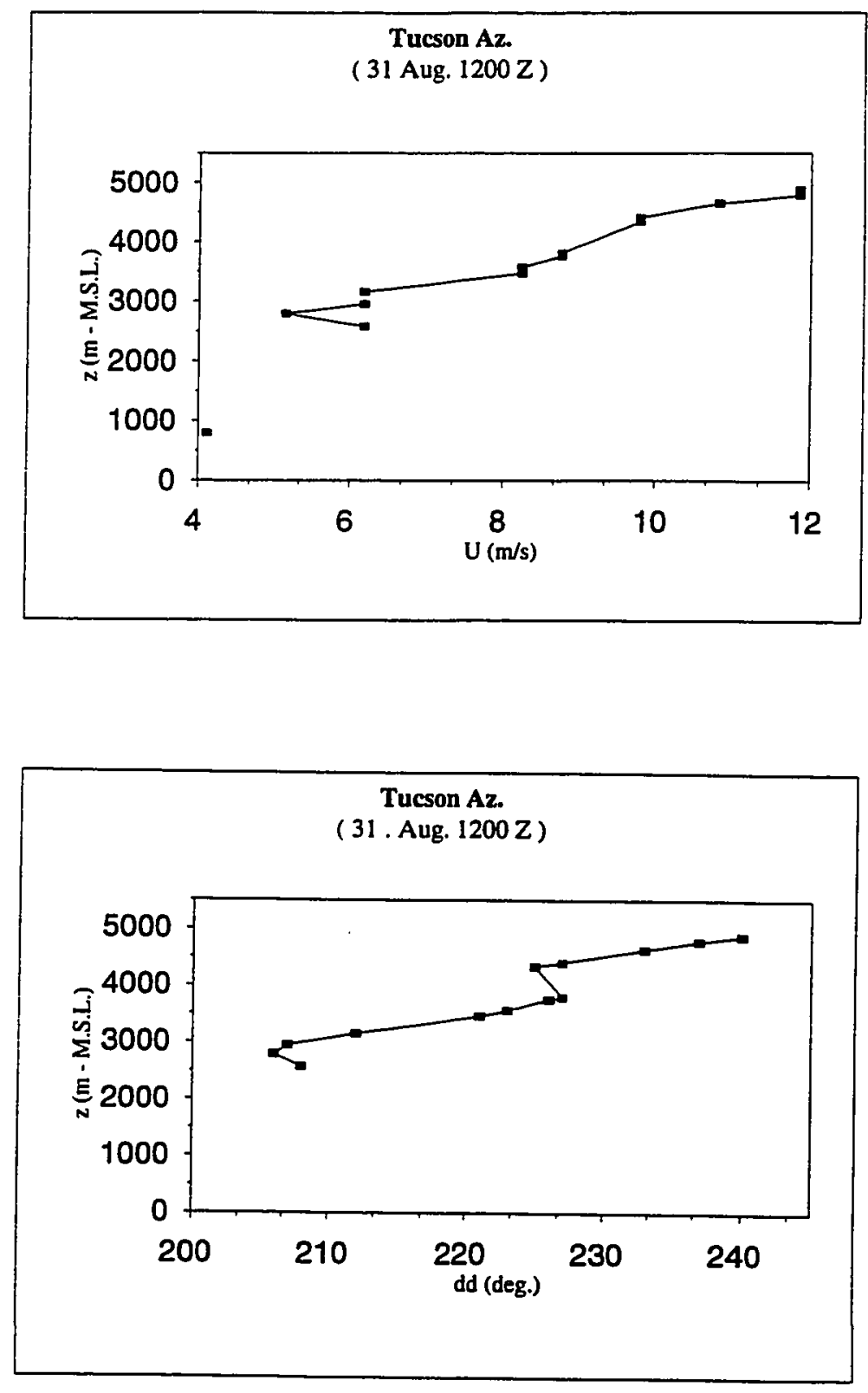

Fig. 6 

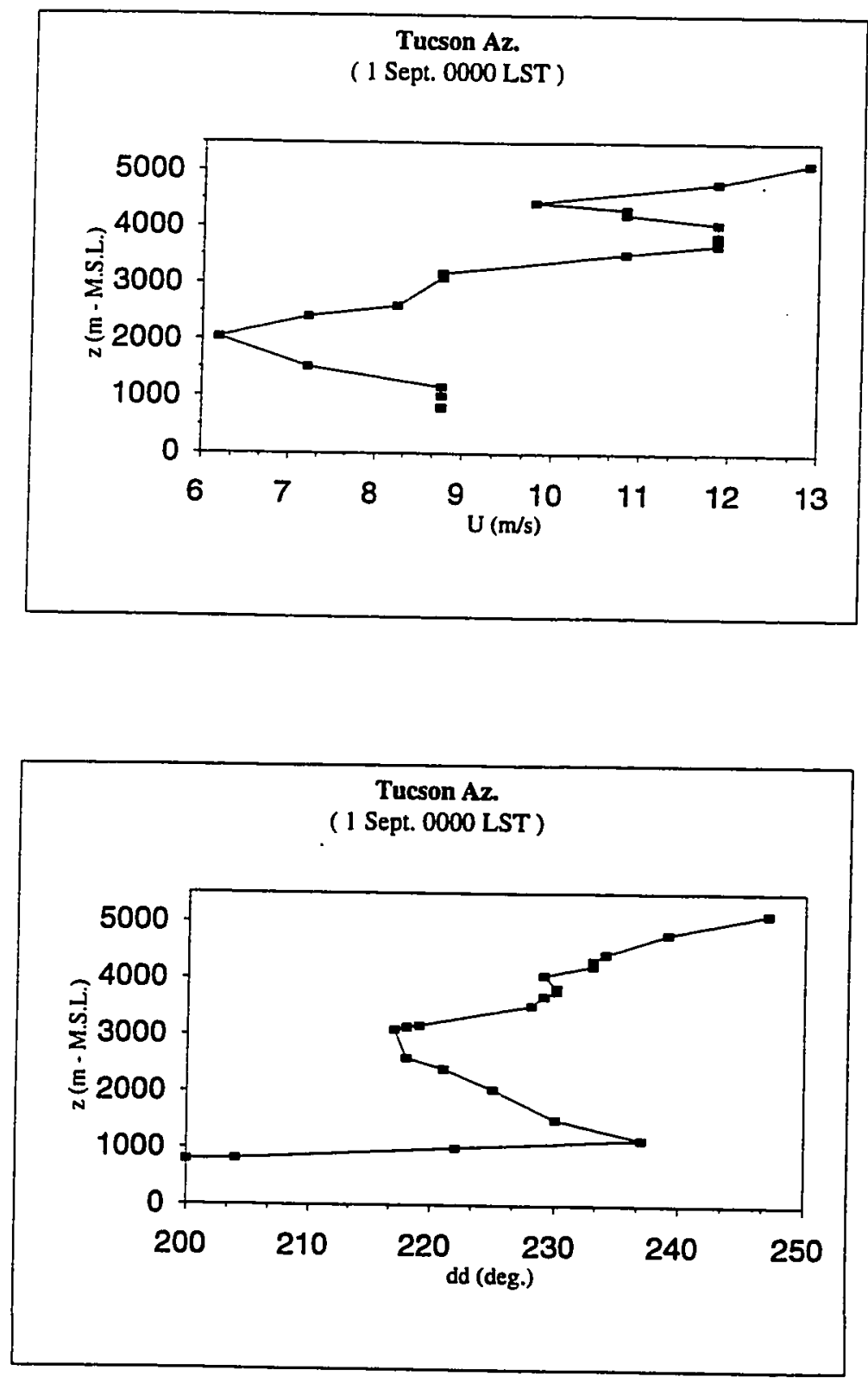

Fig. 7 

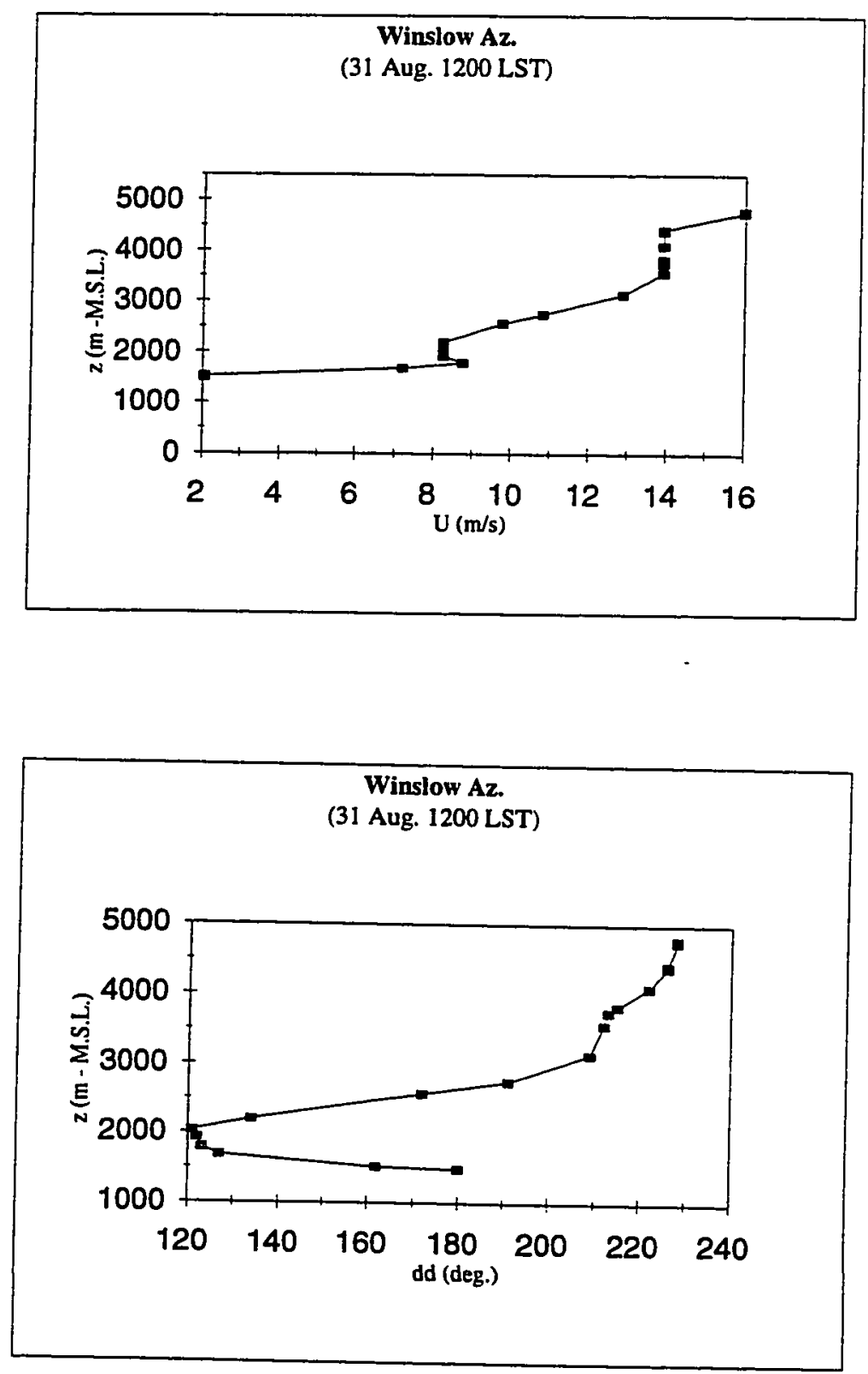

Fig. 8 

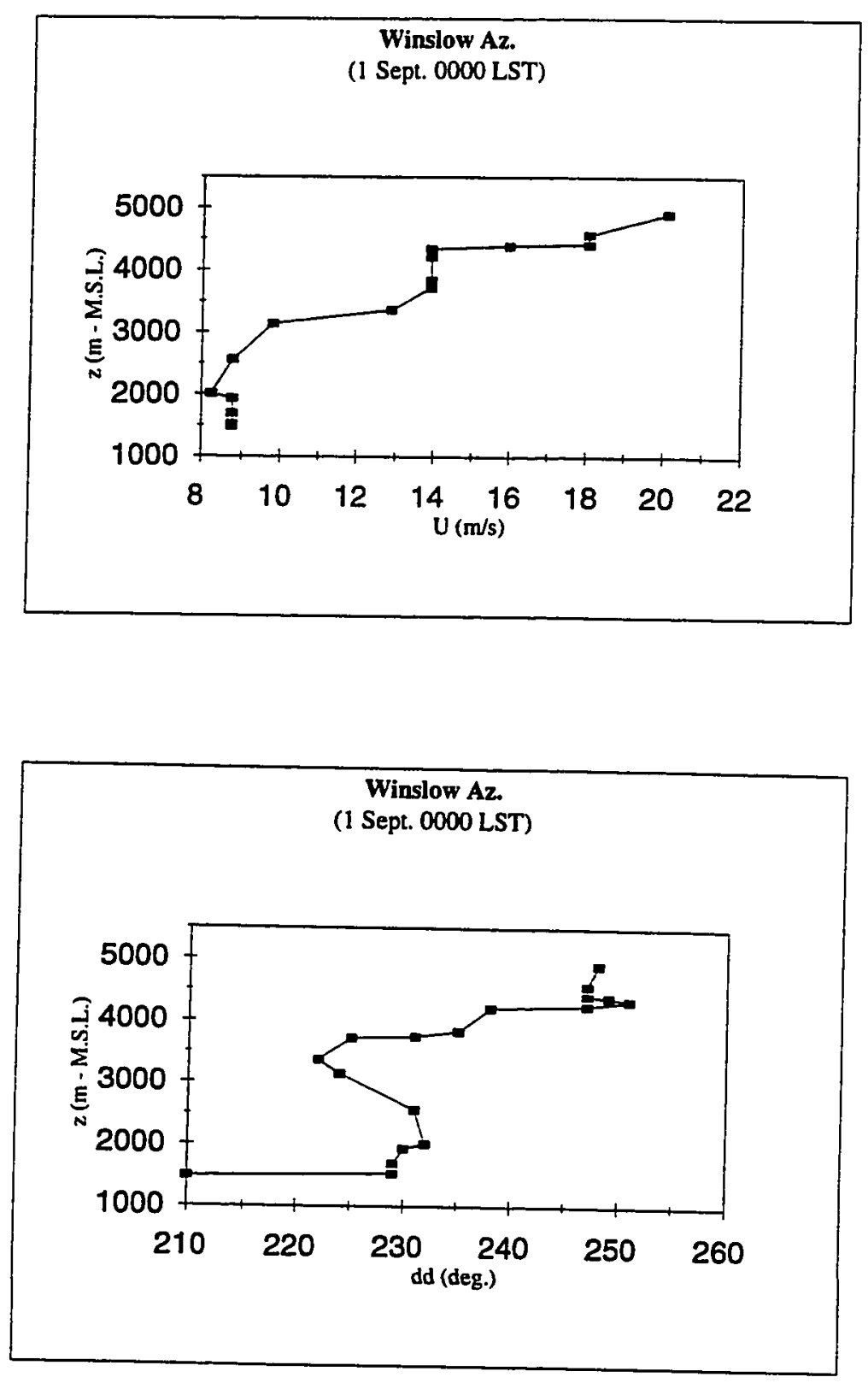

Fig. 9 


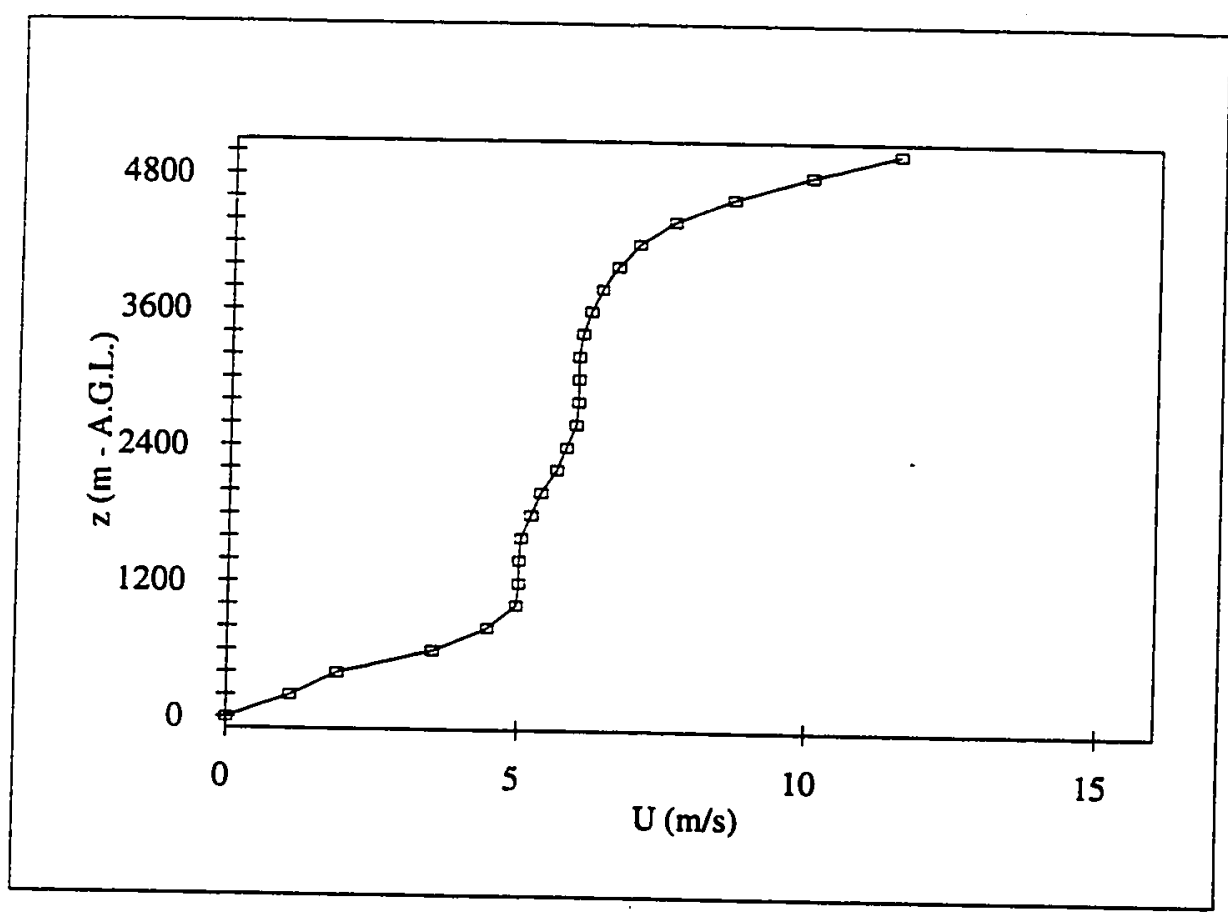

Fig. 10 


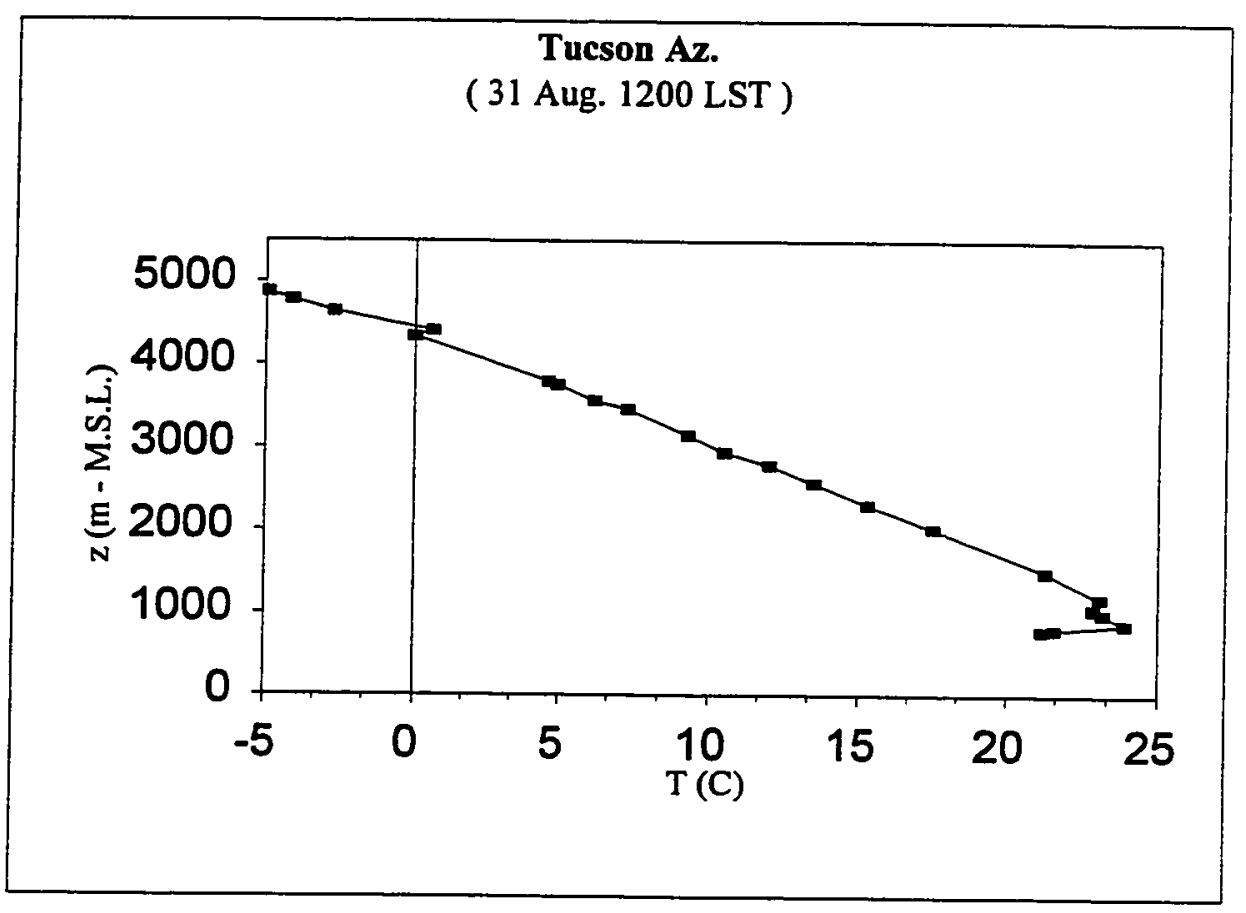

Fig. 11 


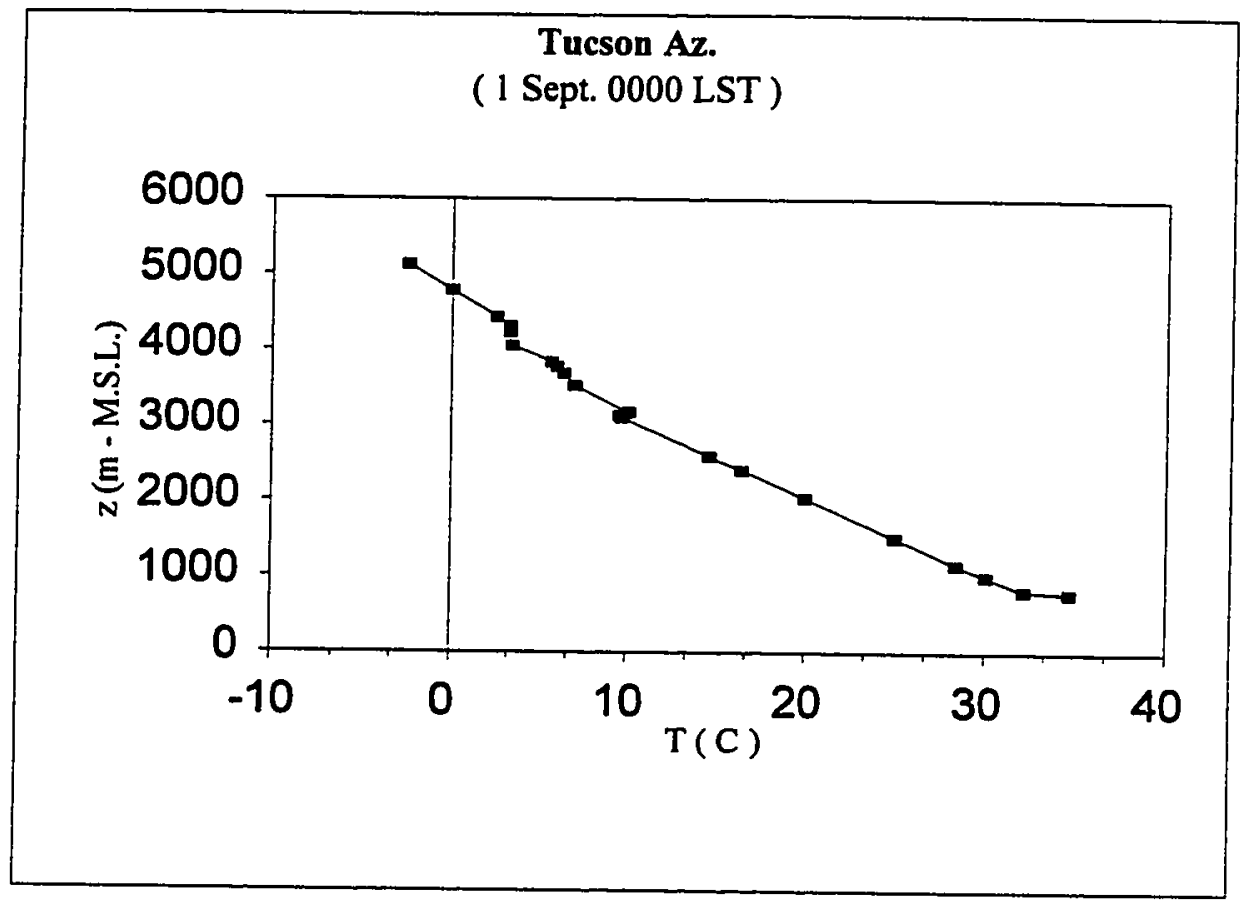

Fig. 12 


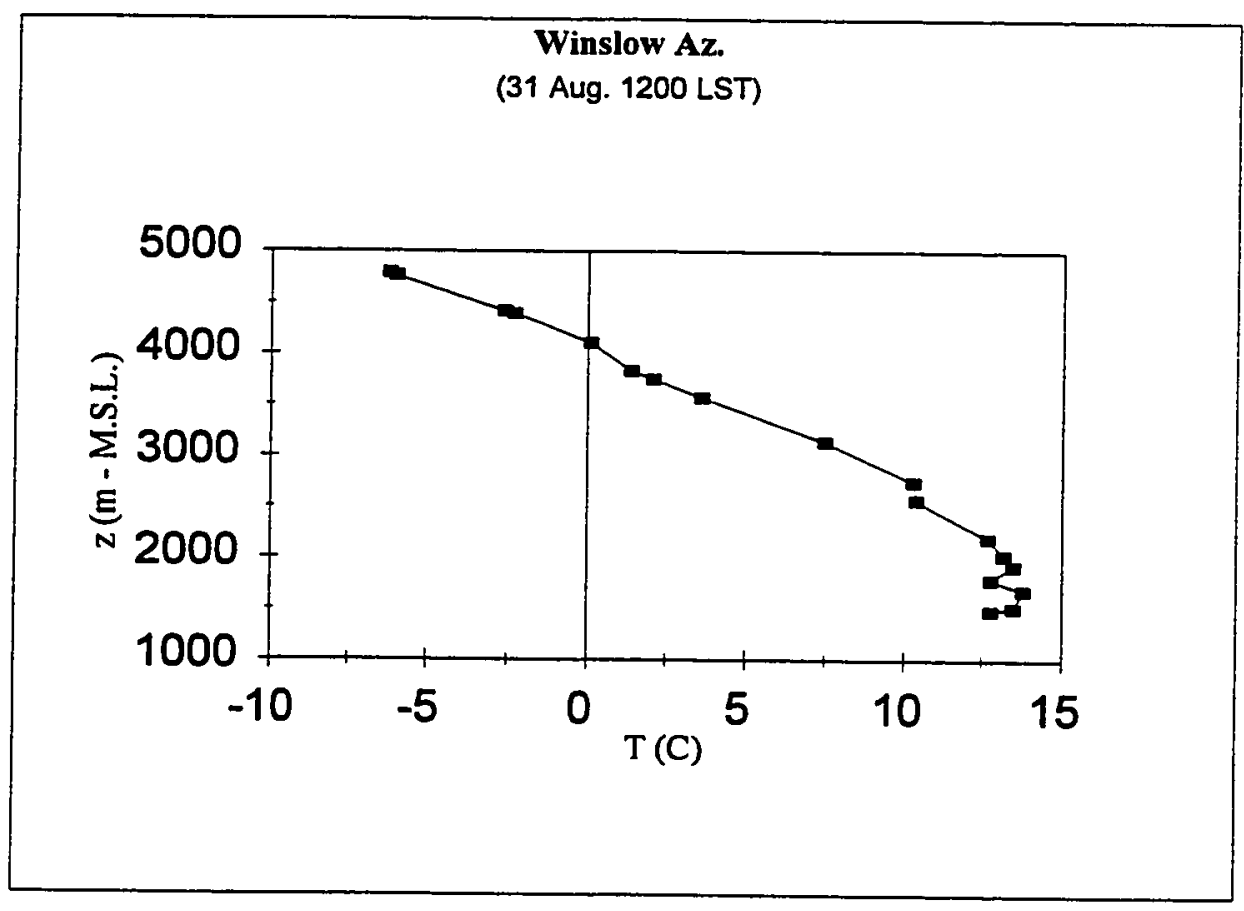

Fig. 13 


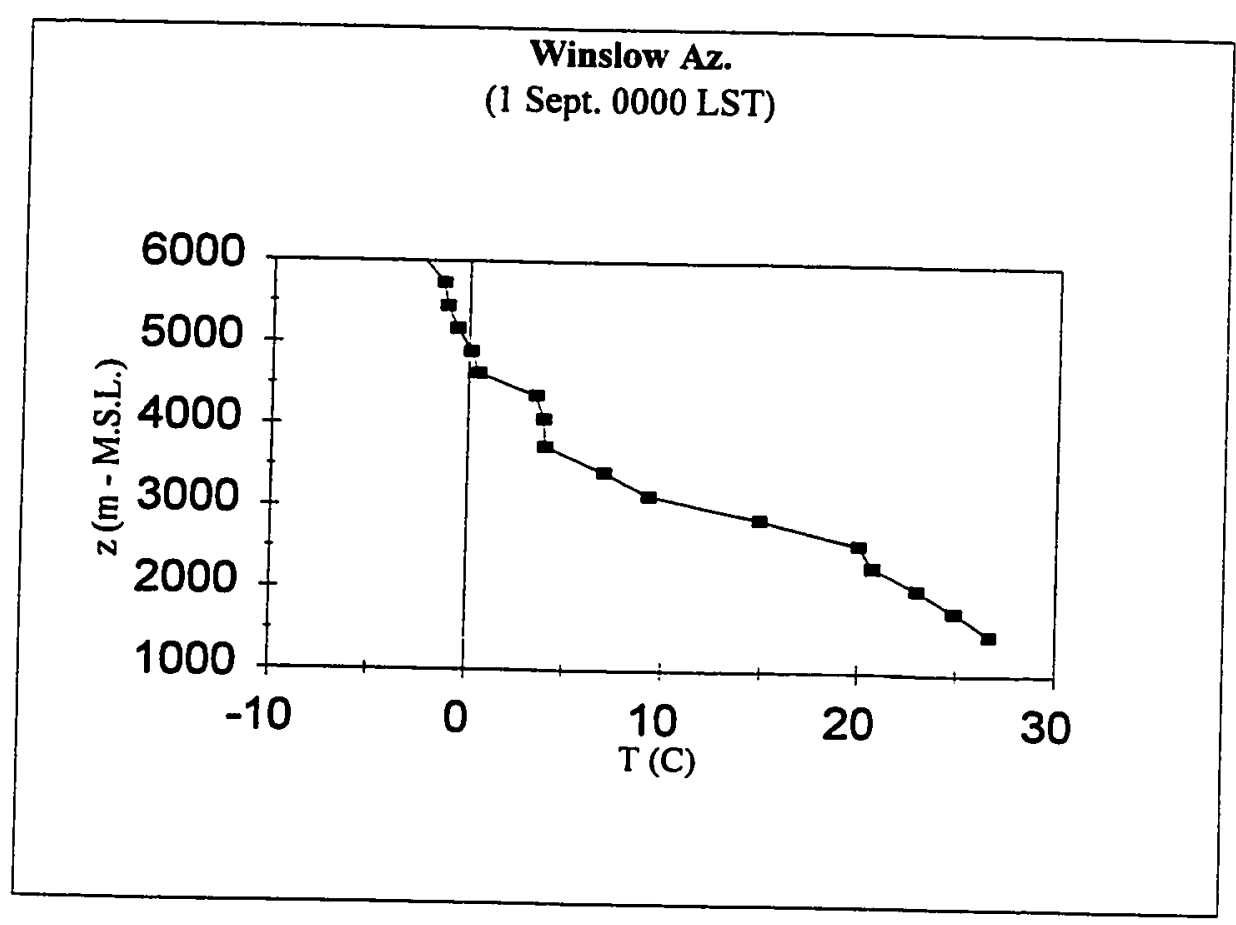

Fig. 14 


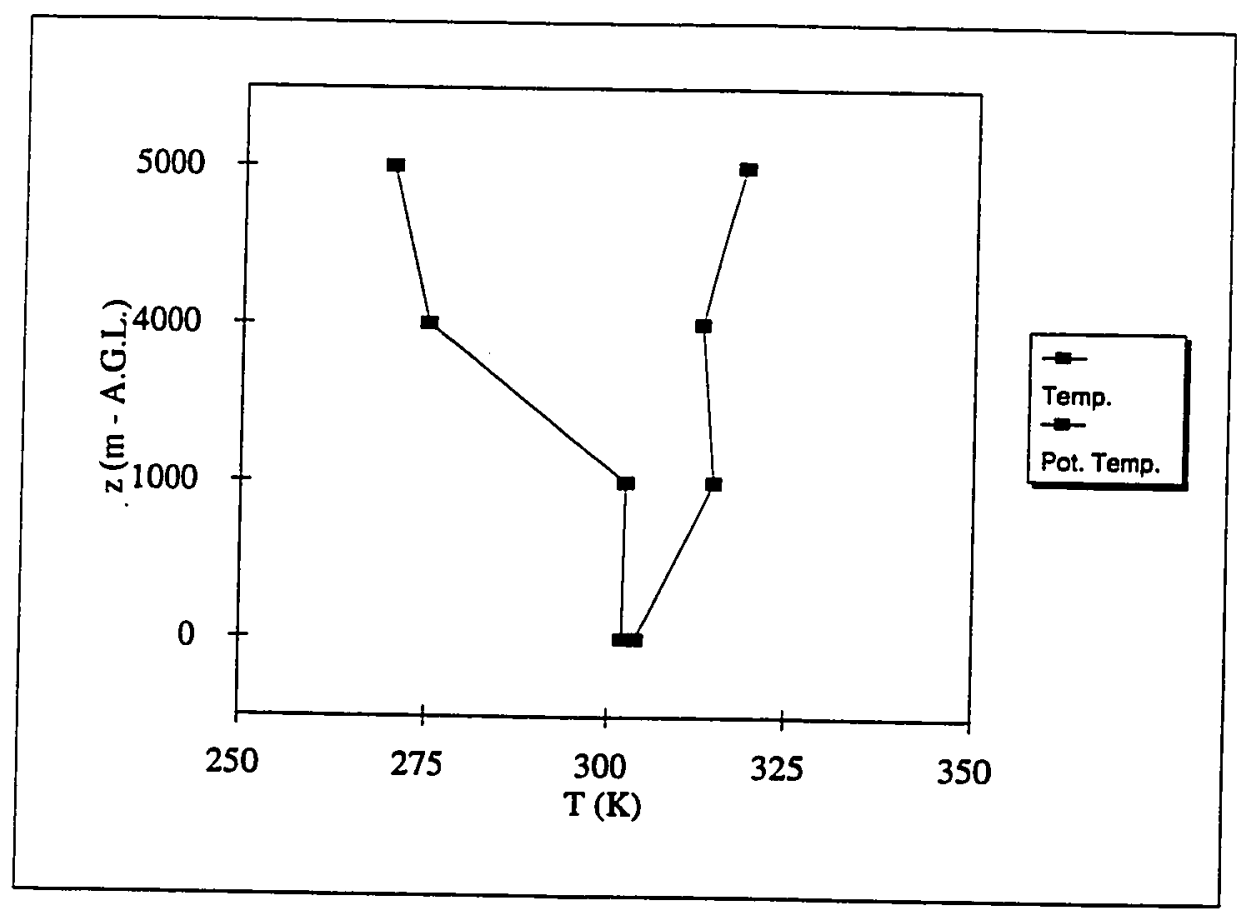

Fig. 15 


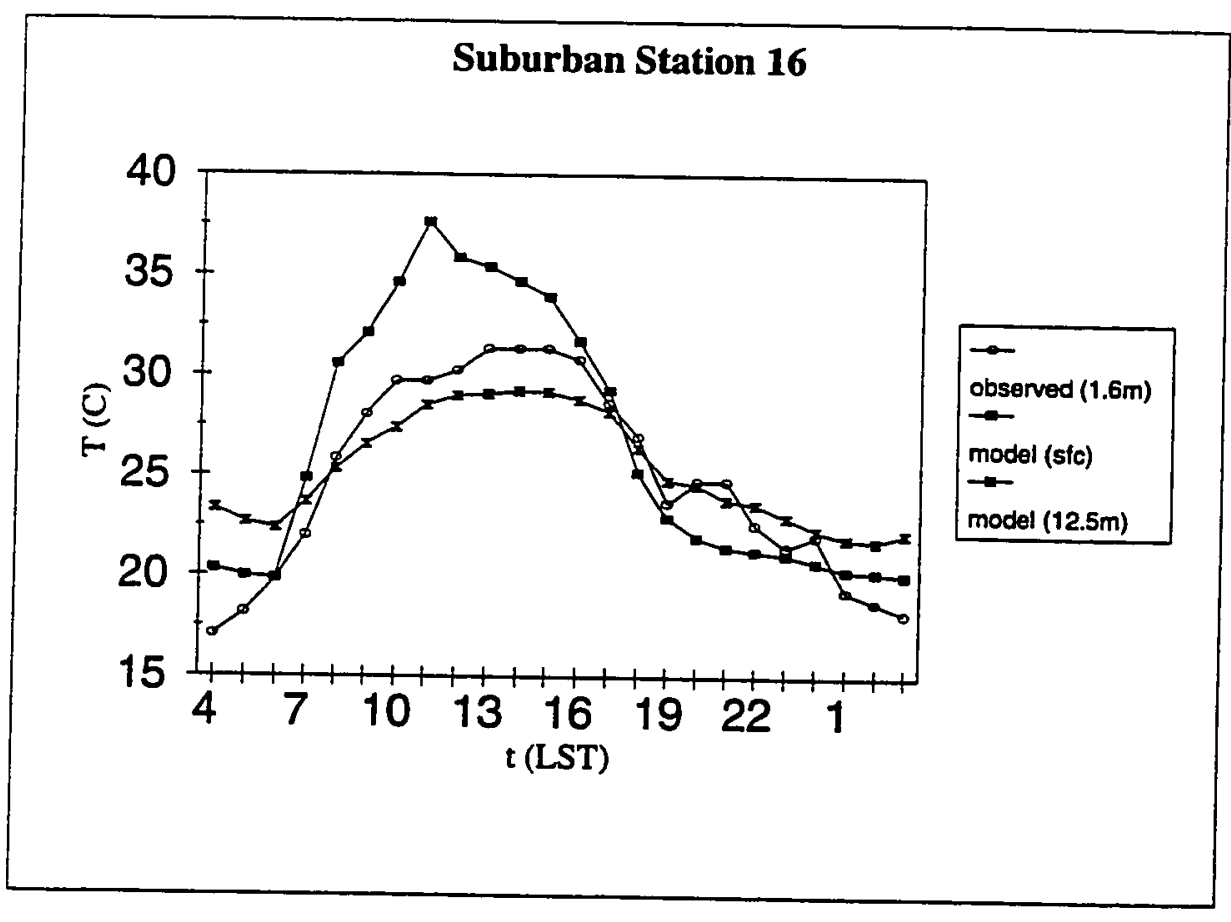

Fig. 16a 


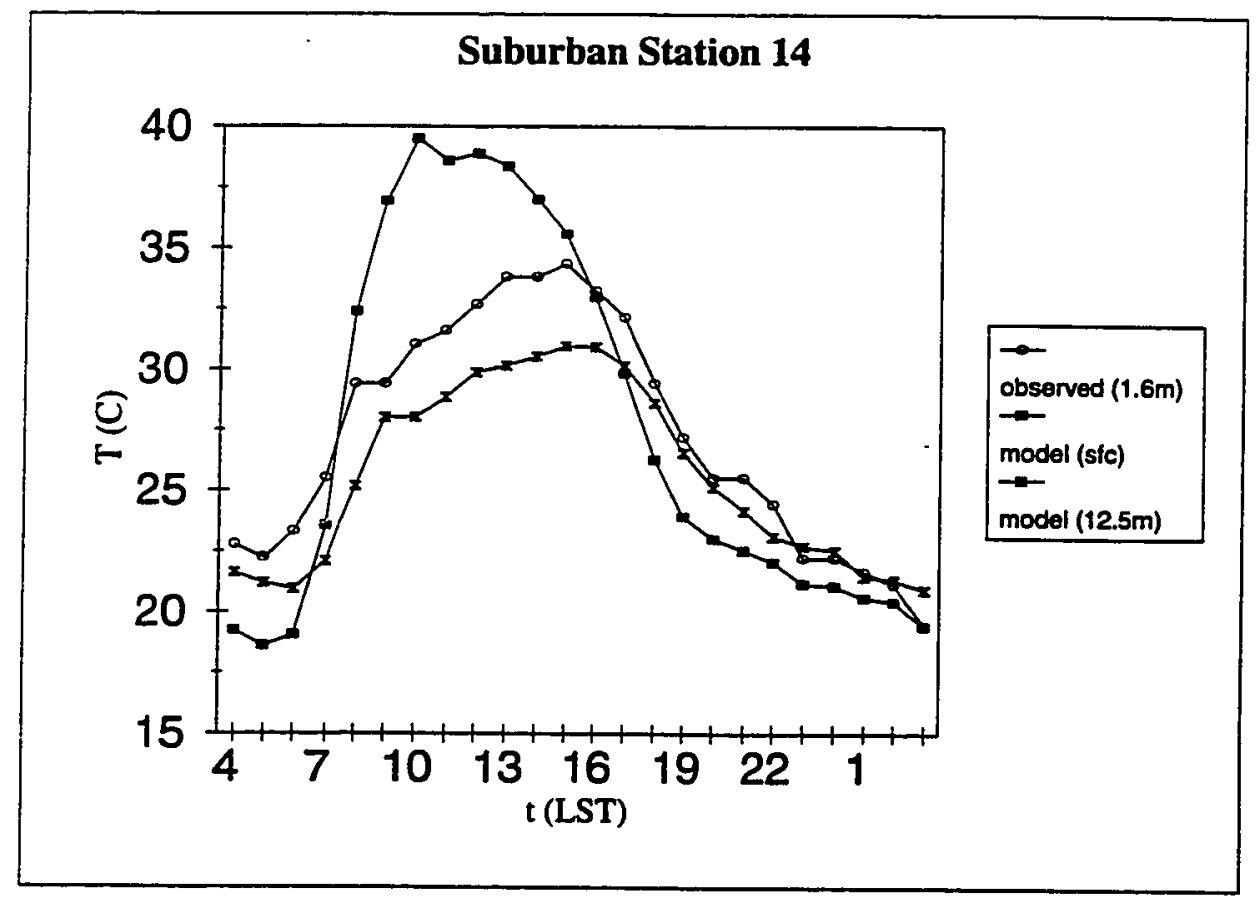

Fig. 16b 


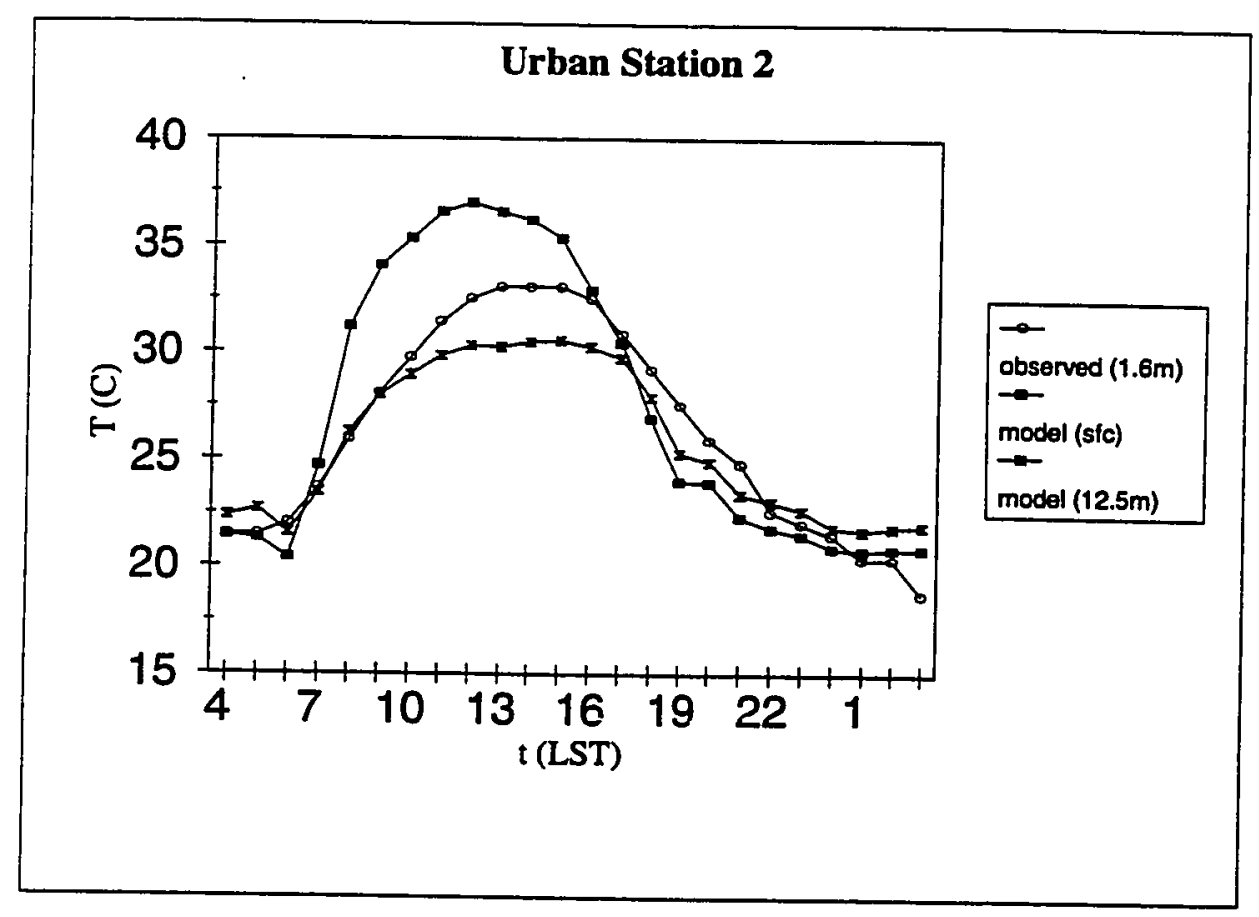

Fig. 16c 


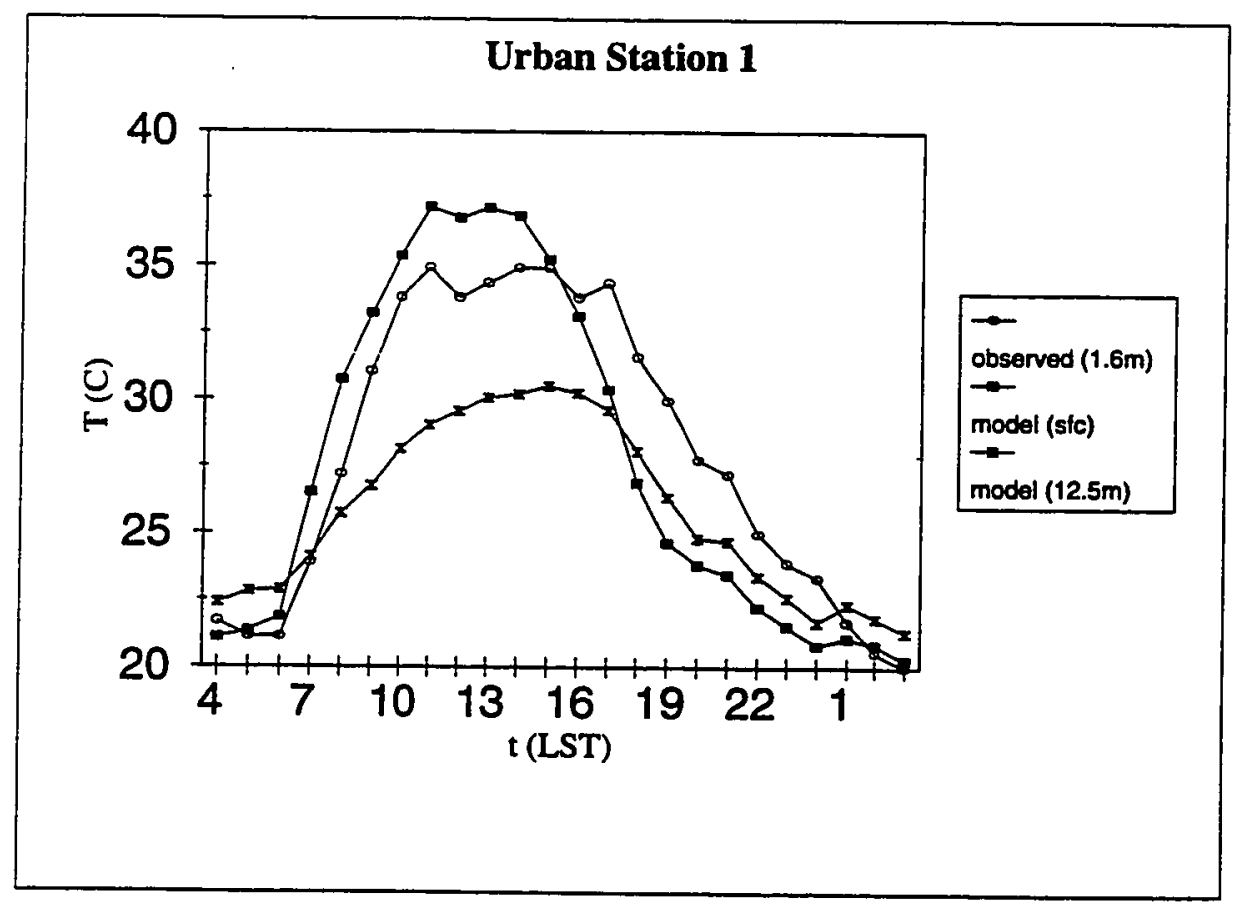

Fig. 16d 


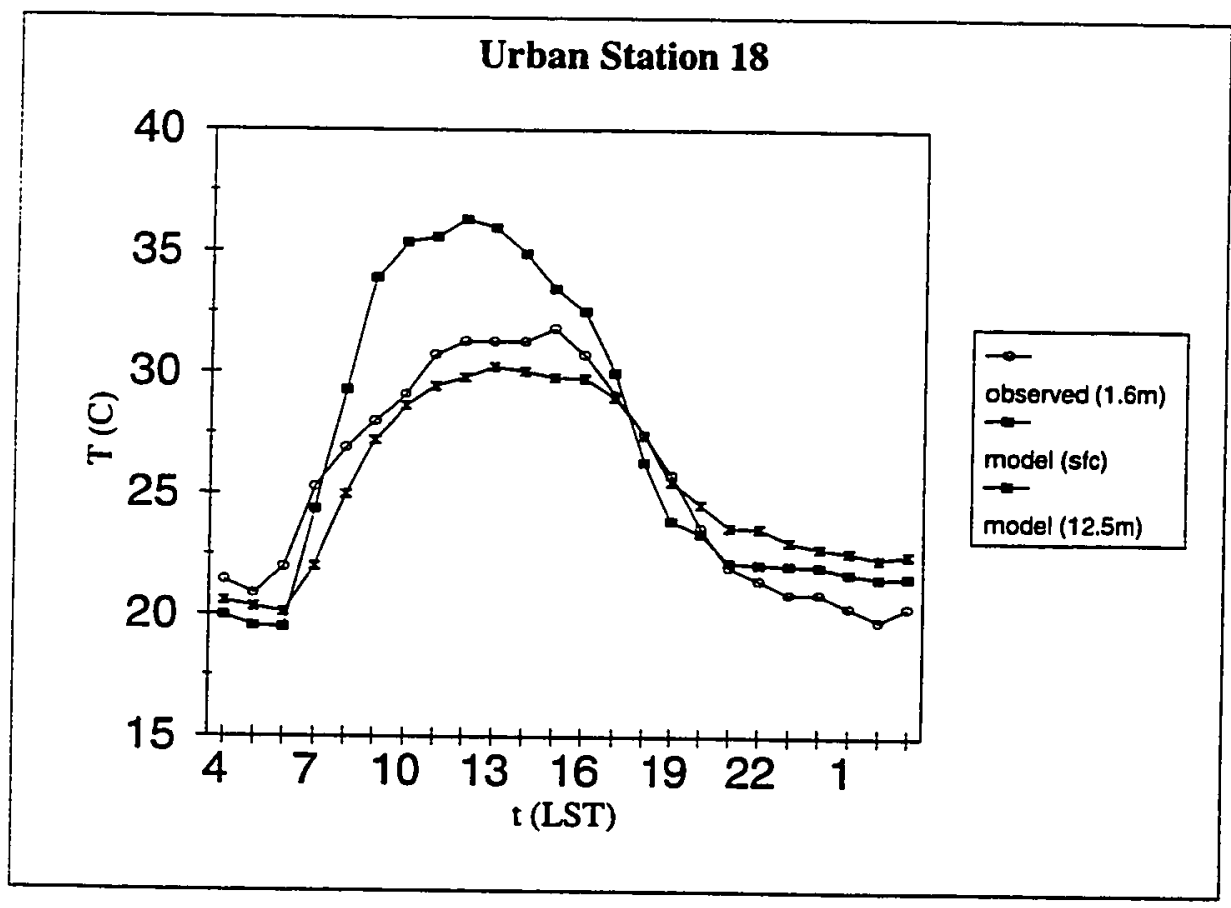

Fig. 16e 


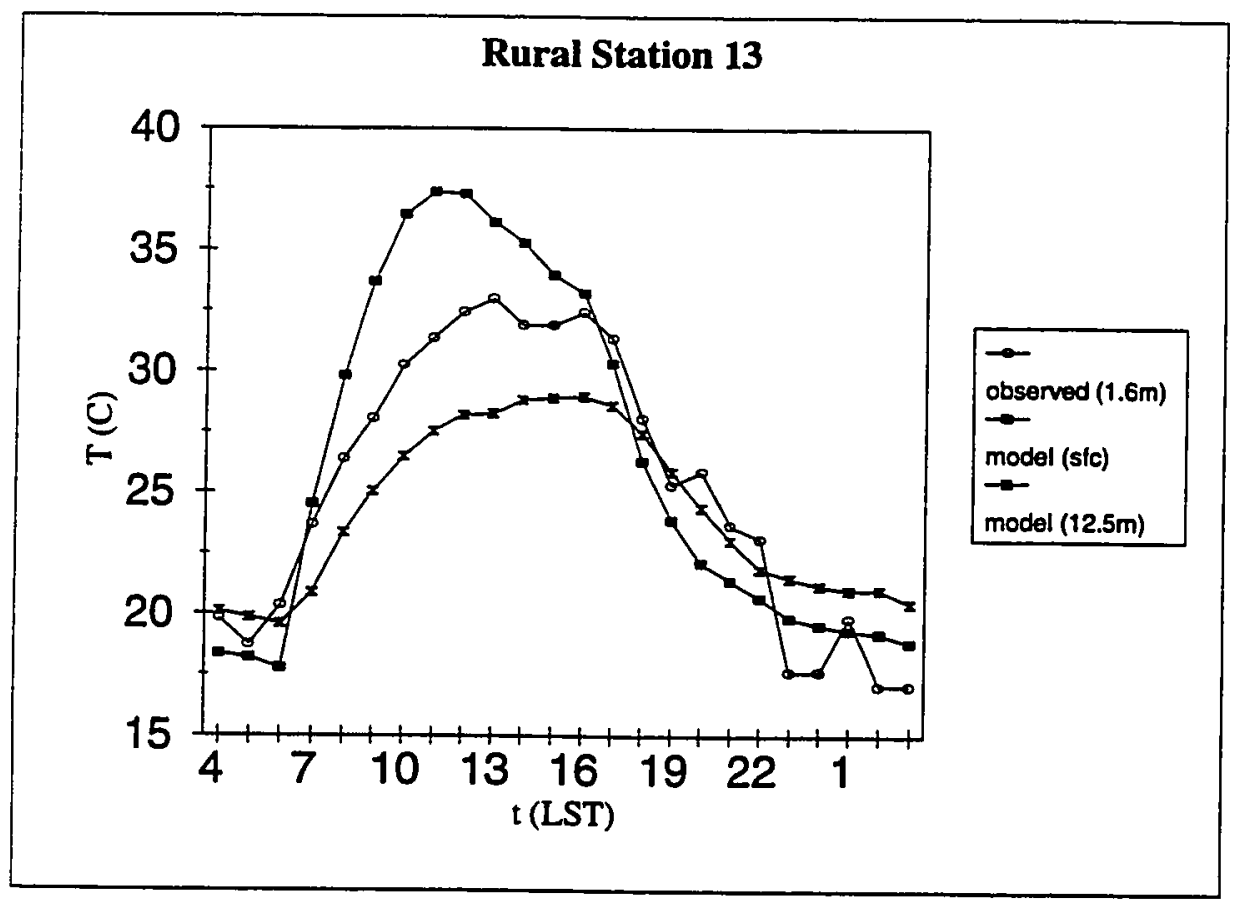

Fig. $16 \mathrm{f}$ 


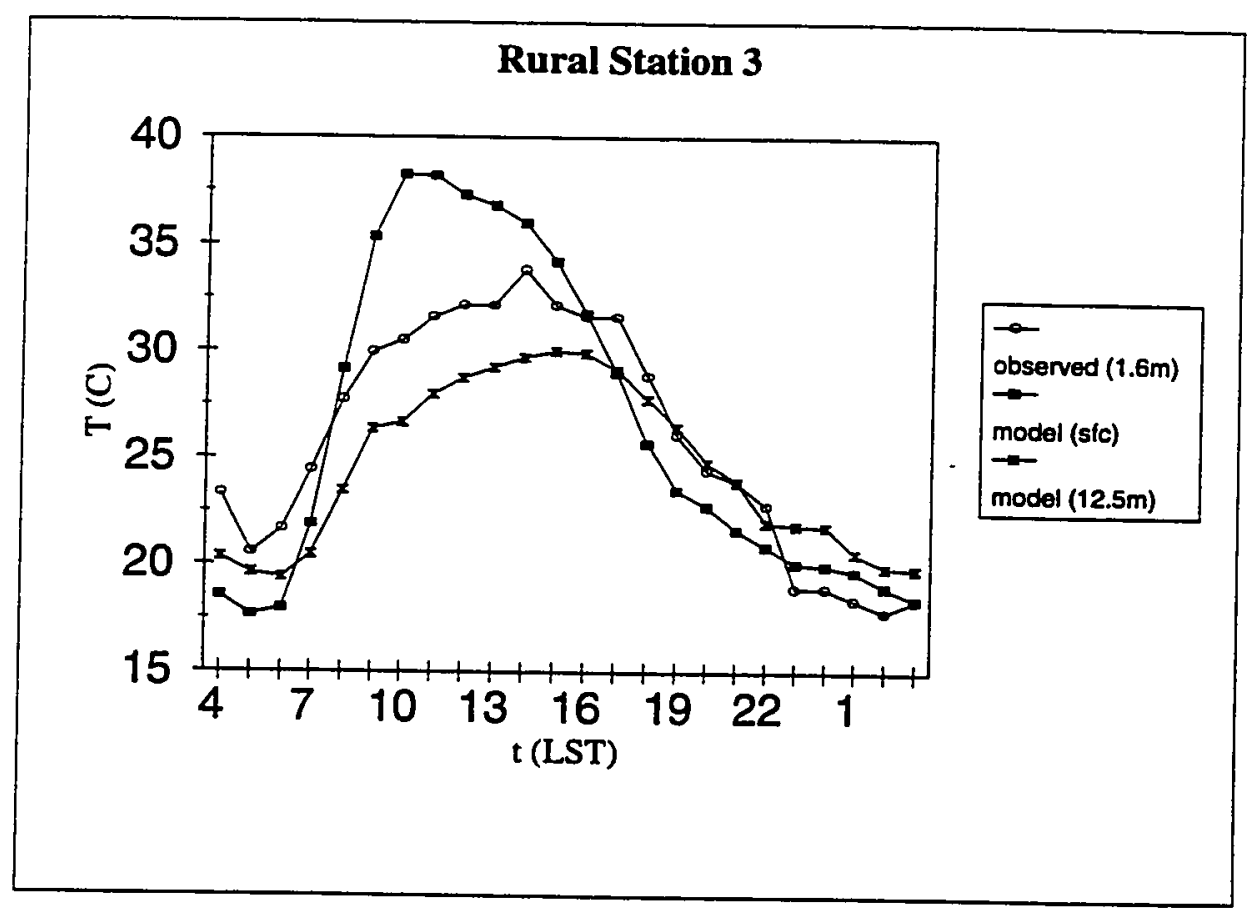

Fig. 16g 


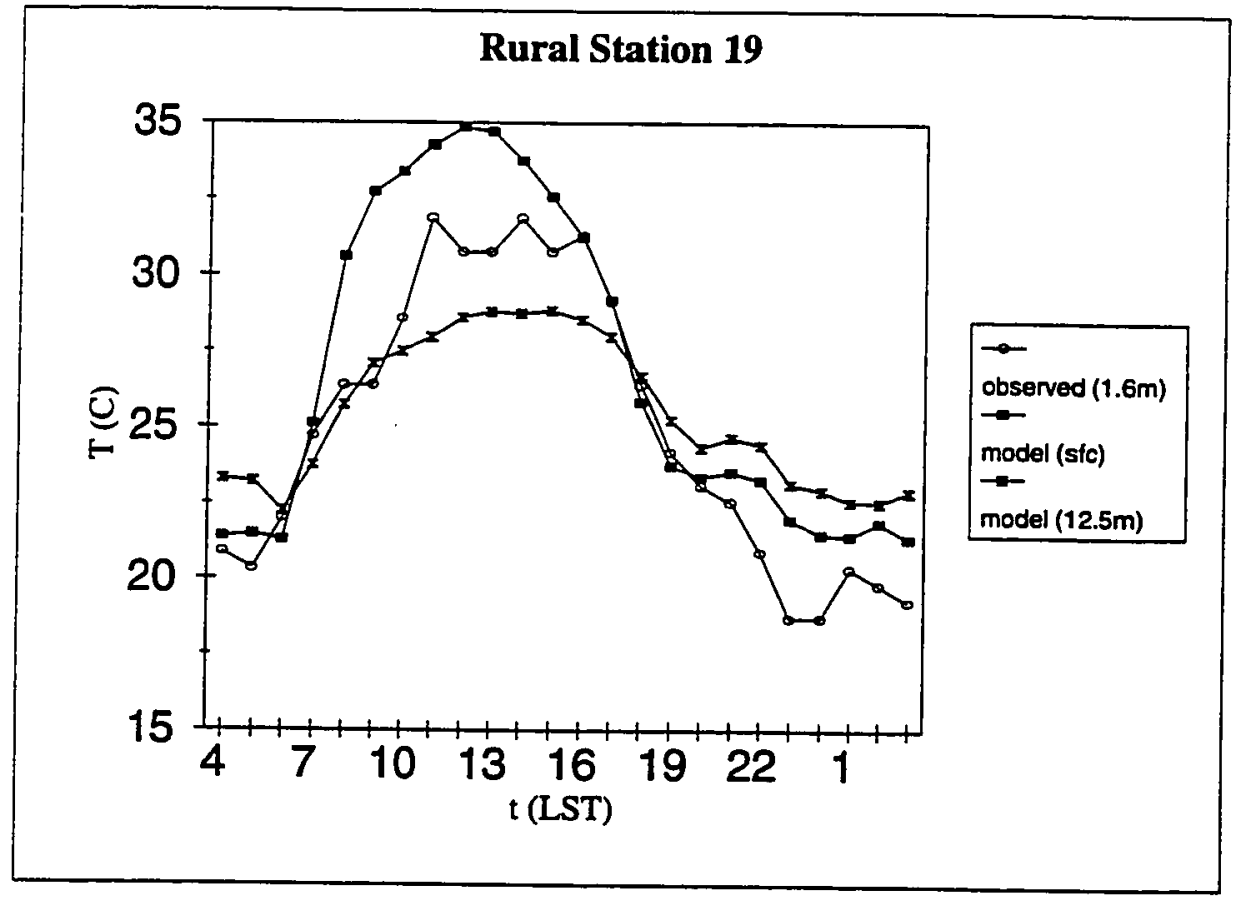

Fig. 16h 


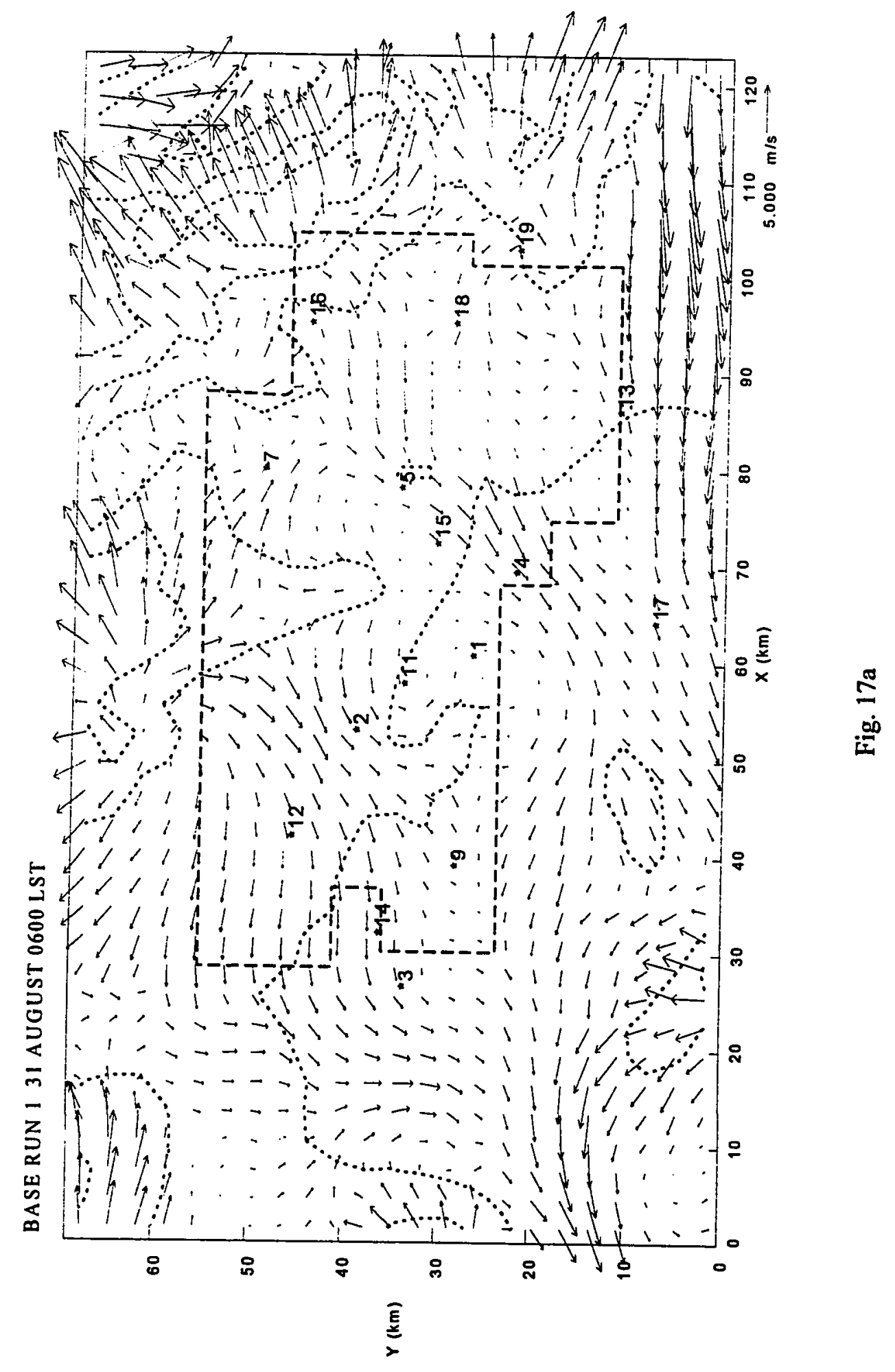




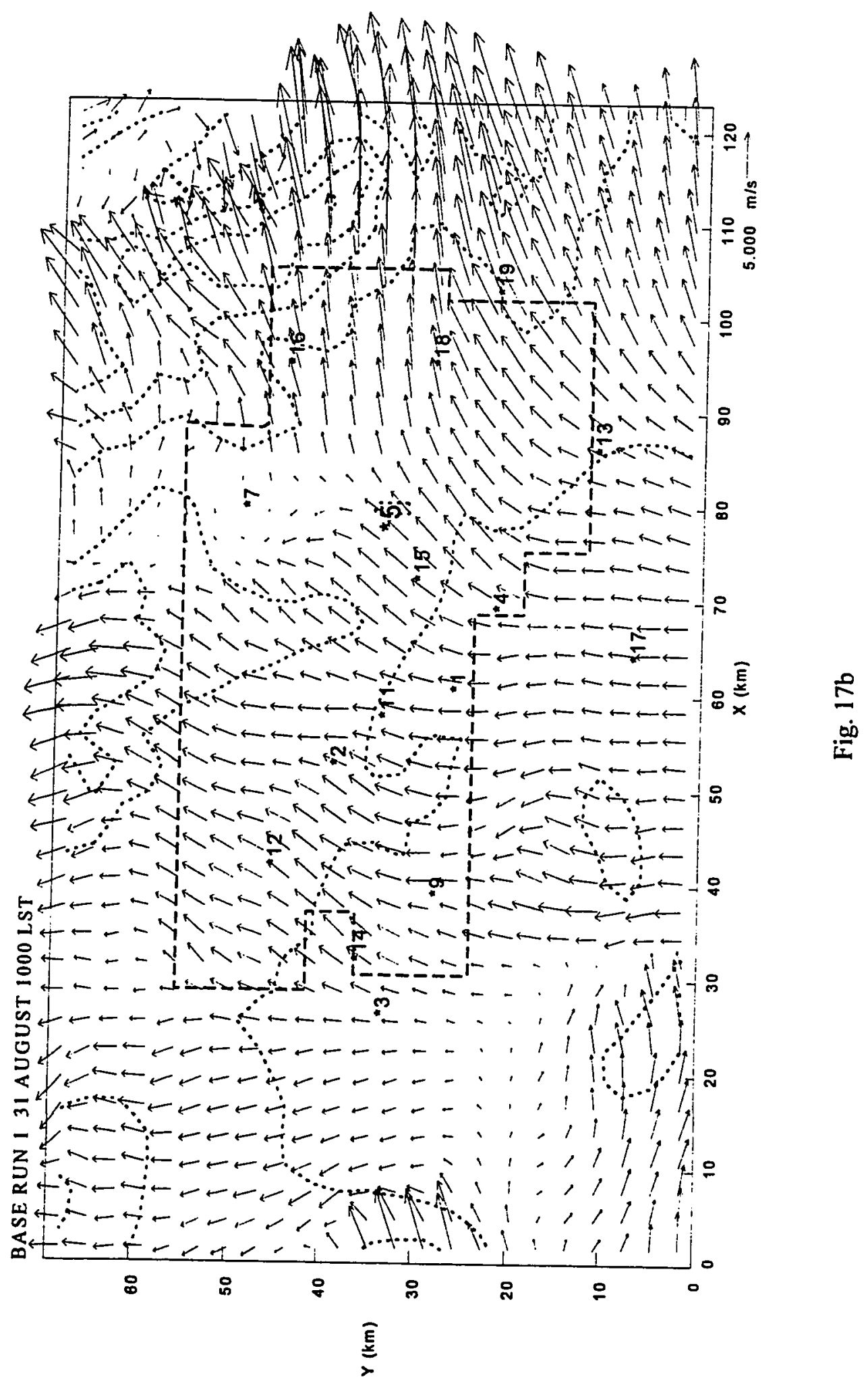




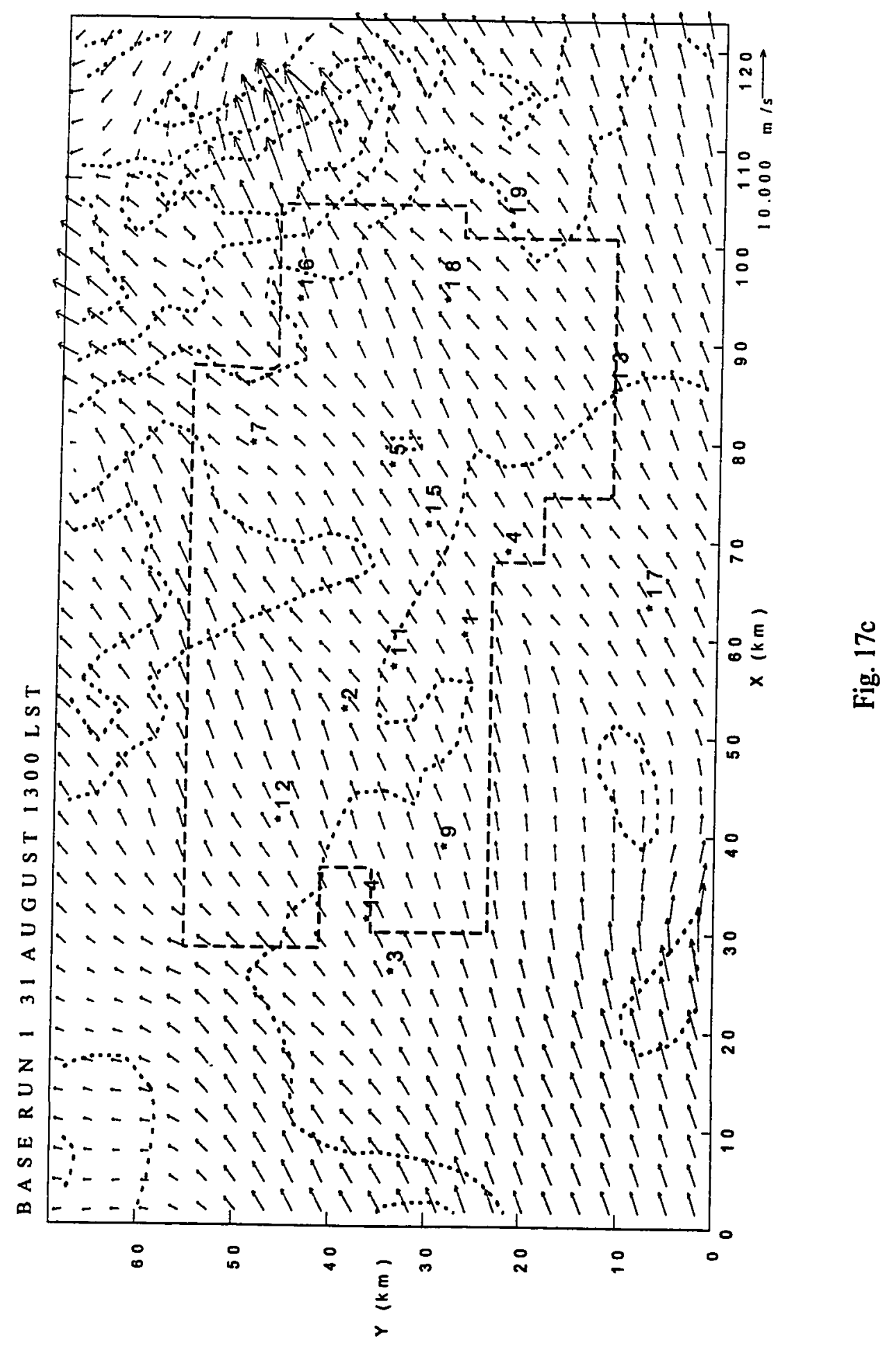




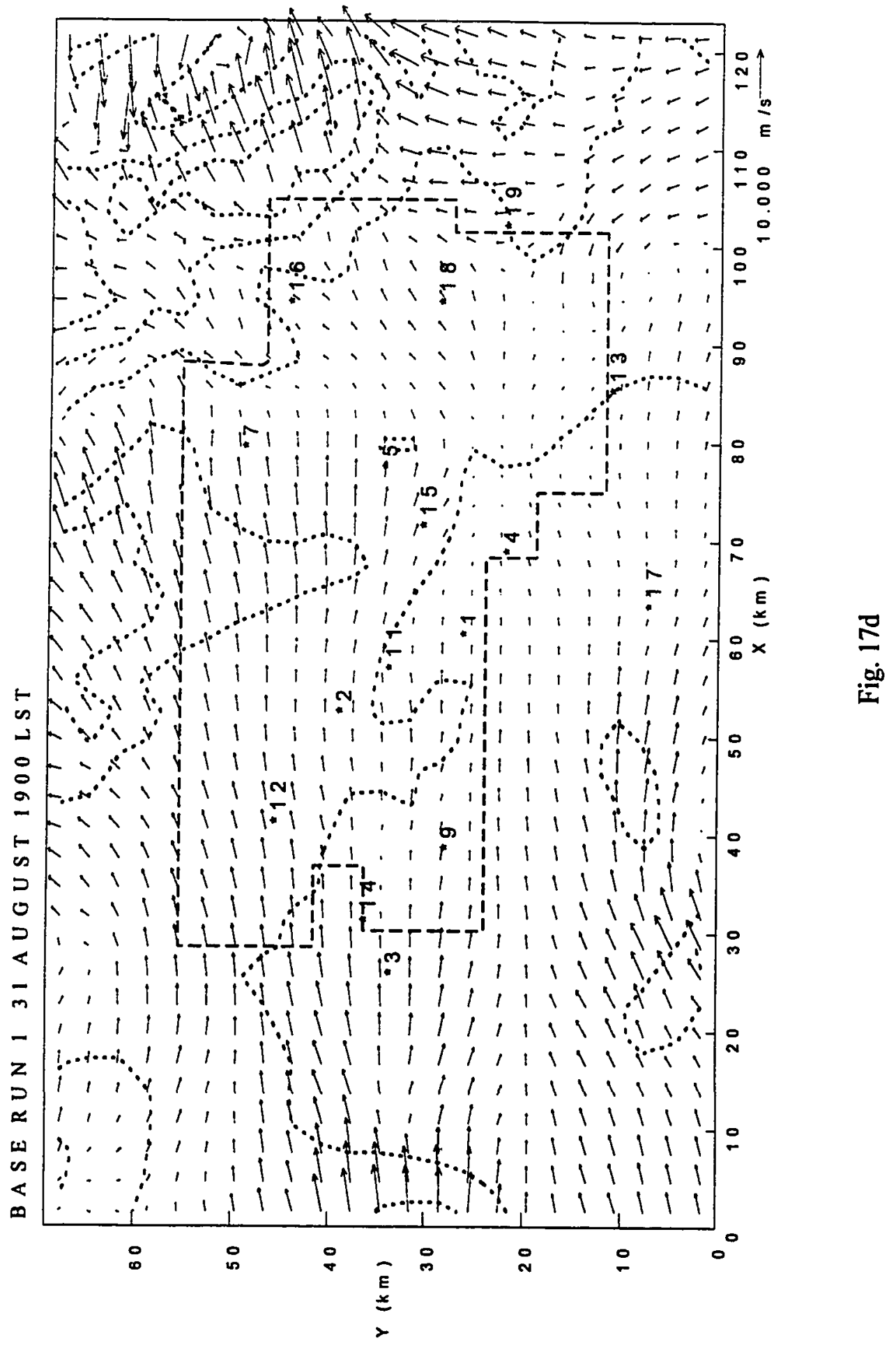




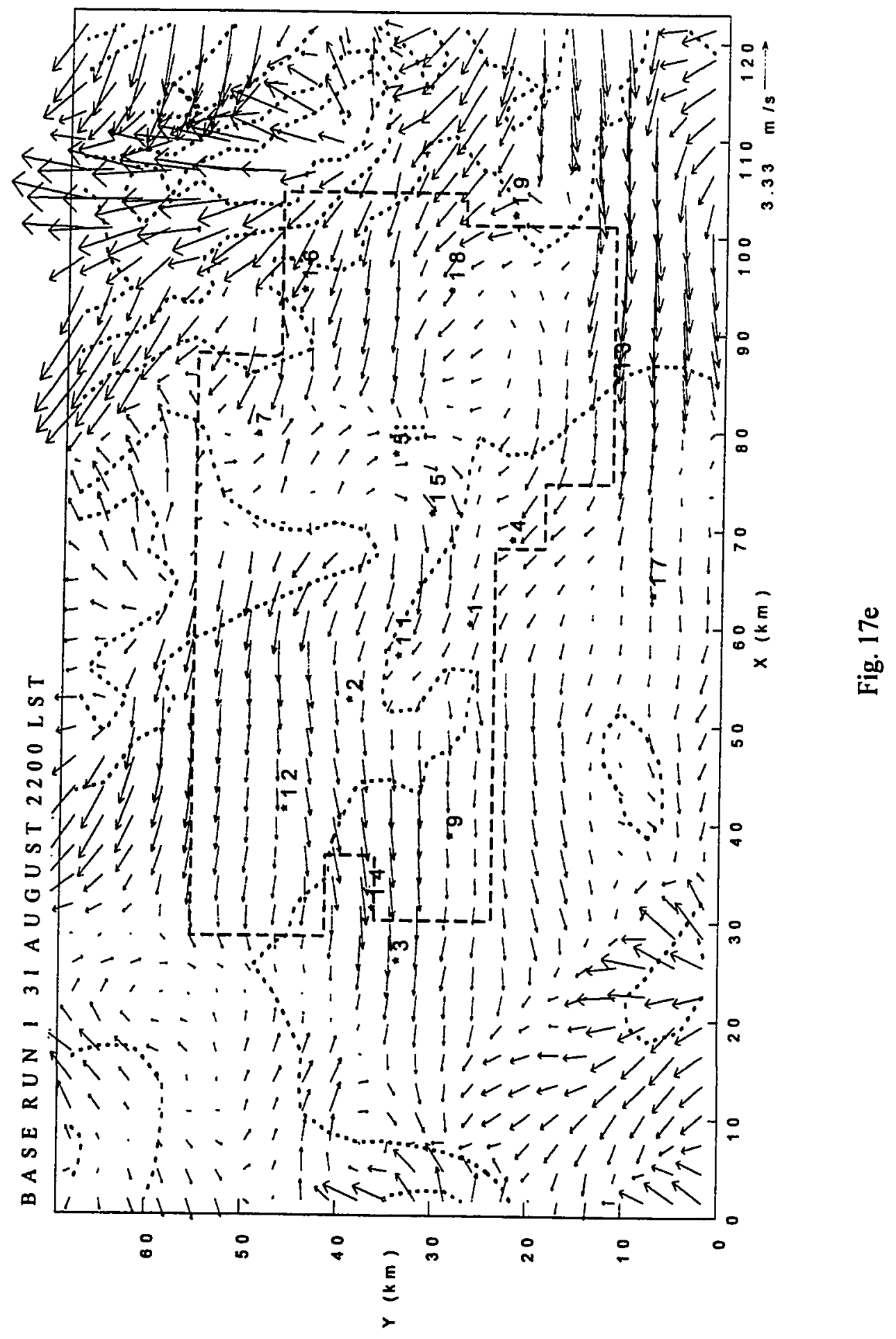




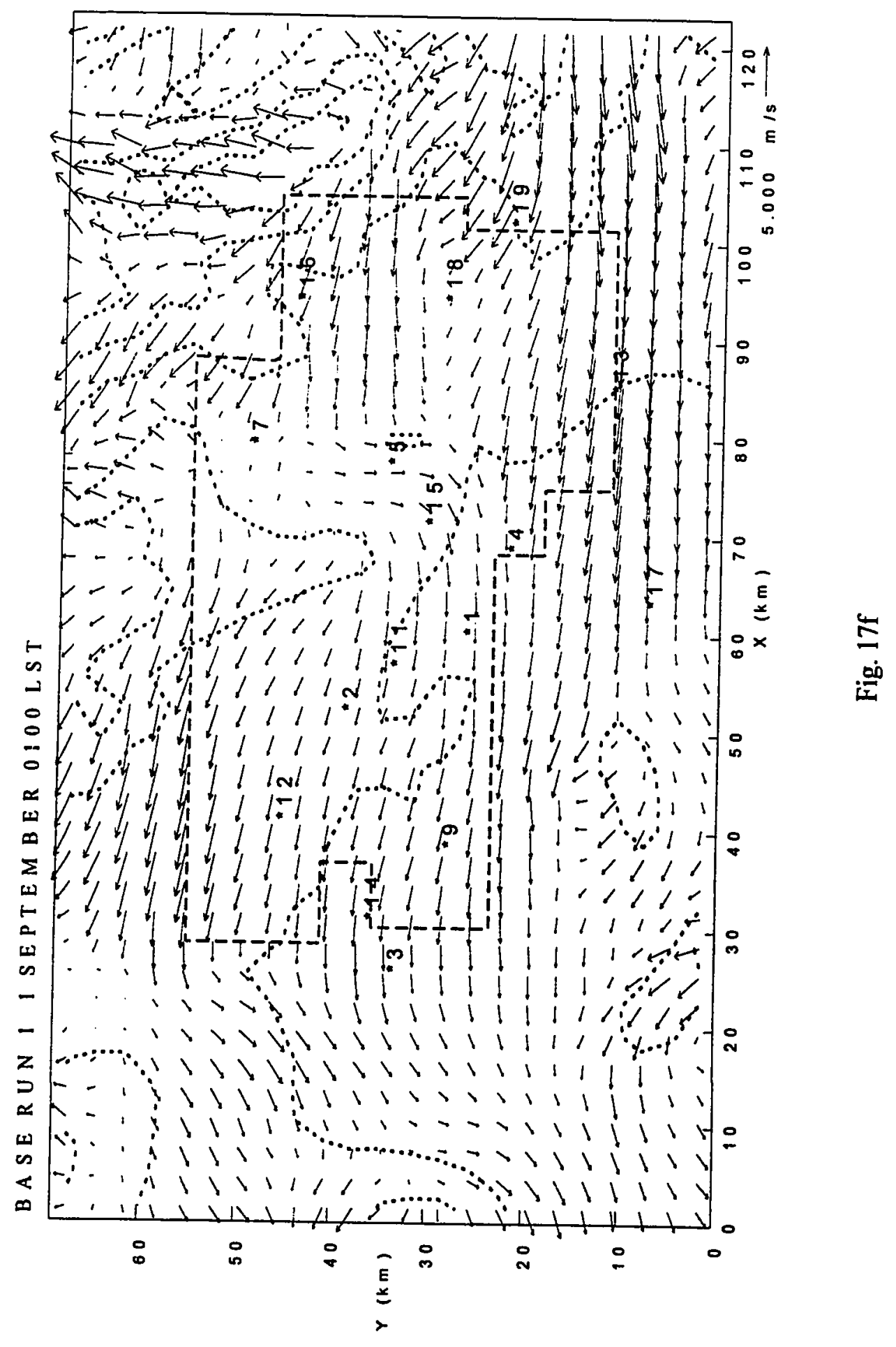




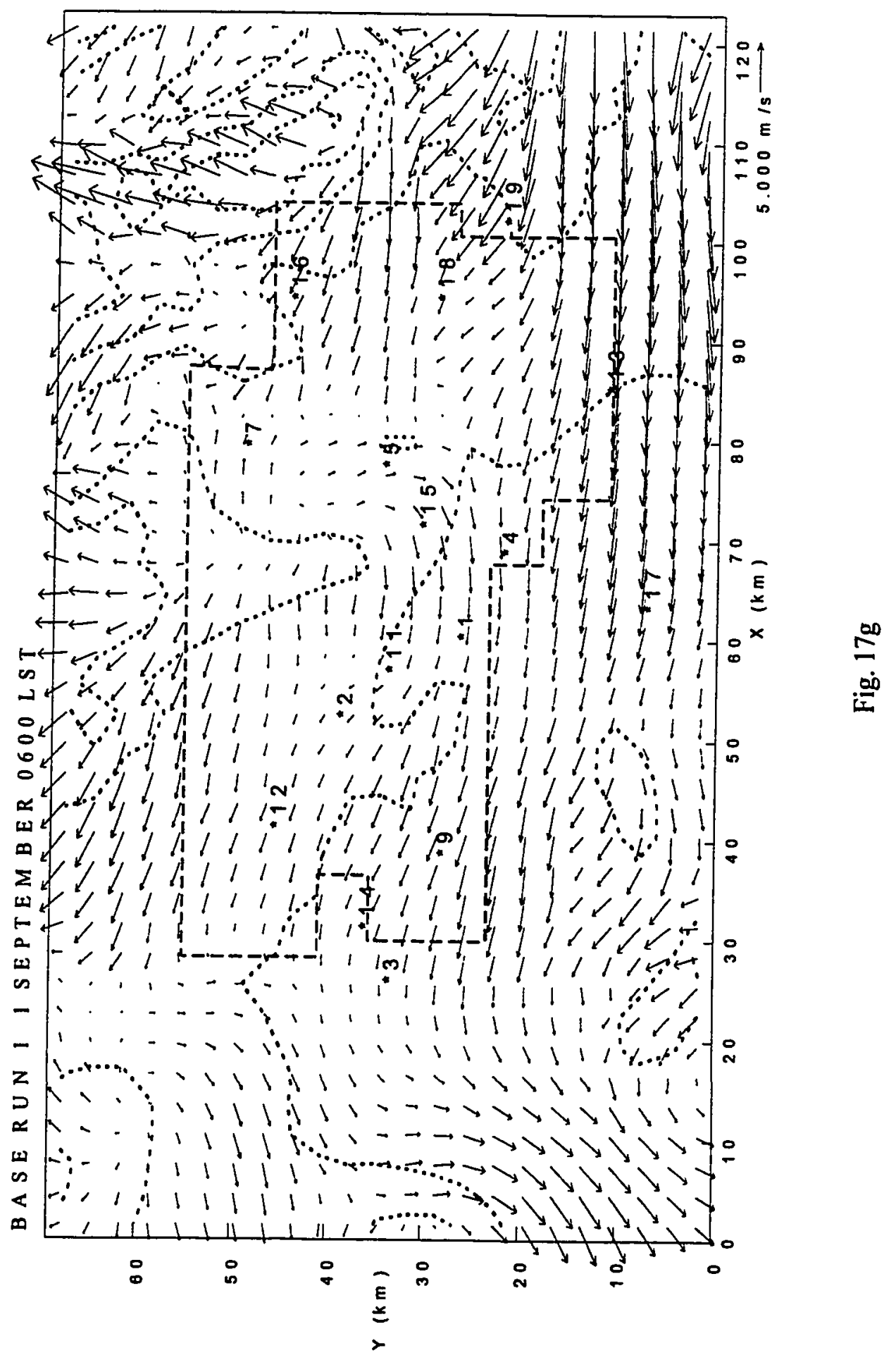




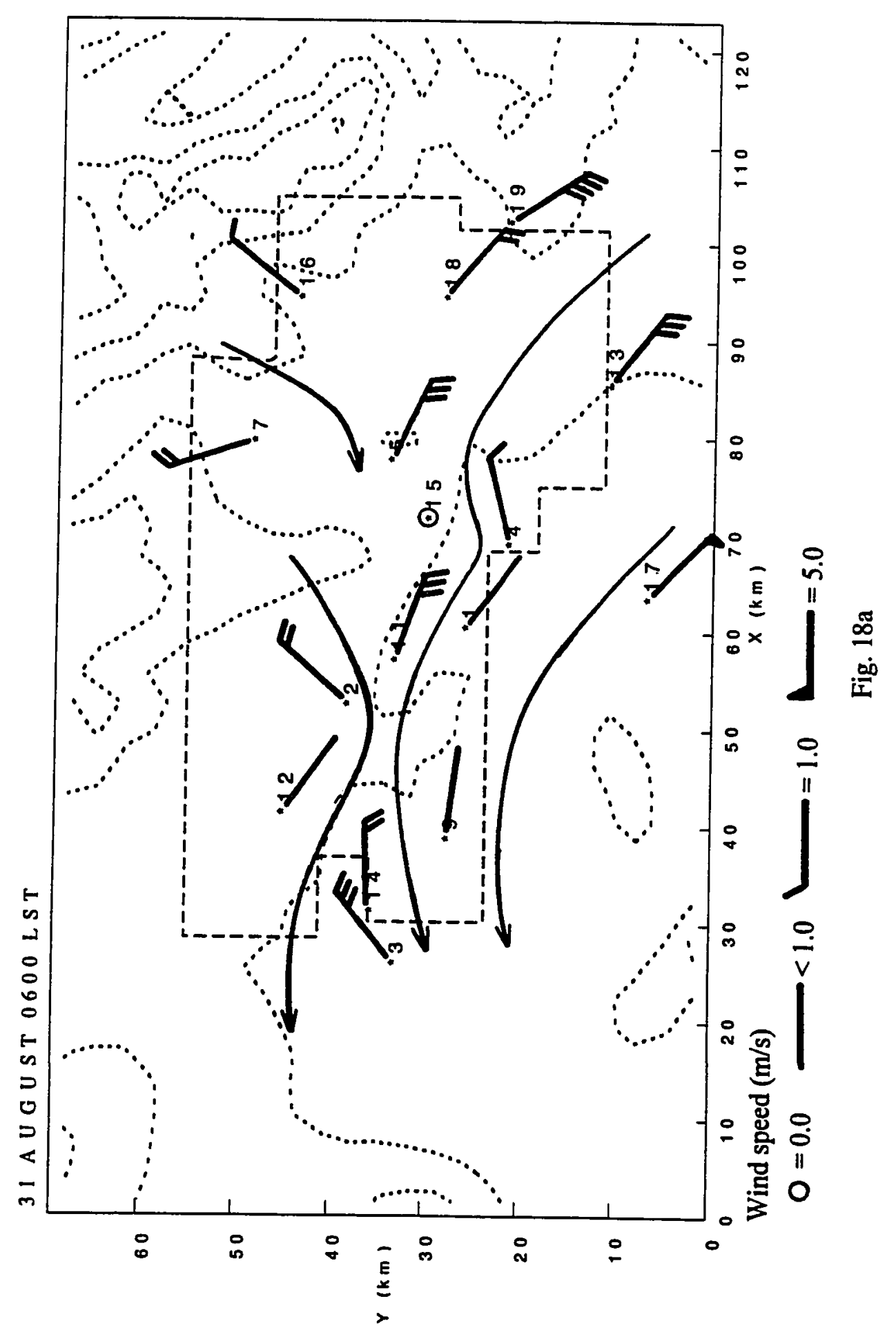




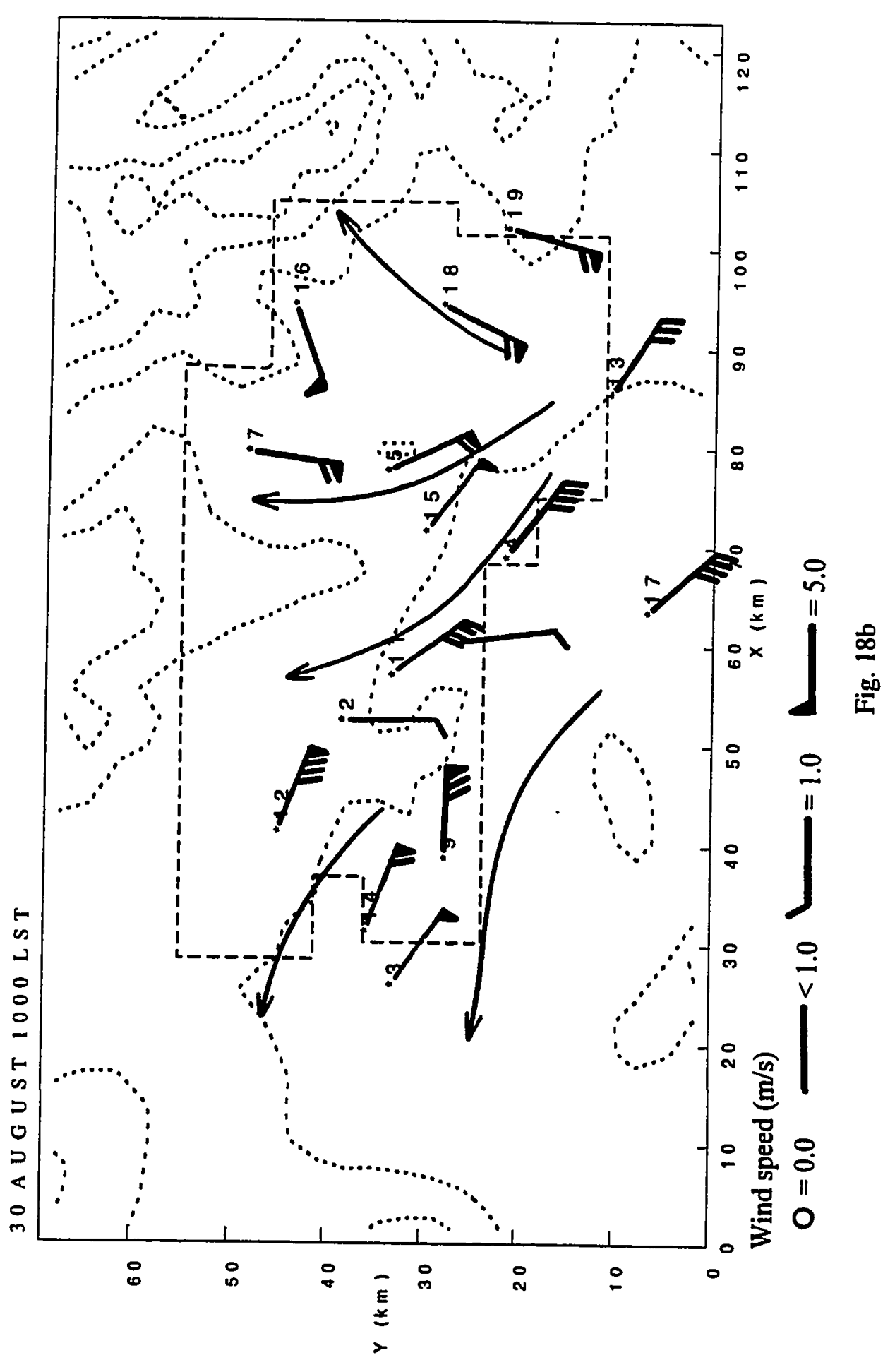




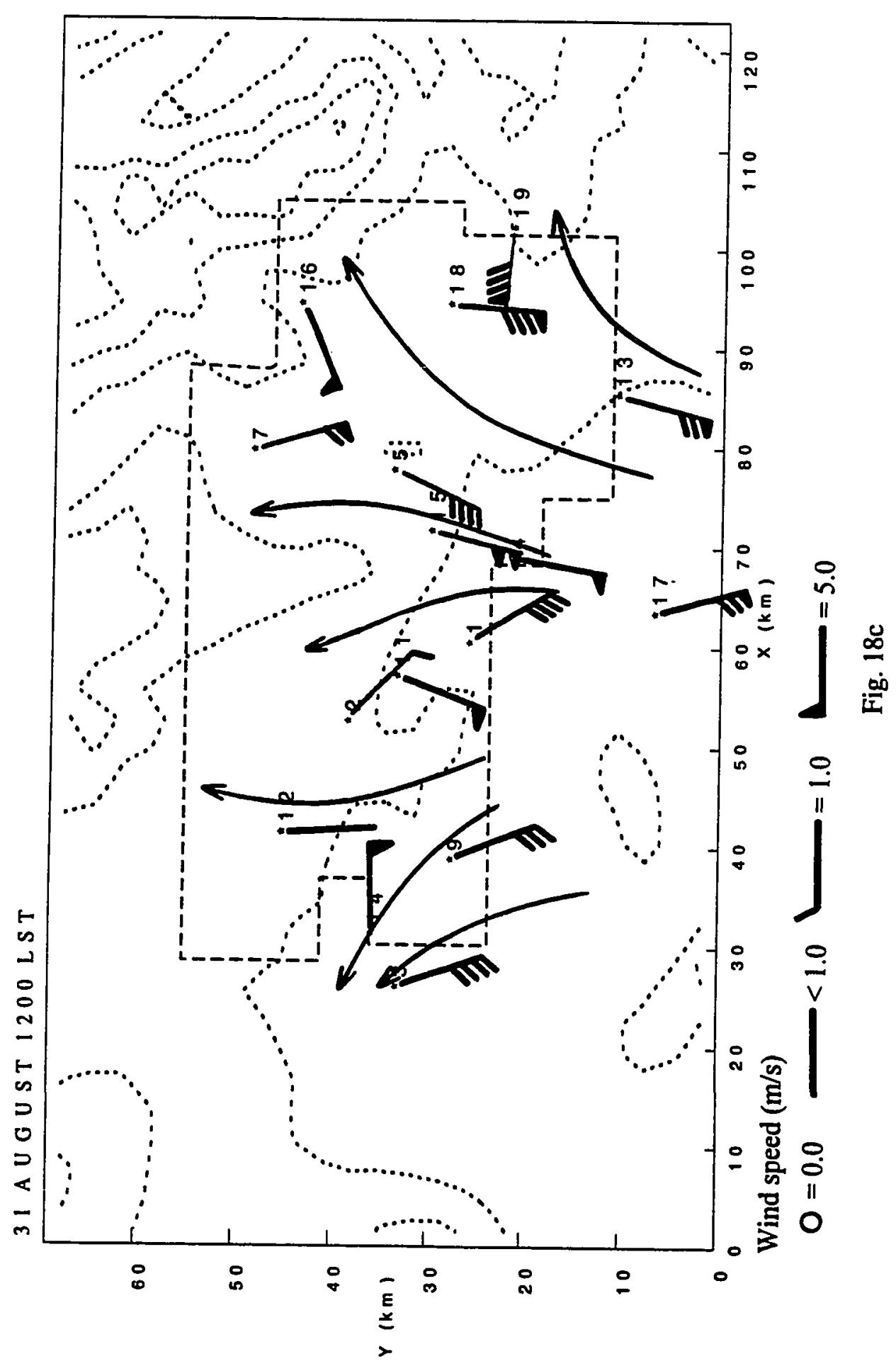




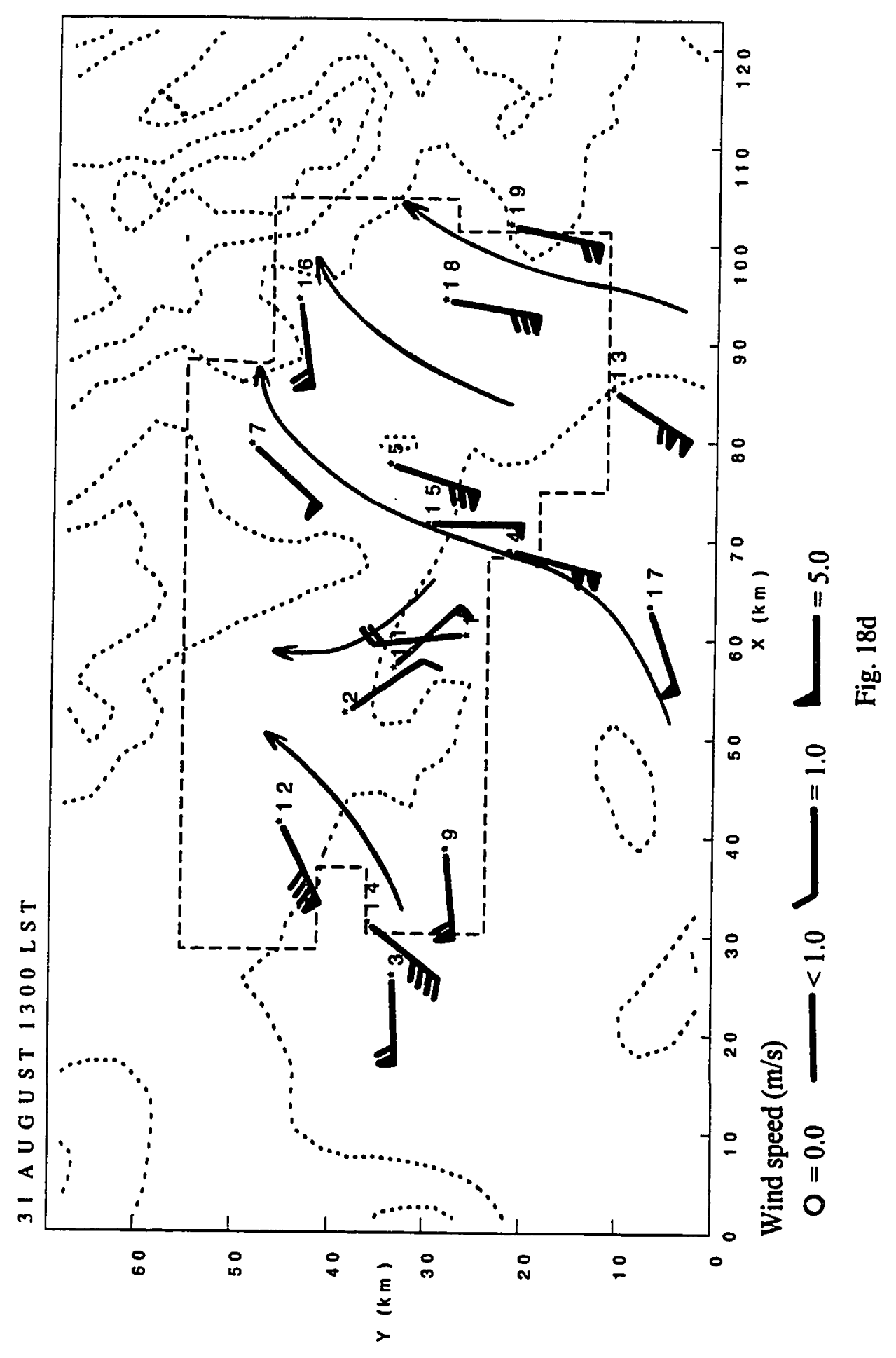




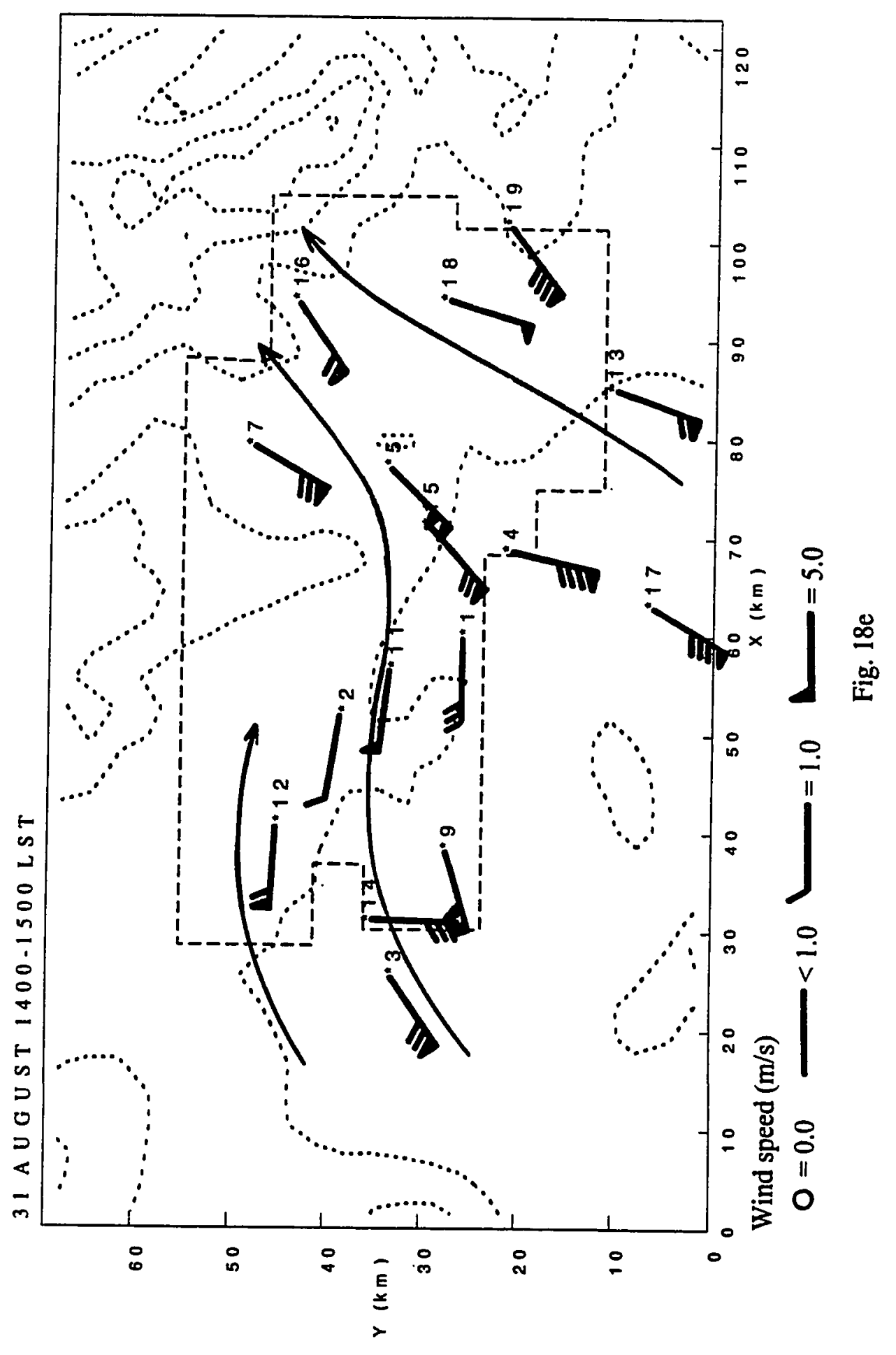




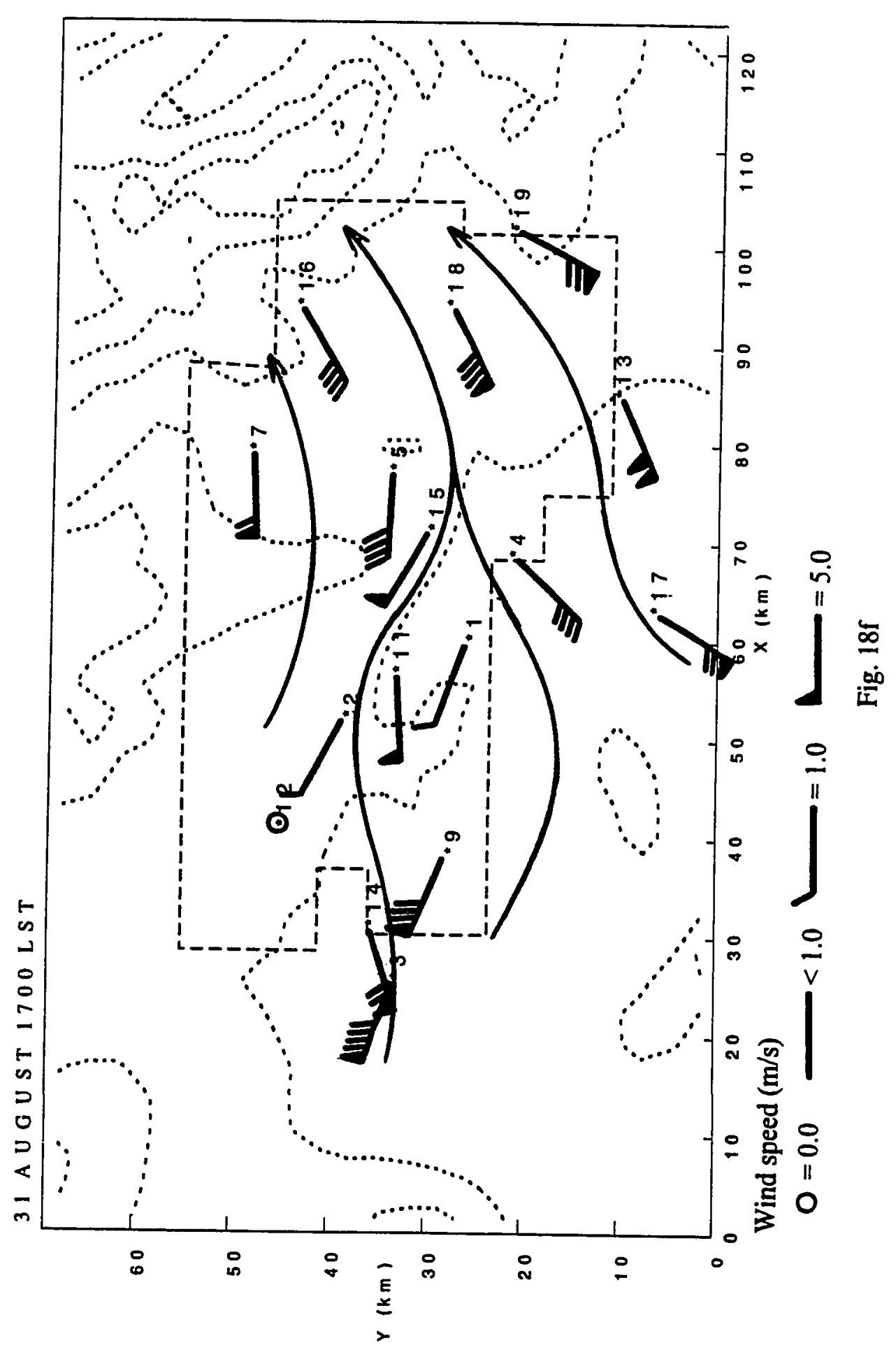




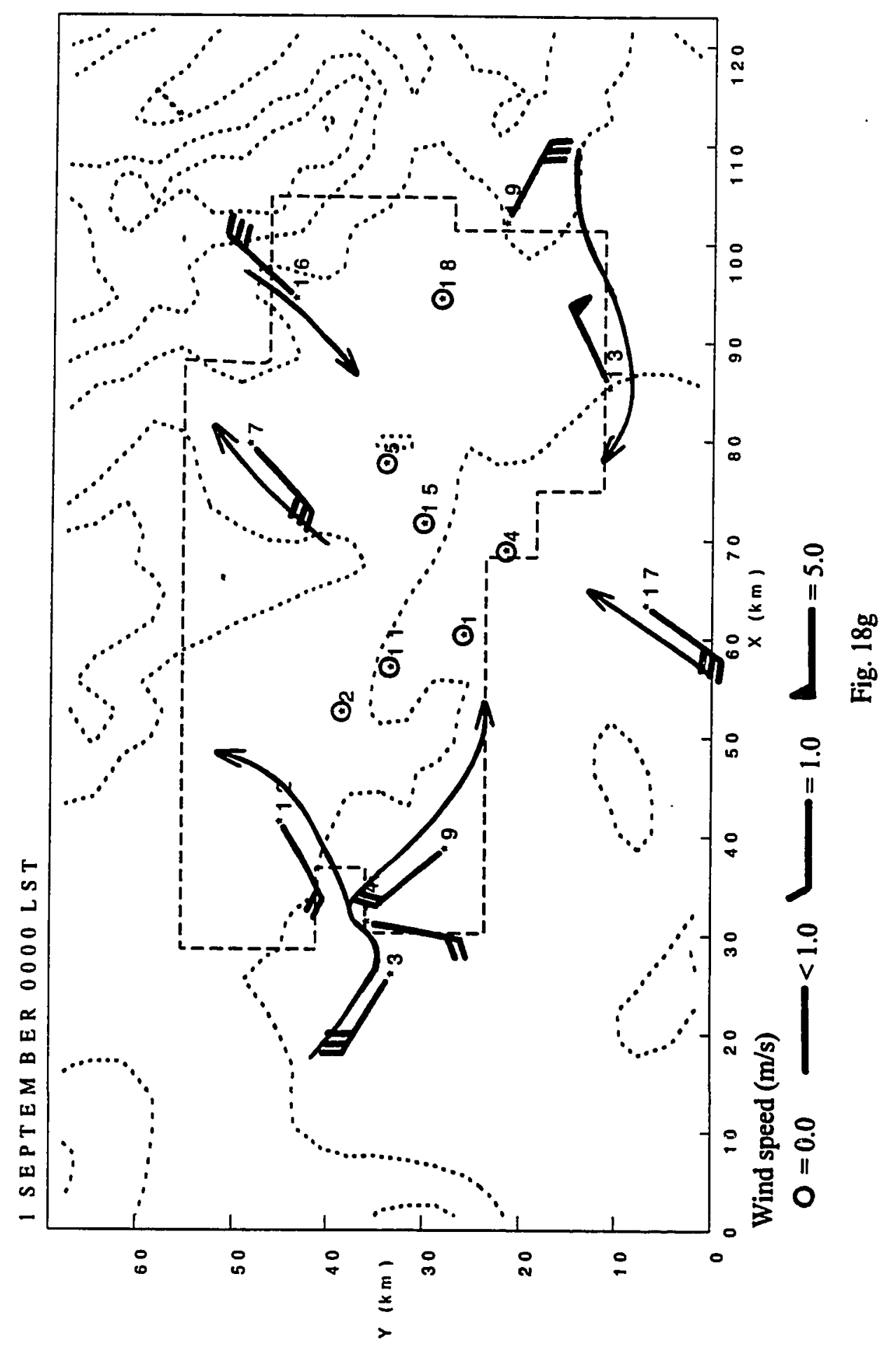




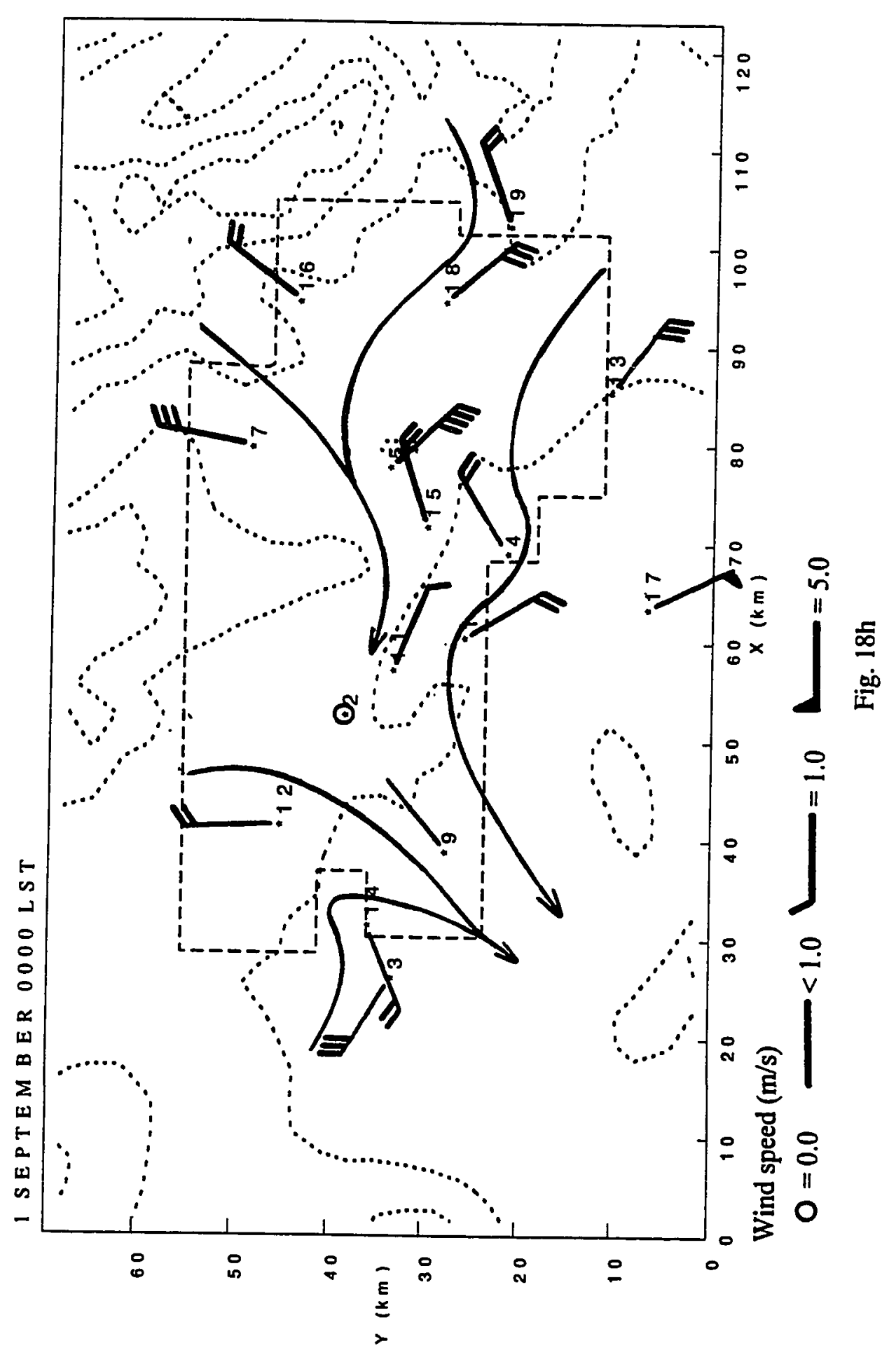




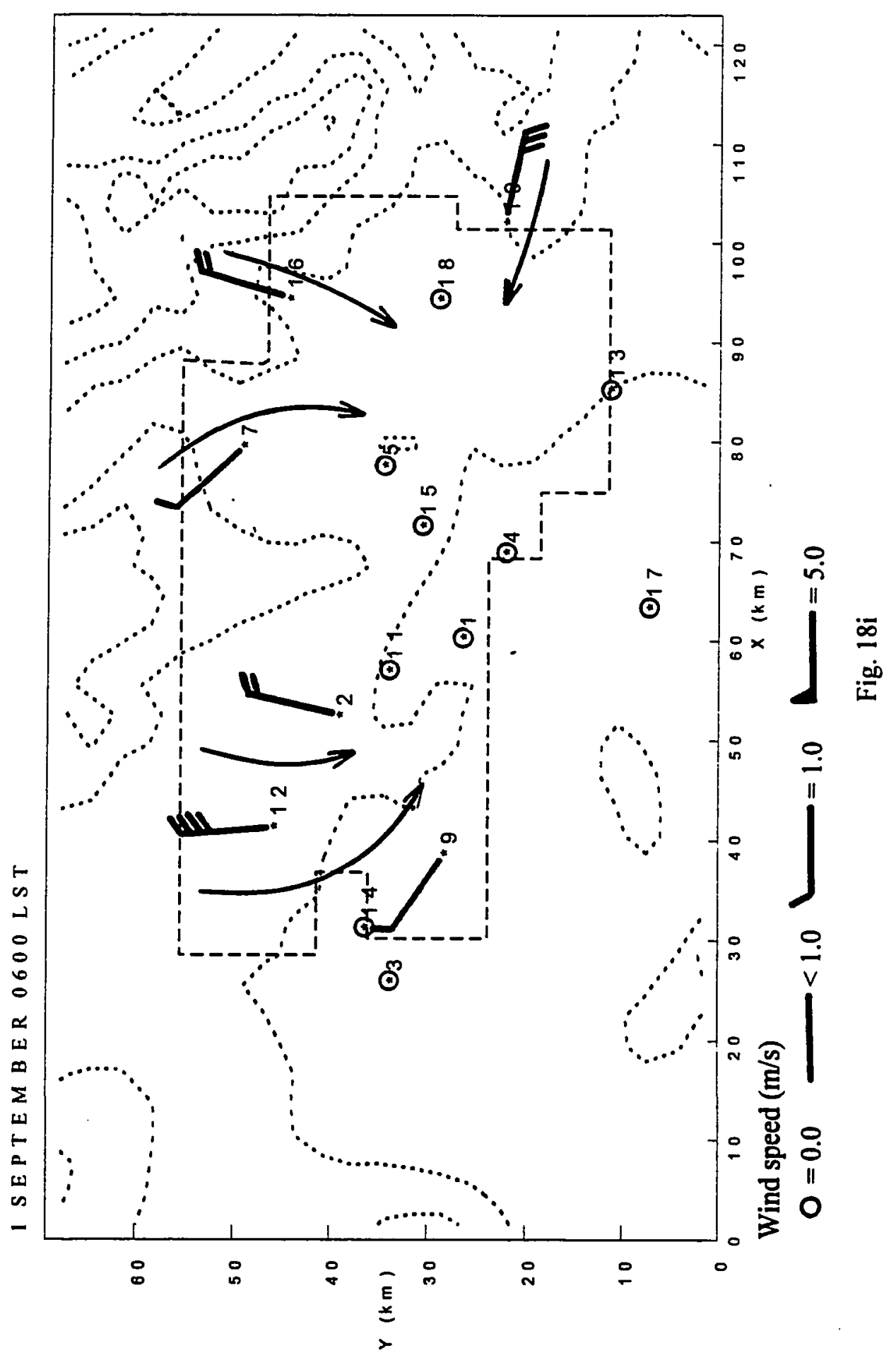



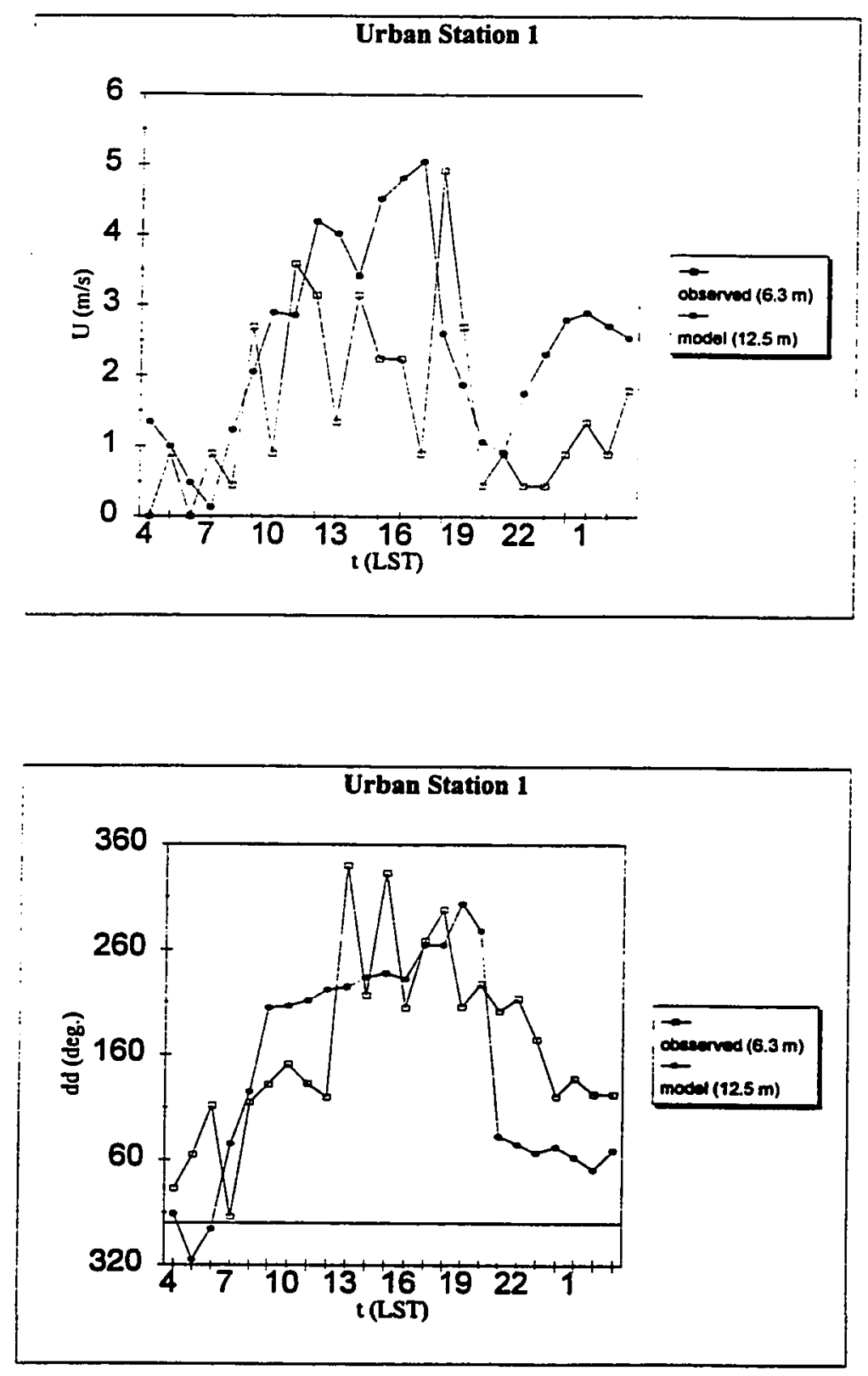

Fig. 19a 

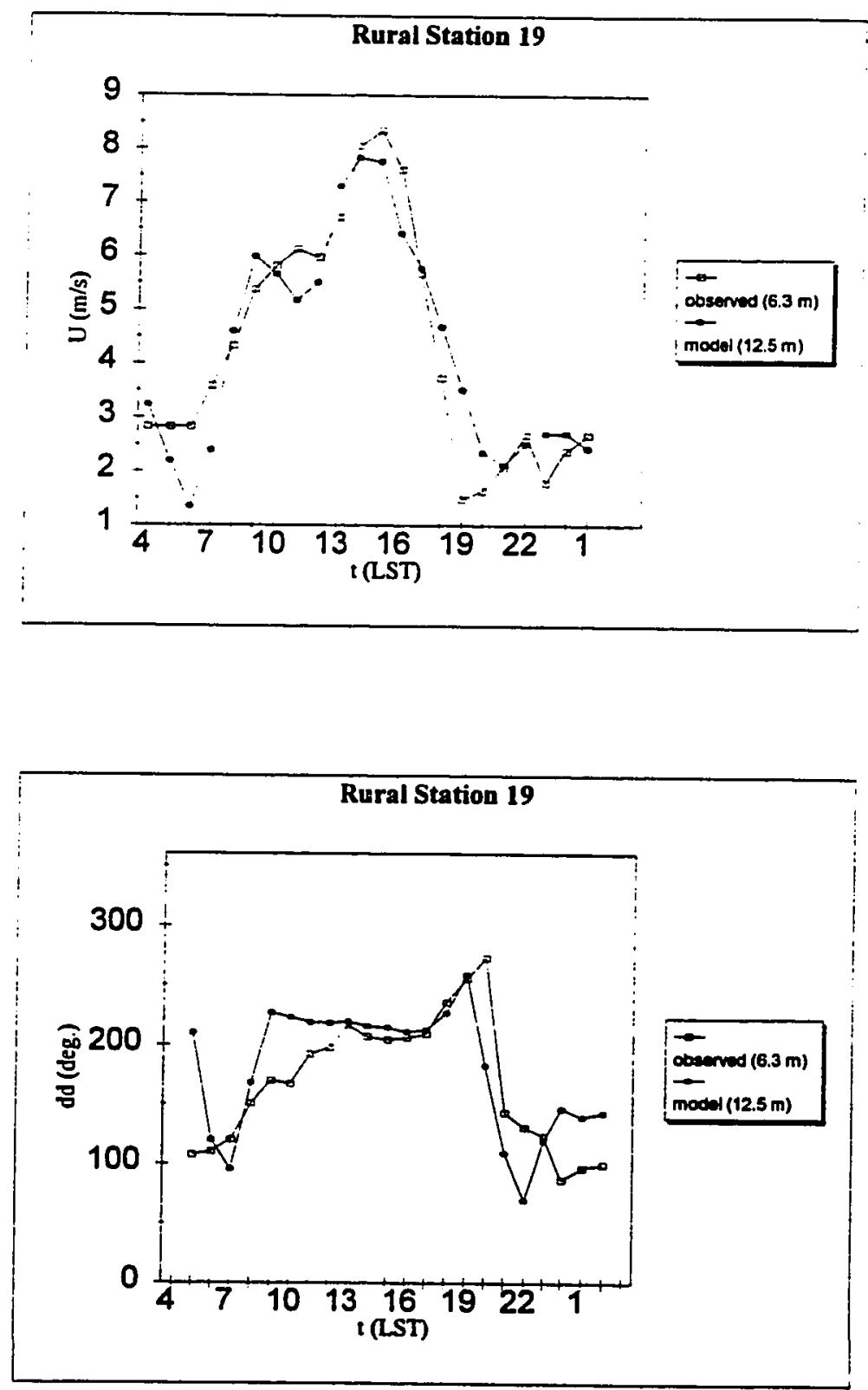

Fig. 19b 

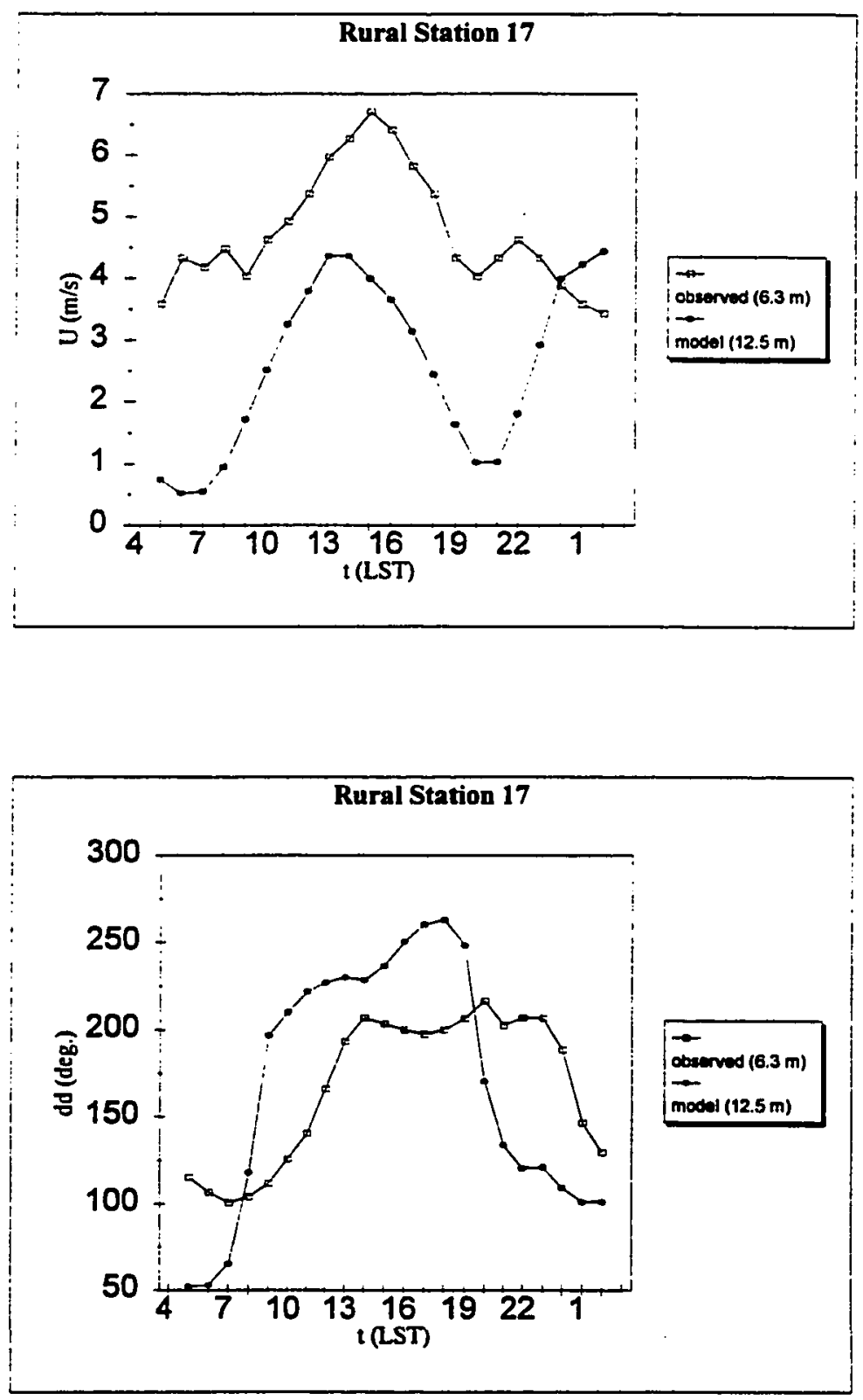

Fig. 19c 

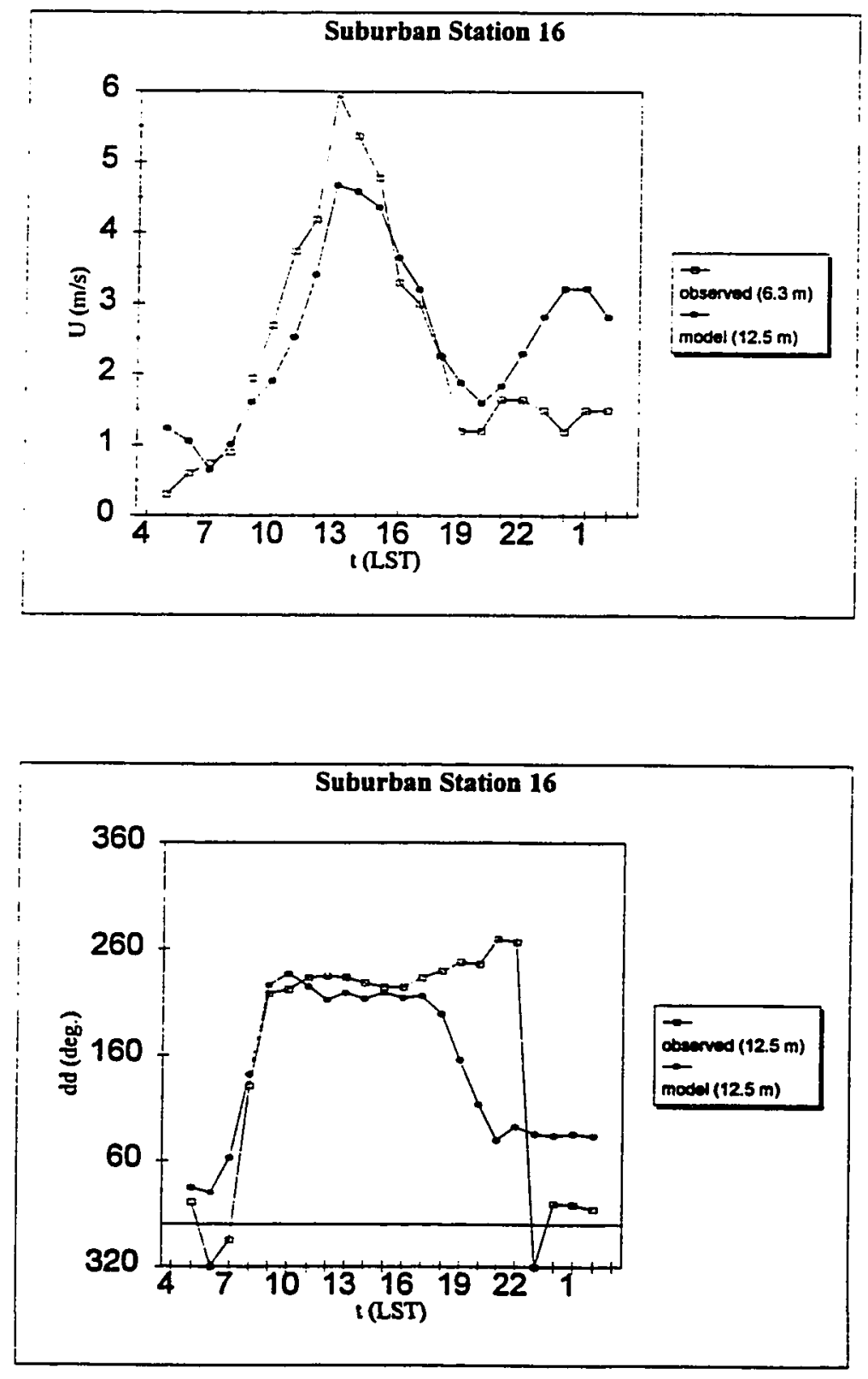

Fig. 19d 

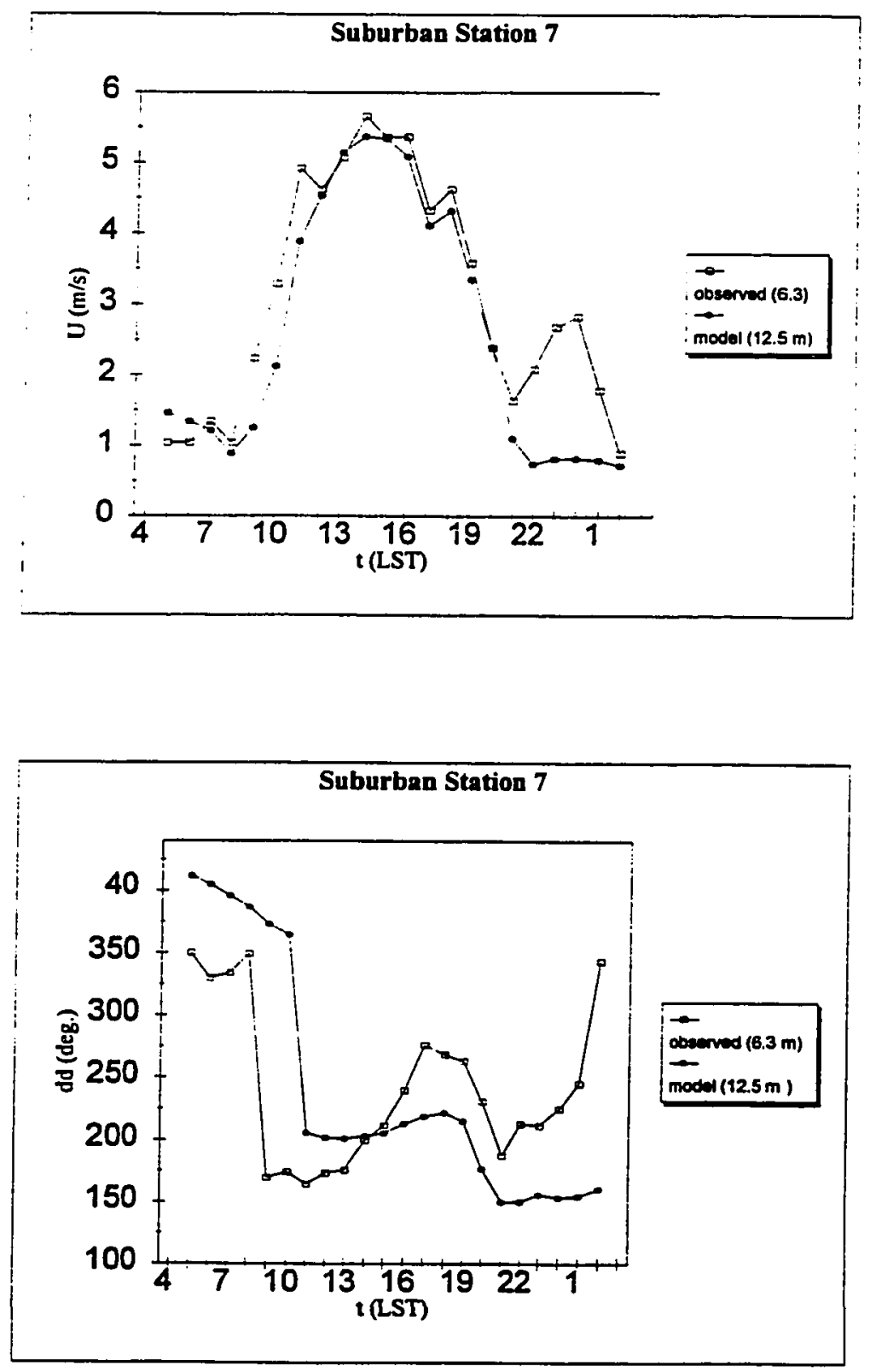

Fig. 19e 

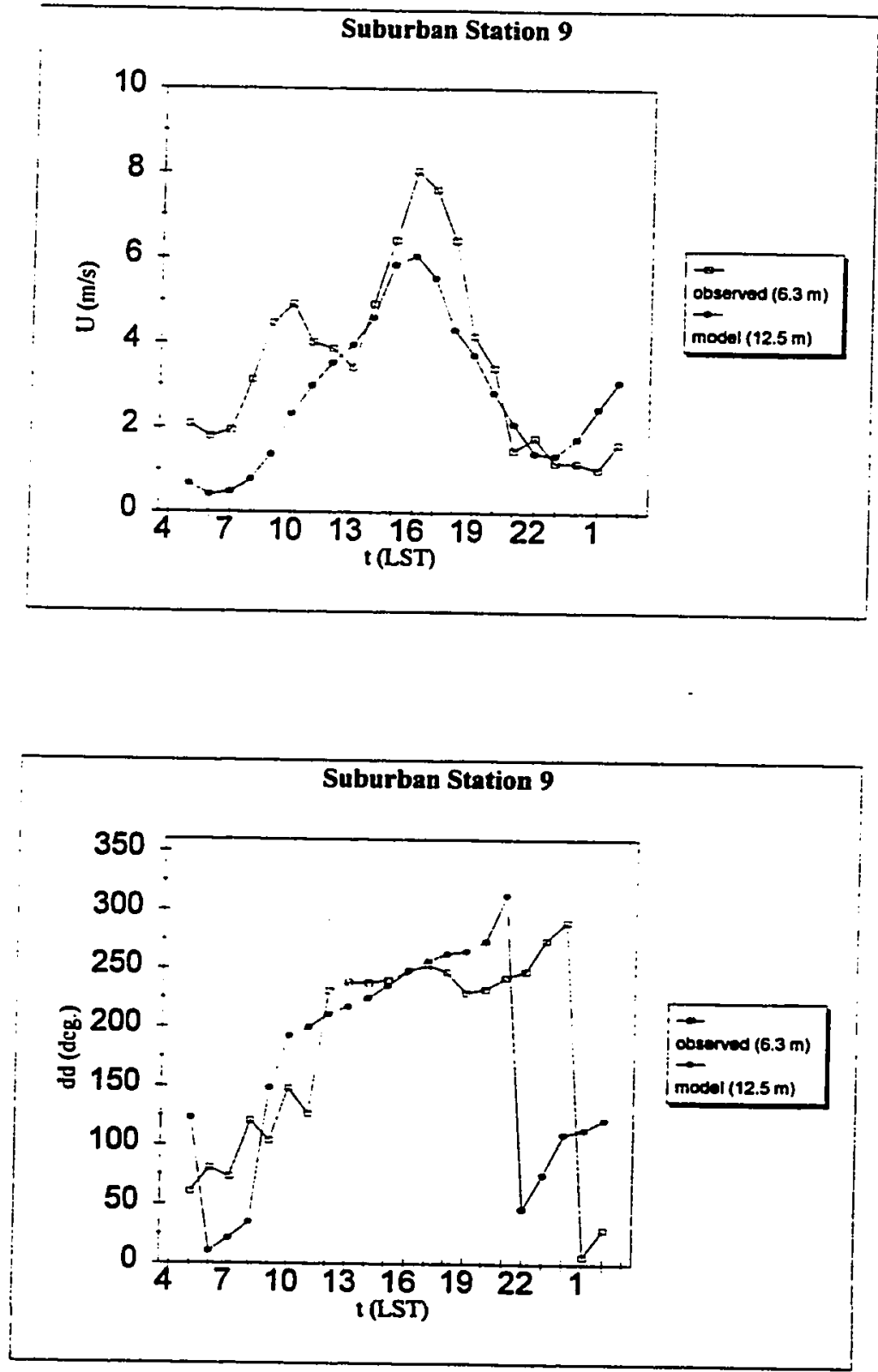

Fig. $19 f$ 

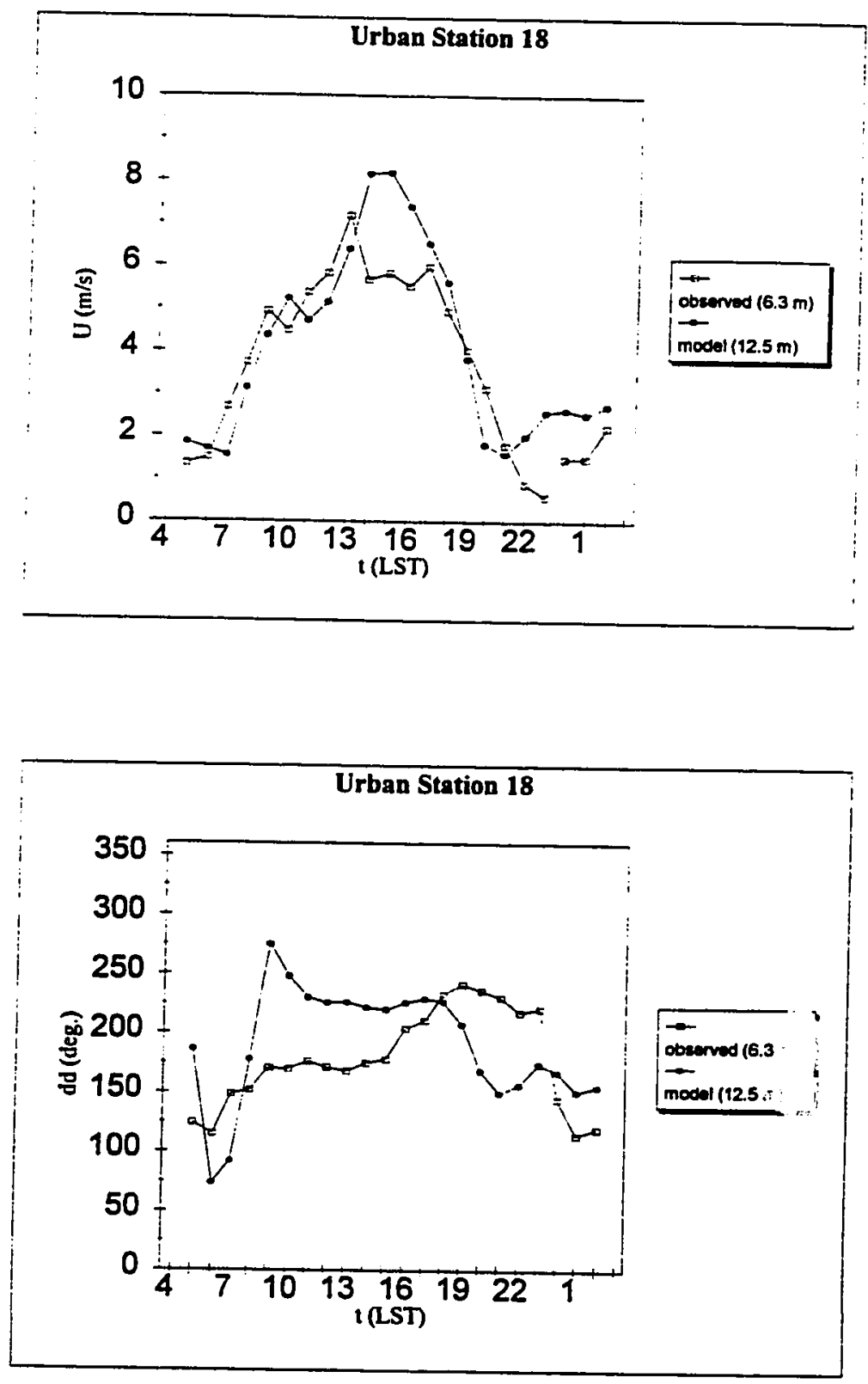

Fig. $19 \mathrm{~g}$ 

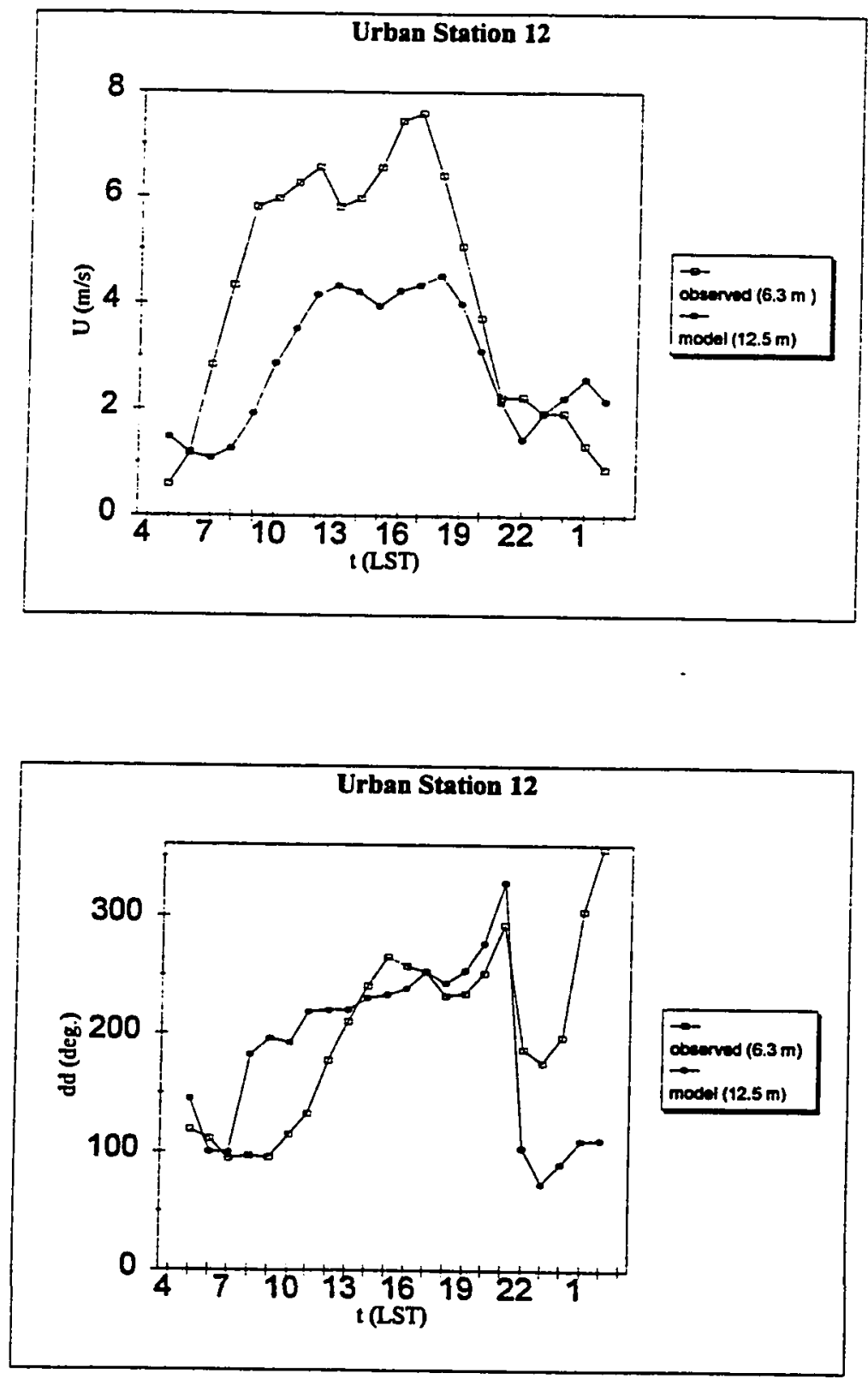

Fig. 19h 

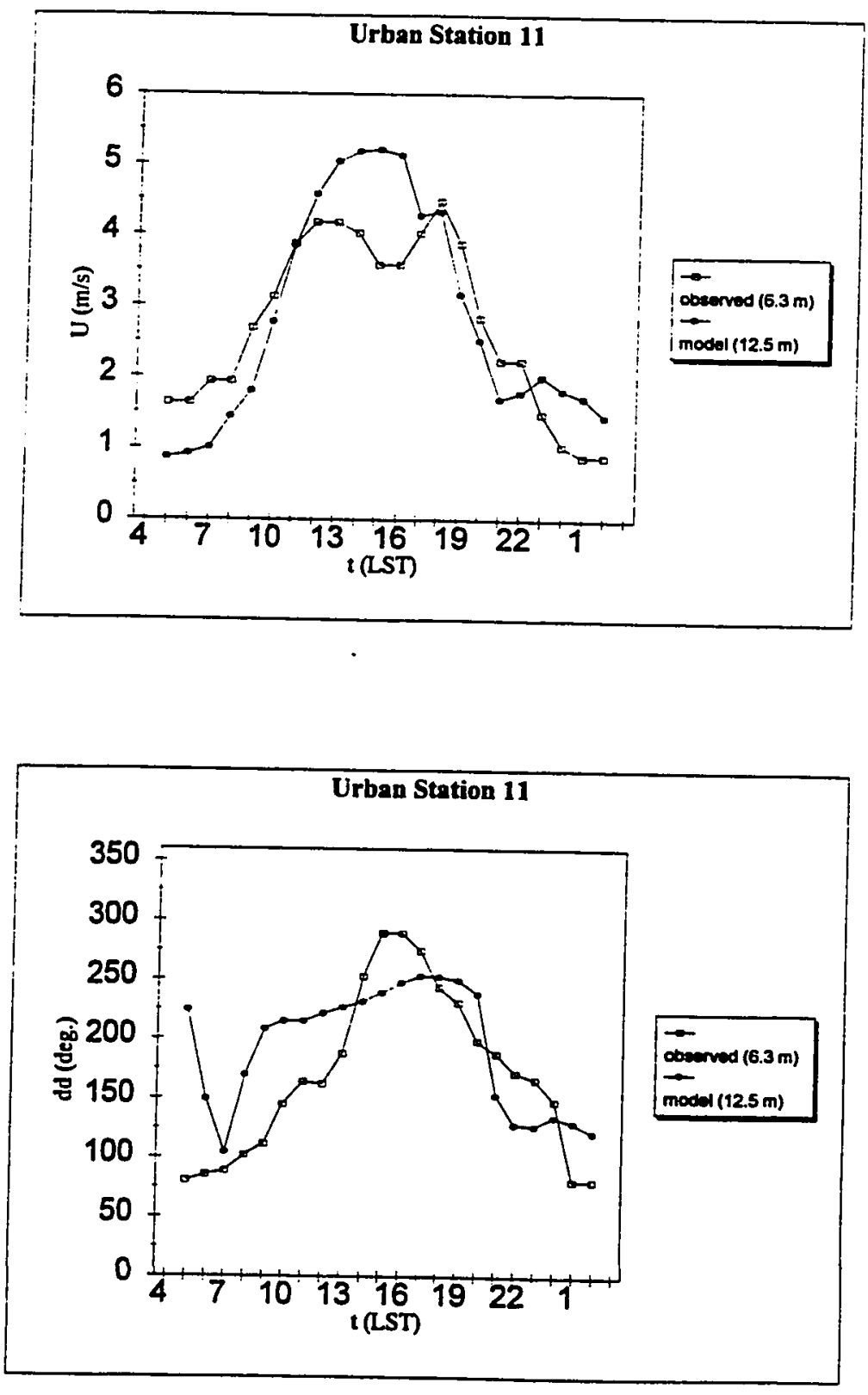

Fig. 19i 


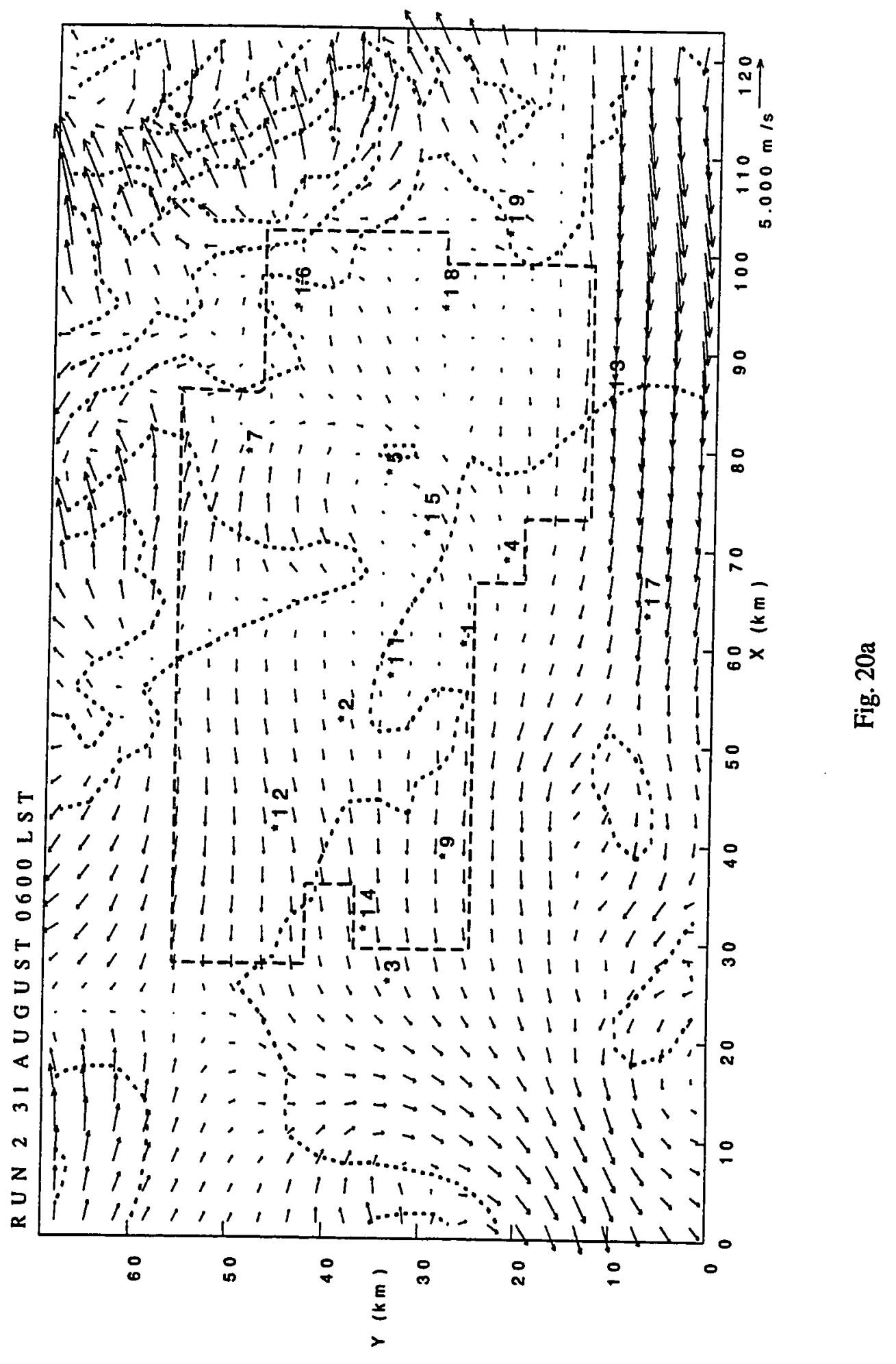




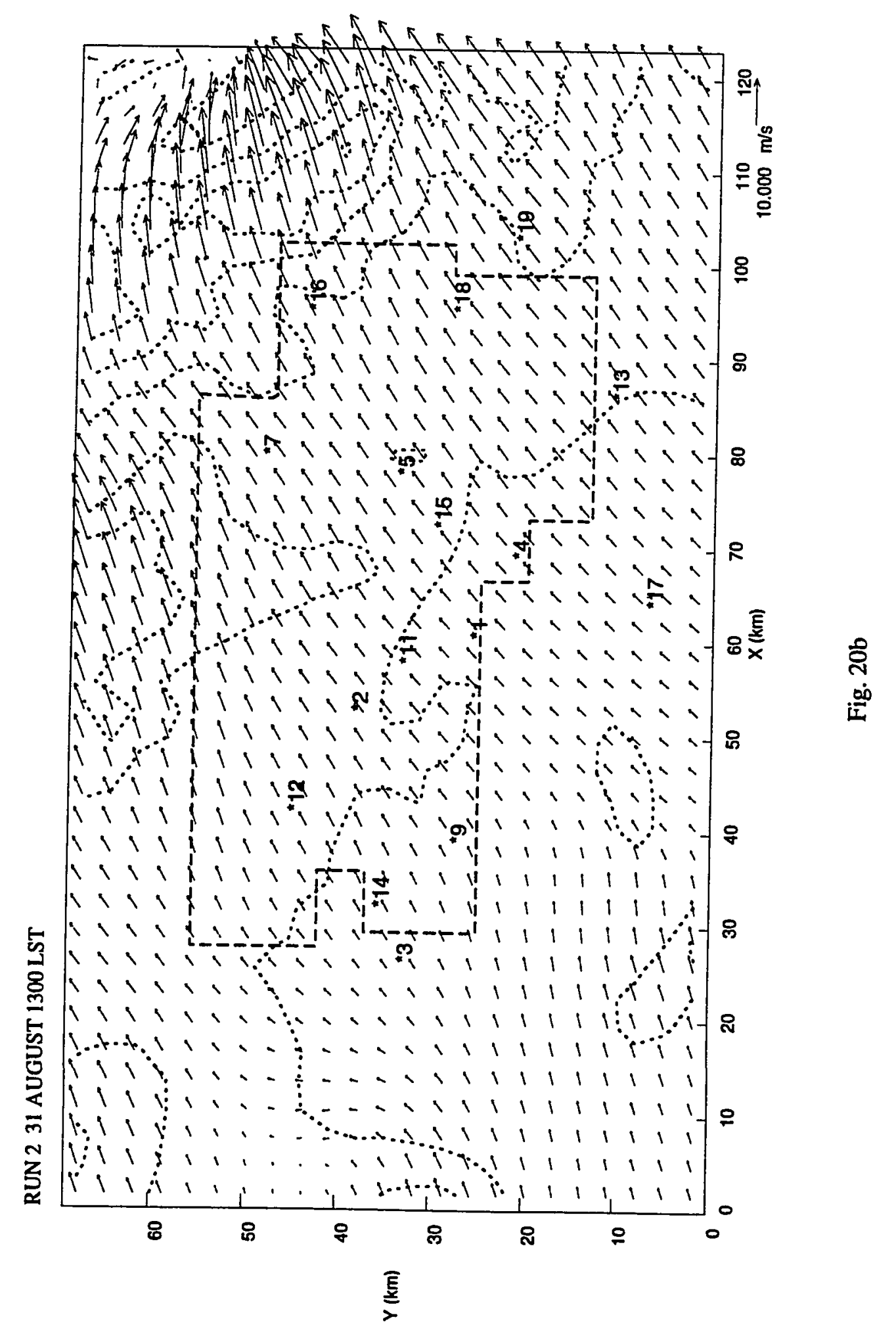




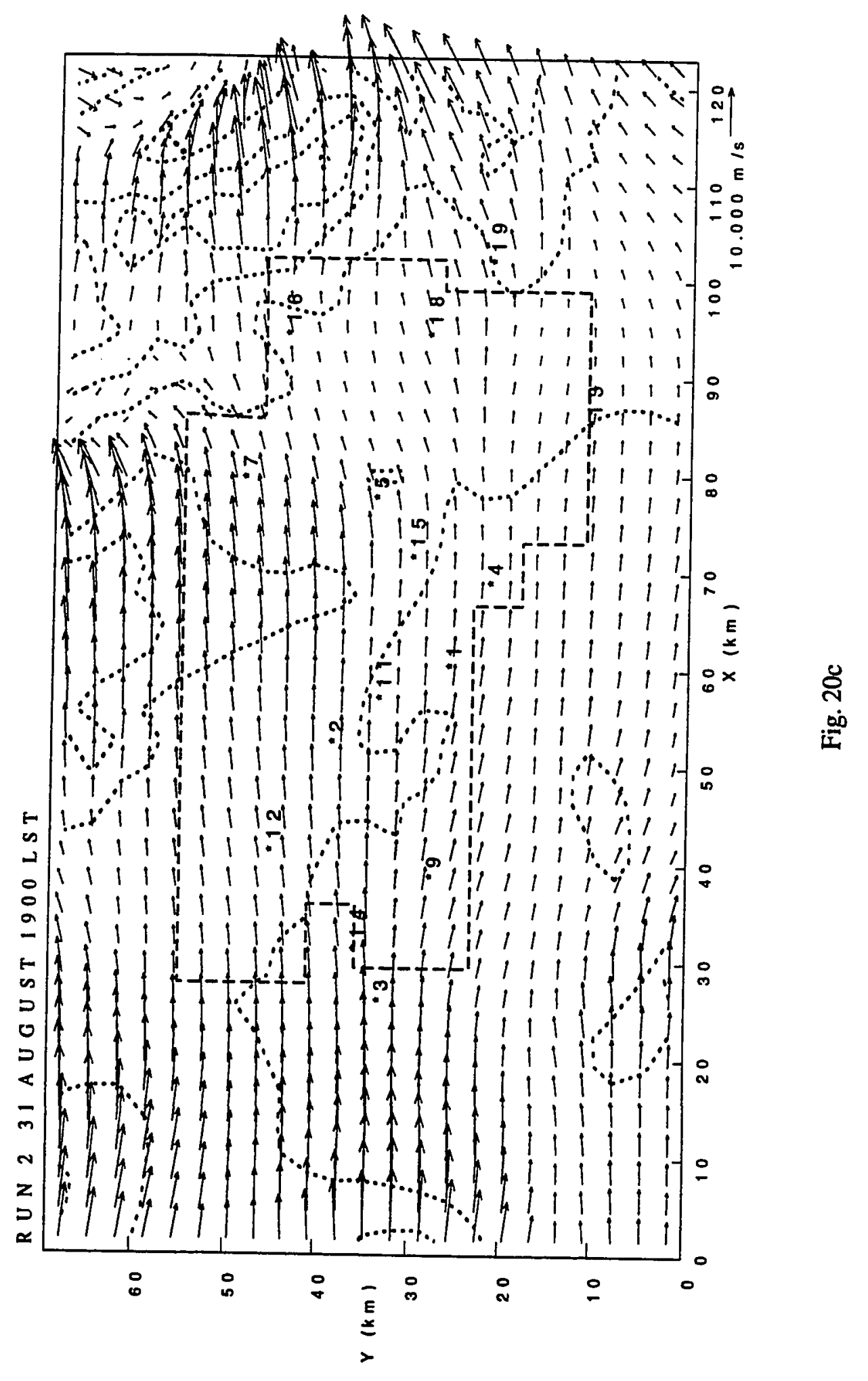




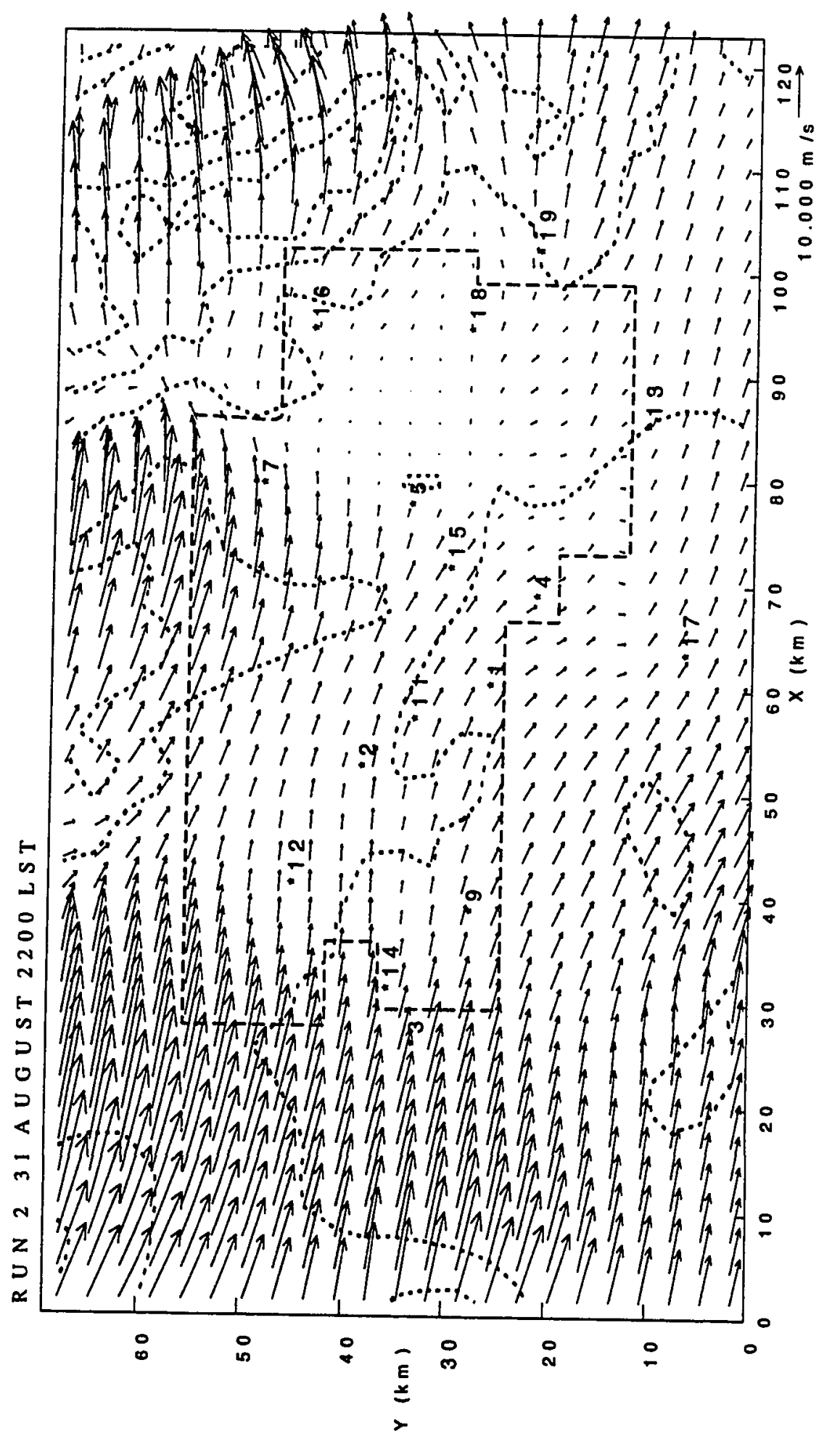




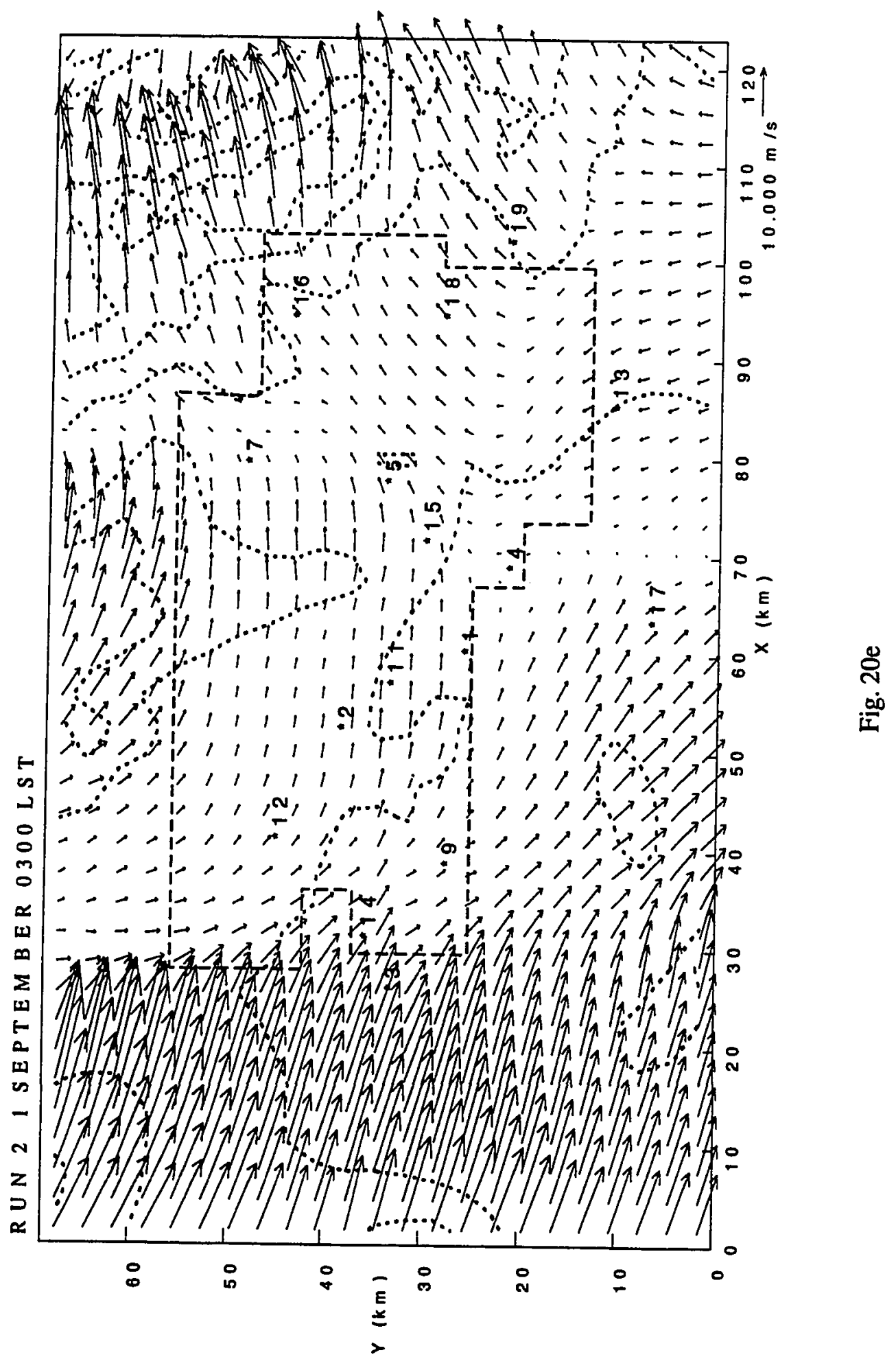




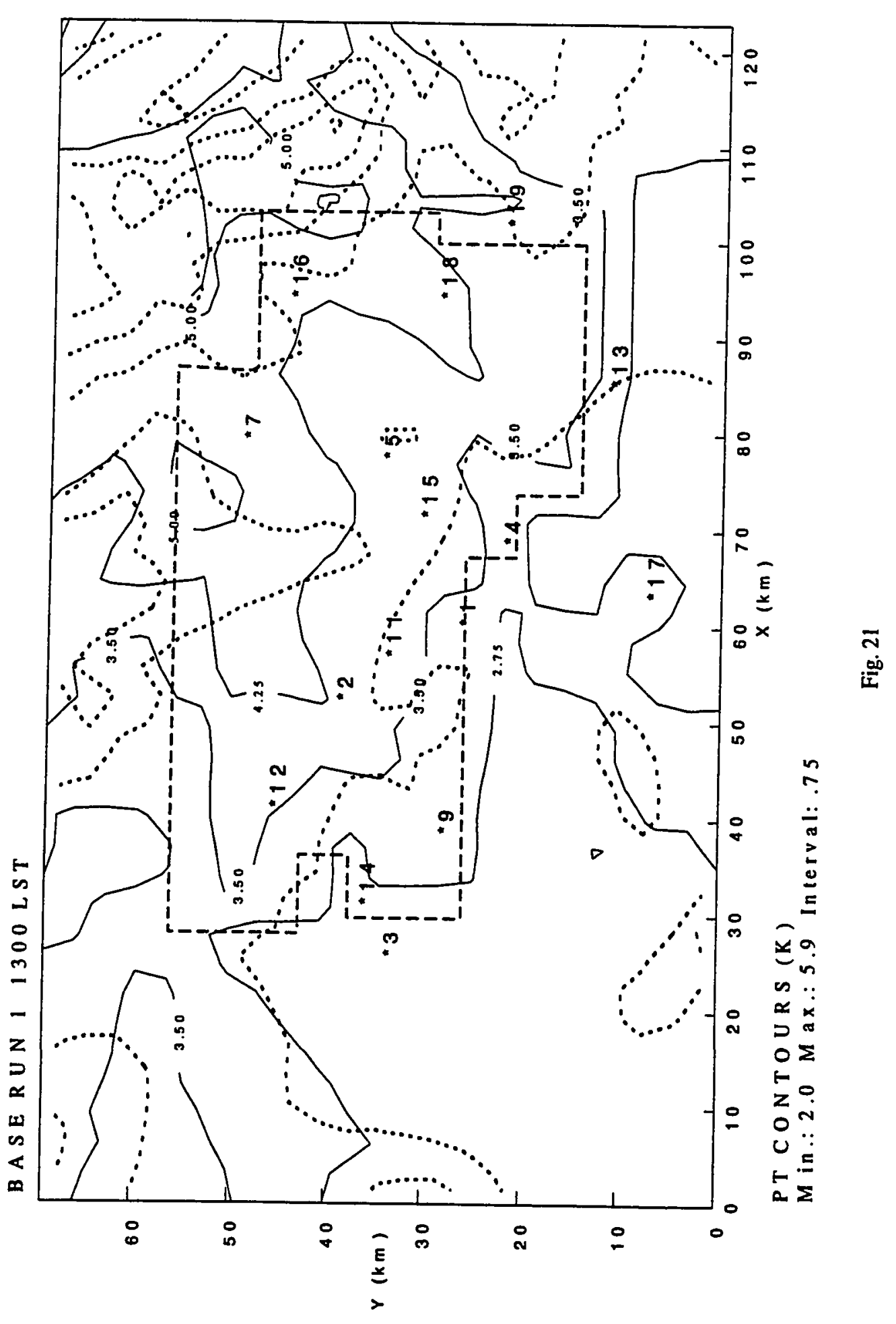




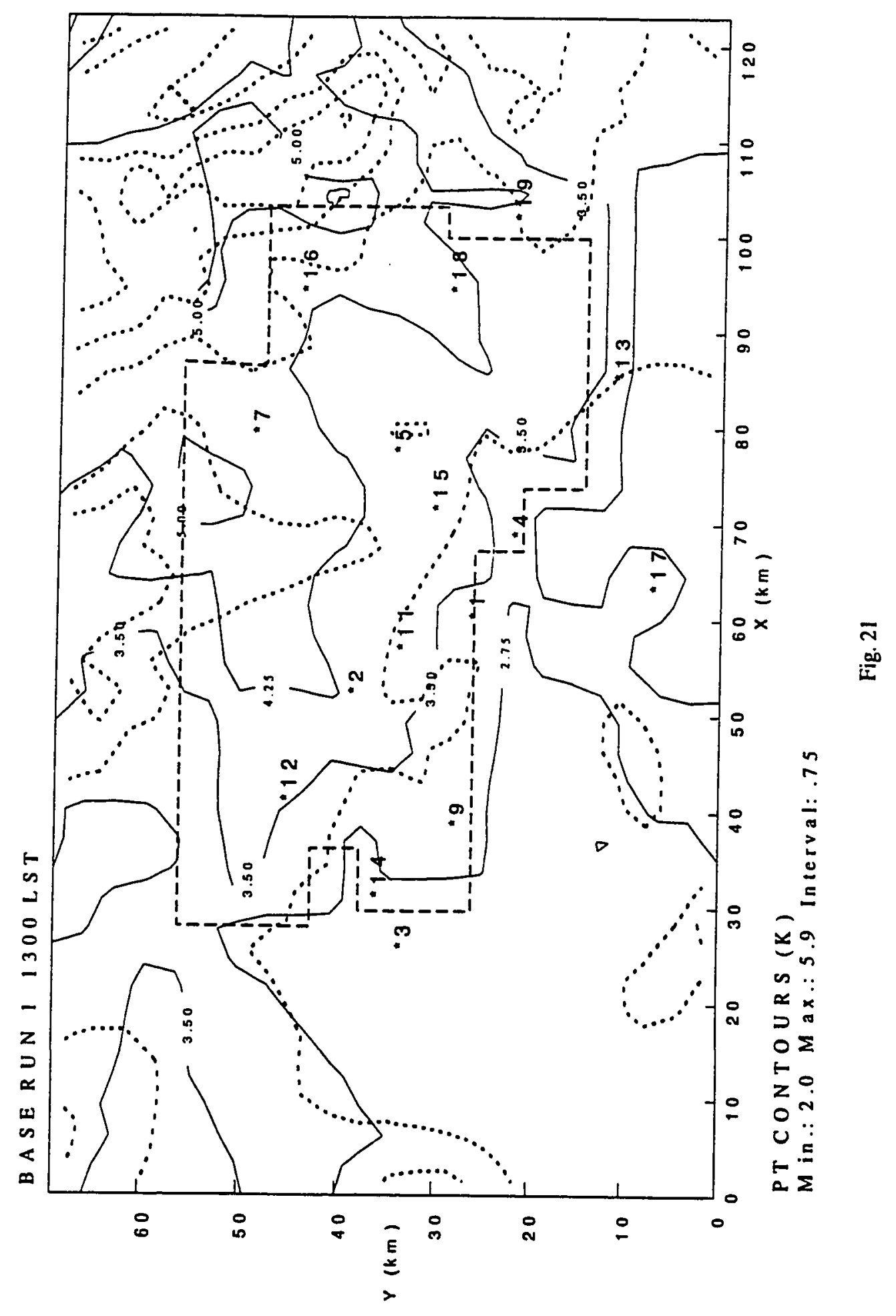




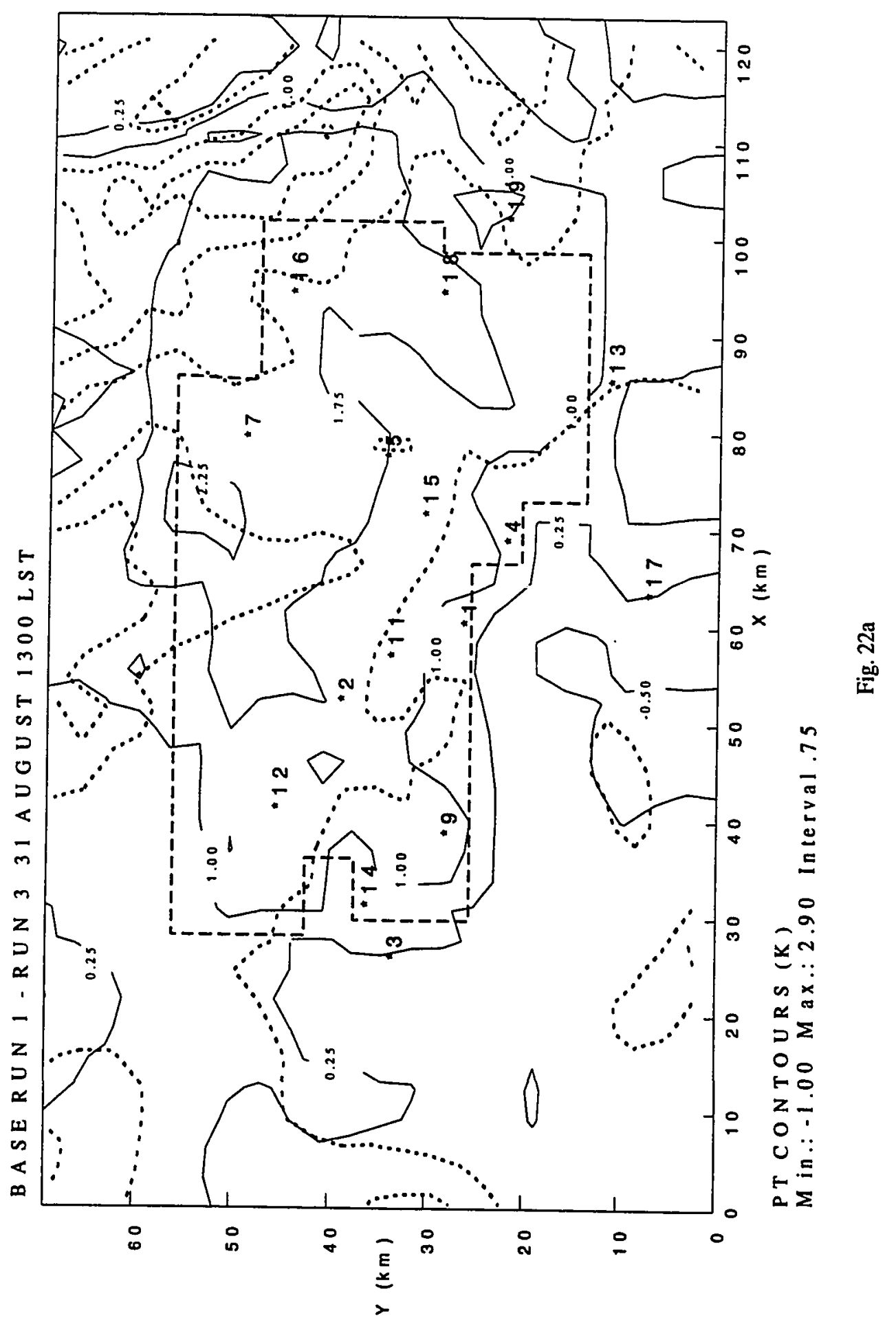




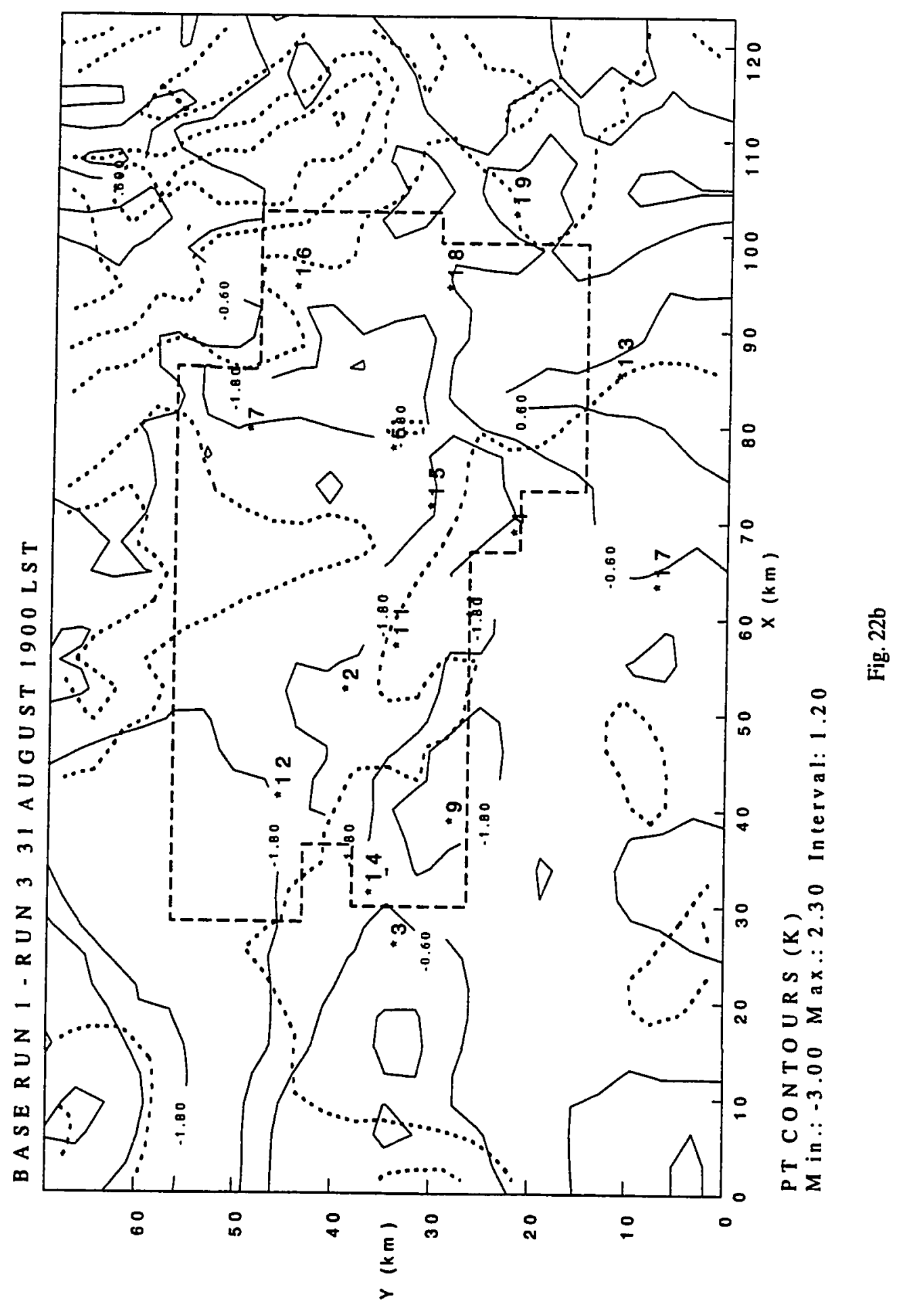




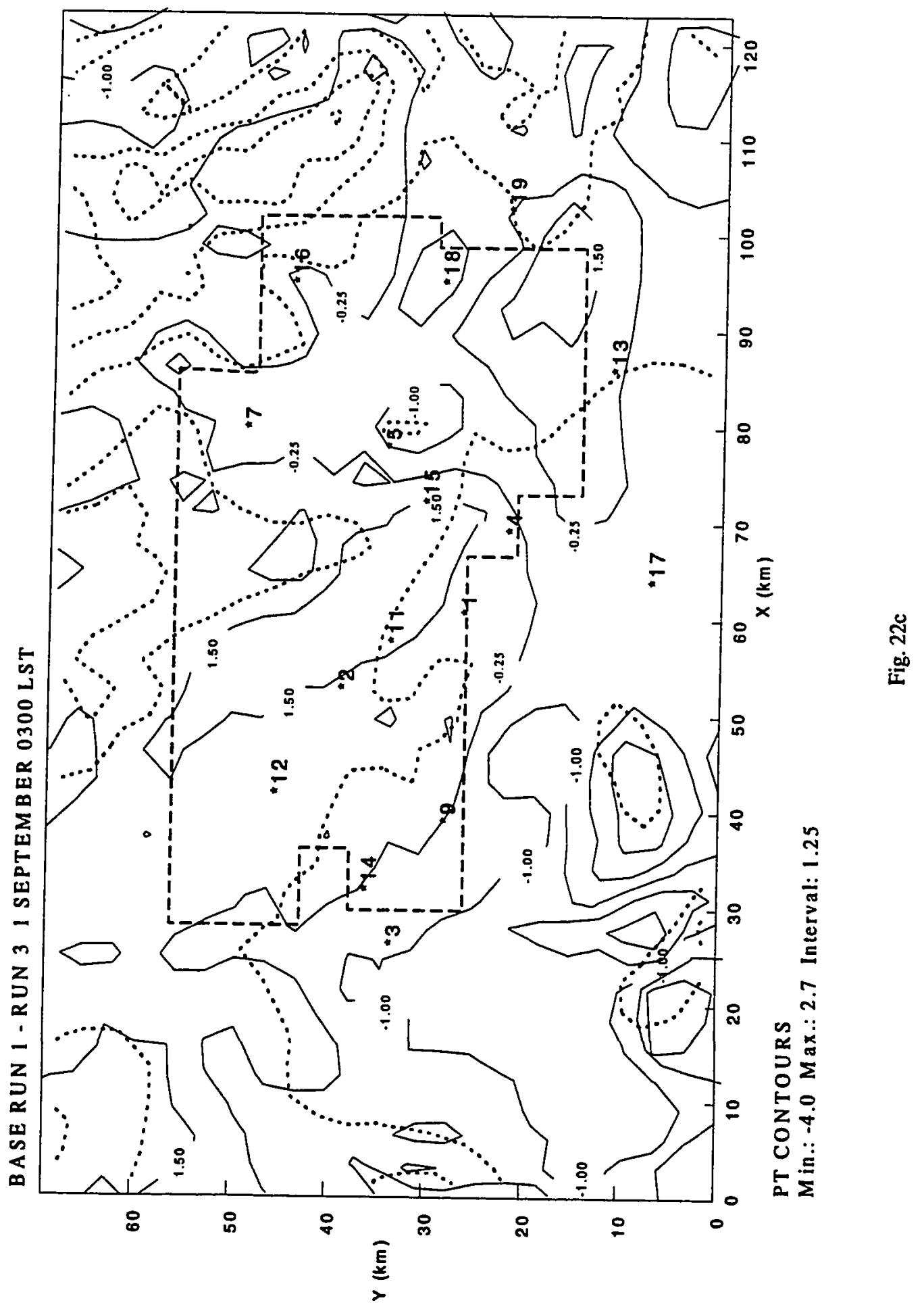




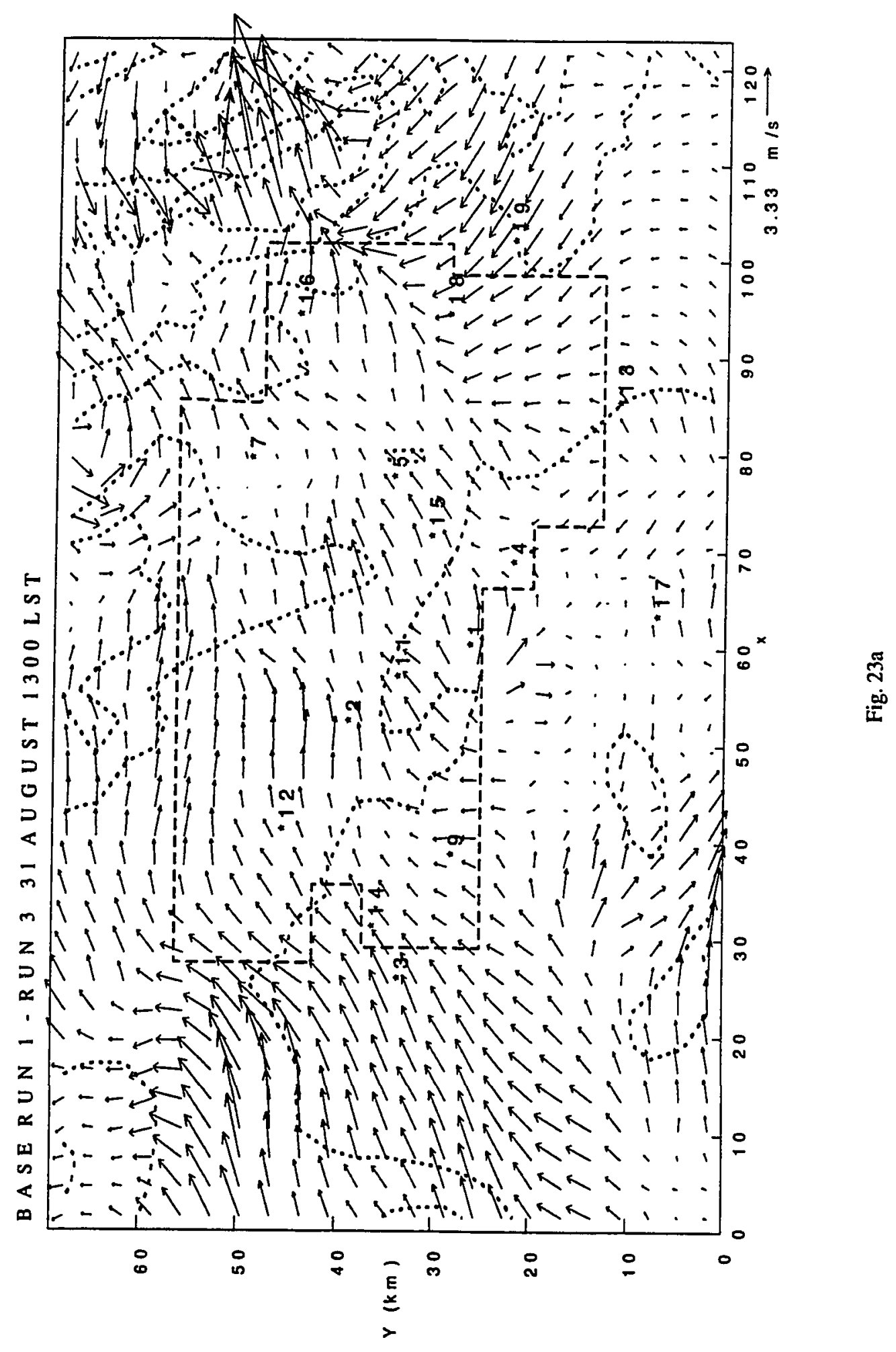




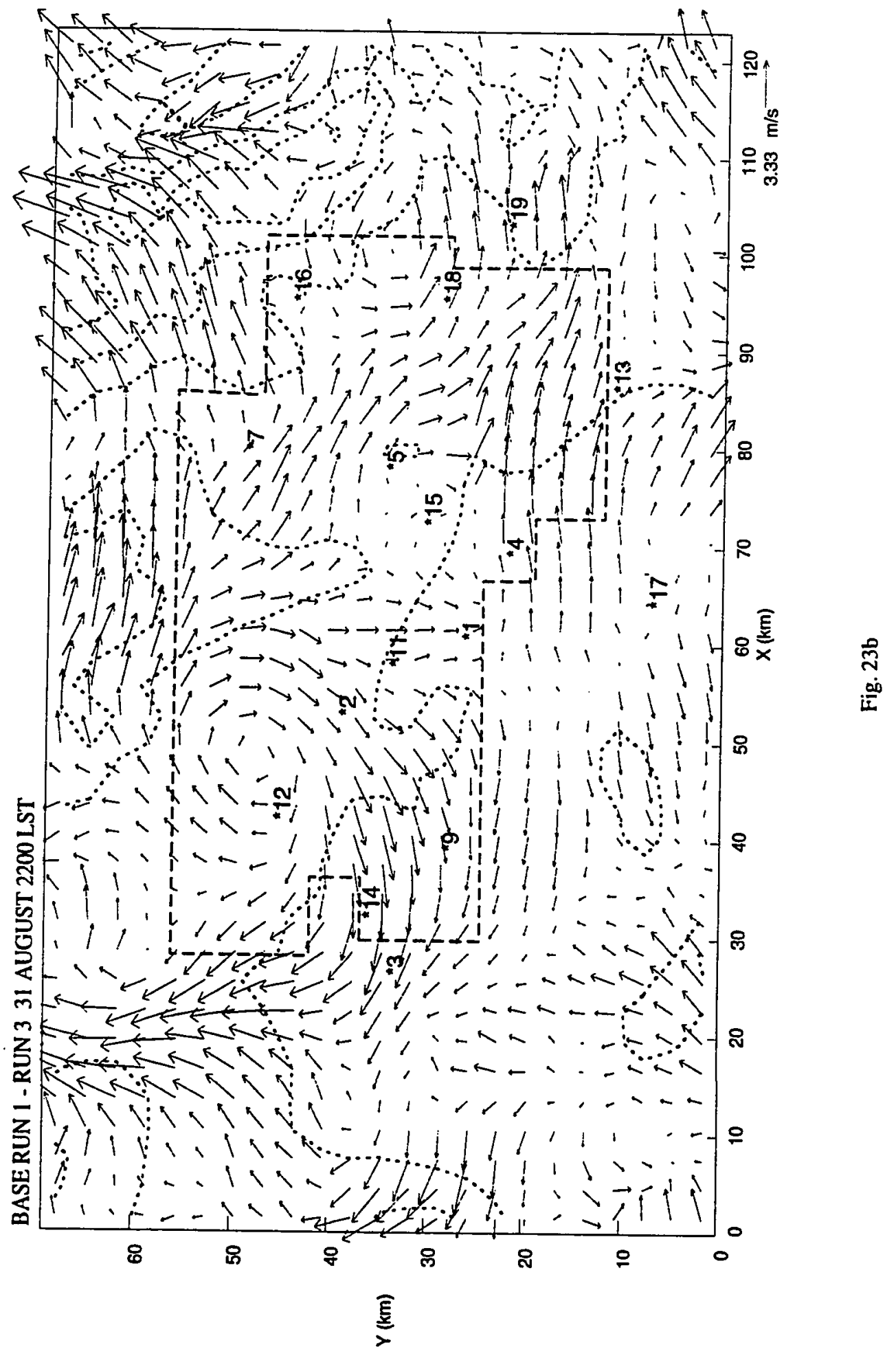




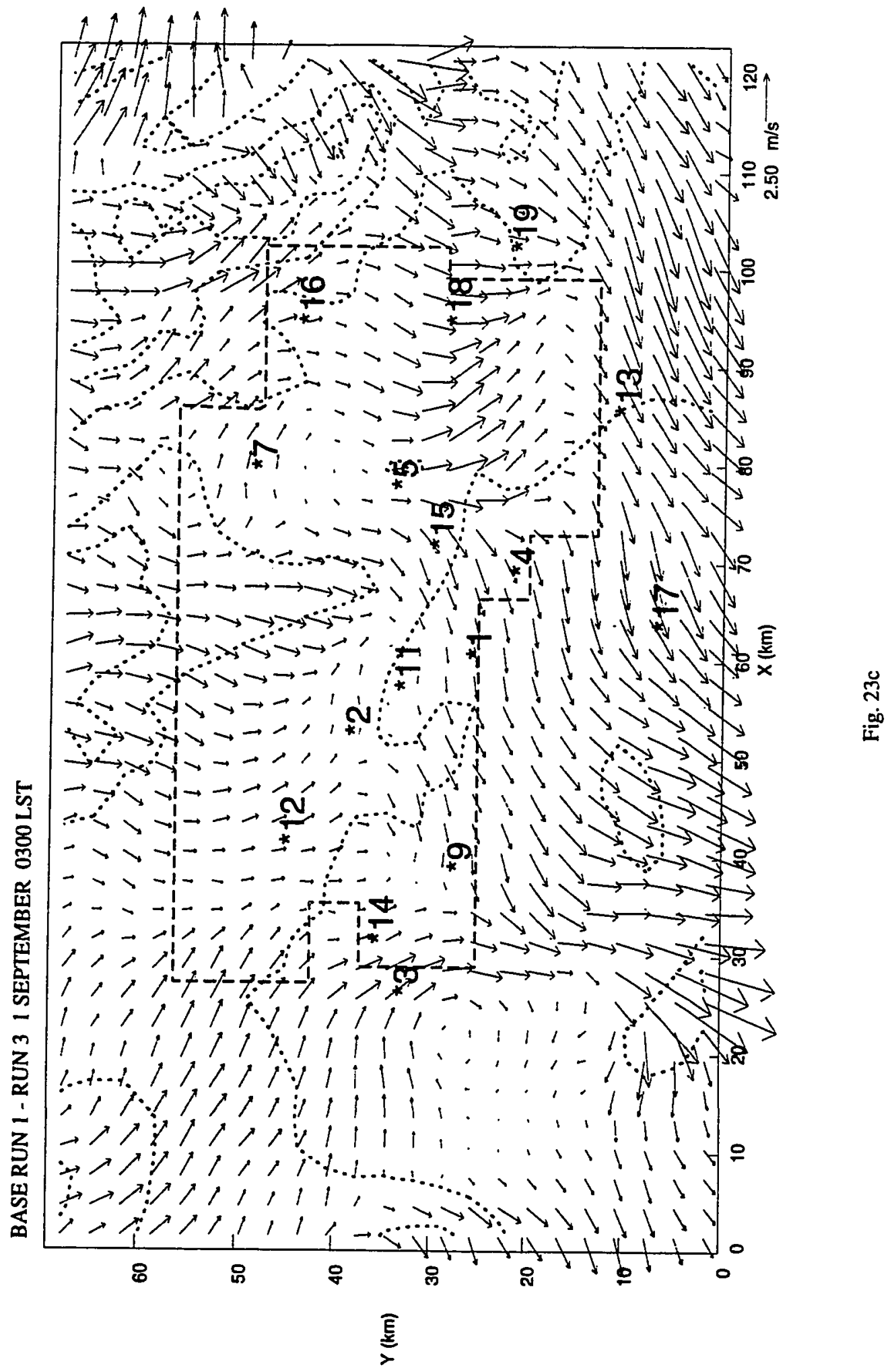




\begin{tabular}{c|c|c} 
A & B & C \\
\hline D & E & F \\
\hline \multicolumn{3}{c}{ Block-1 }
\end{tabular}

\begin{tabular}{c|c|c}
$\mathrm{K}$ & $\mathrm{L}$ & $\mathrm{M}$ \\
\hline $\mathrm{N}$ & $\mathrm{O}$ & $\mathrm{P}$ \\
\hline \multicolumn{3}{|c}{ Block-2 }
\end{tabular}

\begin{tabular}{c|c|c}
$\mathrm{Q}$ & $\mathrm{R}$ & $\mathrm{S}$ \\
\hline $\mathrm{T}$ & $\mathrm{U}$ & $\mathrm{V}$ \\
\hline \multicolumn{3}{|c}{ Block-3 }
\end{tabular}

(a)

\begin{tabular}{|c|c|c|}
\hline F & P & V \\
\hline E & O & U \\
\hline D & N & T \\
\hline C & M & S \\
\hline B & L & R \\
\hline A & K & Q \\
\hline
\end{tabular}

(b)

Fig. B-1 